\author{
Universidade de São Paulo \\ Instituto de Física de São Carlos
}

Henrique Musseli Cezar

\title{
Implementação do método Parallel Tempering Monte Carlo para o estudo de propriedades termodinâmicas de nanoclusters
}

São Carlos 

Henrique Musseli Cezar

\title{
Implementação do método Parallel Tempering Monte Carlo para o estudo de propriedades termodinâmicas de nanoclusters
}

\author{
Dissertação apresentada ao Programa de Pós- \\ graduação em Física do Instituto de Física de \\ São Carlos da Universidade de São Paulo, para \\ a obtenção do título de Mestre em Ciências. \\ Área de concentração: Física Aplicada \\ Opção: Física Computacional \\ Orientador: Prof. Dr. Juarez Lopes Ferreira da \\ Silva \\ Versão corrigida \\ (Versão original disponível na Unidade que aloja o Programa)
}

São Carlos

2015 
AUTORIZO A REPRODUÇÃO E DIVULGAÇÃO TOTAL OU PARCIAL DESTE TRABALHO, POR QUALQÜER MEIO CONVENCIONAL OU ELETRÔNICO PARA FINS DE ESTUDO E PESQUISA, DESDE QUE CITADA A FONTE.

Ficha catalográfica elaborada pelo Serviço de Biblioteca e Informação do IFSC, com os dados fornecidos pelo(a) autor(a)

Cezar, Henrique Musseli

Implementação do método Parallel Tempering Monte Carlo para o estudo de propriedades termodinâmicas de nanoclusters / Henrique Musseli Cezar; orientador Juarez Lopes Ferreira Da Silva - versão corrigida -São Carlos, 2015.

$97 \mathrm{p}$.

Dissertação (Mestrado - Programa de Pós-Graduação em Física Aplicada Computacional) -- Instituto de Física de São Carlos, Universidade de São Paulo, 2015.

1. Propriedades termodinâmicas. 2. Nanoclusters. 3. Método de Monte Carlo. 4. Teoria do funcional da densidade. I. Da Silva, Juarez Lopes Ferreira, orient. II. Título. 




\section{Agradecimentos}

Agradeço primeiramente à minha família. Sem o apoio incondicional e incentivo aos estudos que recebi e continuo recebendo principalmente dos meus pais, Cilas e Ivete, esse trabalho jamais teria sido concluído. Agradeço também especialmente à minha namorada Beatriz, que a quatro anos se mantém ao meu lado em todos os momentos, sempre me apoiando, incentivando, tranquilizando e fazendo dos meus dias mais felizes. Agradeço aos meus amigos, que pela internet ou pessoalmente, proporcionaram ao longo desses dois anos várias horas de jogo, churrascos, conversas e risadas.

Também gostaria de agradecer ao meu orientador, Prof. Dr. Juarez Lopes Ferreira da Silva, por todo o apoio e pelas discussões, com as quais, aprendi muito e pude enriquecer a minha formação. Agradeço a todos os membros do grupo de Teoria Quântica de Nanomateriais do IQSC, também pelas discussões e apoio nos momentos necessários. Em especial sou grato ao colega Gustavo Garcia Rondina que iniciou o desenvolvimento do código GOTNano com a implementação do RBHMC, facilitando em muitos aspectos o meu trabalho. Agradeço também ao Stack Overflow e seus usuários, pois sem os seus tópicos e respostas, as dúvidas que tive durante o desenvolvimento dos códigos e scripts poderiam jamais ter sido sanadas.

Agradeço à infraestrutura fornecida pelo IFSC, IQSC, CISC, LCCA e pela USP, pois sem essas a realização desse trabalho seria impossível. Agradeço também a FAPESP pelo apoio financeiro dado a essa pesquisa. 

"Vivemos em uma sociedade extraordinariamente dependente da ciência e da tecnologia, em que quase ninguém sabe nada sobre ciência e tecnologia."

Carl Sagan 



\section{Resumo}

CEZAR, H. M. Implementação do método Parallel Tempering Monte Carlo para o estudo de propriedades termodinâmicas de nanoclusters 2015. 97 p. Dissertação (Mestrado em Ciências) - Instituto de Física de São Carlos, Universidade de São Paulo, São Carlos, 2015.

O uso de nanomateriais em aplicações como catálise e medicina, despertou nos últimos anos o interesse no estudo das propriedades de nanoclusters. O estudo das propriedades termodinâmicas desses sistemas é essencial, pois mudanças estruturais originadas de mudanças de fase podem alterar propriedades como atividade catalítica, momento magnético e propriedades óticas. A dinâmica molecular vêm sendo utilizada para o estudo computacional das propriedades termodinâmicas de diversos nanomateriais, enquanto o uso de métodos de Monte Carlo (MC), nesse contexto, tem se restringido ao estudo de nanoclusters de Lennard-Jones (LJ). Para avaliar a viabilidade do uso de métodos de $\mathrm{MC}$ no estudo de propriedades de sistemas reais, uma implementação do método Parallel Tempering Monte Carlo (PTMC) utilizando algoritmos do estado da arte para realização de trocas, determinação de temperaturas e ajuste de deslocamentos foi construída. Através de testes, é mostrado que alguns dos algoritmos implementados podem não ser adequados ao estudo do problema em questão. A implementação foi validada com o estudo das propriedades termodinâmicas de nanoclusters de LJ com 38,55 e 147 átomos, que possuem resultados conhecidos na literatura. Além disso, resultados para propriedades do nanocluster $L J_{98}$ são apresentados, e devido à características estruturais desse sistema, é observada uma transição sólido-sólido entre as estruturas tetraédricas e icosaédricas em temperatura abaixo da de fusão. A hipótese do uso do algoritmo PTMC para o estudo de propriedades de materiais reais, foi testada nas nanoligas $(\mathrm{PtCo})_{55}$ e $(\mathrm{PtNi})_{55}$, descritas pelo potencial de Gupta. Através da comparação das estruturas de mais baixa energia com resultados de teoria do funcional da densidade (DFT, do inglês), é mostrado que o uso do potencial de Gupta pode ser justificado, dados os baixos desvios no comprimento de ligação (menores que $2.4 \%$ ) e a semelhança de outras características estruturais. Os resultados obtidos indicam que o método PTMC é capaz de identificar as mudanças de fase das nanoligas estudadas. Essas mudanças são ilustradas e analisadas com o uso de um algoritmo para a comparação da similaridade de estruturas, com o qual foi possível analisar a fusão dos nanoclusters $\mathrm{Co}_{55}, \mathrm{Ni}_{55}$, $\mathrm{Pt}_{30} \mathrm{Co}_{25}$ e $\mathrm{Pt}_{40} \mathrm{Ni}_{15}$ (obtida em temperaturas entre 900 e $1100 \mathrm{~K}$ ); além da fusão, a $727 \mathrm{~K}$, e transição sólido-sólido, a $300 \mathrm{~K}$, para a $\mathrm{Pt}_{55}$. Com as estruturas mais frequentes, encontradas através da análise de similaridade, e com a realização de cálculos DFT, foi possível observar um deslocamento do centro da banda $d$ em direção ao HOMO (Highest Occupied Molecular Orbital) causado pelo aumento da temperatura. Esse deslocamento, segundo o modelo da banda $d$ válido para superfícies, pode indicar uma maior reatividade dos nanoclusters nesses casos. 
Palavras-chaves: Propriedades termodinâmicas. Nanoclusters. Método de Monte Carlo. Teoria do funcional da densidade. 


\section{Abstract}

CEZAR, H. M. Implementation of the Parallel Tempering Monte Carlo method to the study of thermodynamic properties of nanoclusters 2015. 97 p. Dissertação (Mestrado em Ciências) Instituto de Física de São Carlos, Universidade de São Paulo, São Carlos, 2015.

The use of nanomaterials in applications such as catalysis and medicine, aroused in the last years interest in studying properties of nanoclusters. The study of thermodynamic properties of these systems is essential, since structural changes originated from phase changes can alter properties such as catalytic activity, magnetic moment and optical properties. Molecular dynamics have been used for the computational study of thermodynamic properties of various nanomaterials, while the use of Monte Carlo methods (MC), in this context, has been restricted to the study of Lennard-Jones (LJ) nanoclusters. To evaluate the feasibility of using MC methods to study properties of real systems, an implementation of the Parallel Tempering Monte Carlo (PTMC) method using state of the art algorithms to perform exchanges, determine the temperature set and adjust the maximum displacement, was built. Through testing, it is shown that some of the implemented algorithms may not be suitable for the study of the problem in question. The implementation was validated by studying the thermodynamic properties of LJ nanoclusters with 38,55 and 147 atoms, which have results known in the literature. In addition, results for the properties of the $\mathrm{LJ}_{98}$ nanocluster are reported, and due to the structural features of this system, a solid-solid transition between the tetrahedral and icosahedral structures in a temperature below melting is observed. The possibility of using the PTMC algorithm in the study of properties of real materials, is tested in the $(\mathrm{PtCo})_{55}$ and $(\mathrm{PtNi})_{55}$ nanoalloys, described by the Gupta potential. By comparing the lowest energy structures with density functional theory (DFT) results, it is shown that the use of the Gupta potential can be justified, given the small deviation in the bond lenght (less than 2.4\%) and the similarity of other structural features. The results indicate that the PTMC method is able to identify the phase changes in the studied nanoalloys. These changes are illustrated and analyzed with the use of an algorithm for comparing the structure similarity, which made possible the analysis of the melting of the $\mathrm{Co}_{55}, \mathrm{Ni}_{55}, \mathrm{Pt}_{30} \mathrm{Co}_{25}$ e $\mathrm{Pt}_{40} \mathrm{Ni}_{15}$ nanoclusters (obtained at temperatures between 900 e $1100 \mathrm{~K}$ ); and the melting at $727 \mathrm{~K}$, and solid-solid transition at $300 \mathrm{~K}$, for $\mathrm{Pt}_{55}$. With the most frequent structures, obtained by the similarity analysis, and through DFT calculations, it was possible to observe a shift in the $d$ band center to the HOMO (Highest Occupied Molecular Orbital) caused by the temperature increase. This shift, following the $d$ band model valid for surfaces, may indicate a higher reactivity of the nanocluster in these cases.

Key-words: Thermodynamic properties. Nanoclusters. Monte Carlo method. Density functional theory. 



\section{Lista de figuras}

Figura 1 - Esquema do $i$-ésimo passo de PTMC . . . . . . . . . . . . . . . . . . 32

Figura 2 - Ilustração dos esquemas (a) PID e PIE e (b) Al, utilizados para a troca de réplicas no PTMC. . . . . . . . . . . . . . . . . . . . . . . . . . . . 34

Figura 3 - Esquema mostrando as listas, separadas por espécie, contendo as distâncias atômicas ordenadas da estrutura $A$. . . . . . . . . . . . . . . . . . . 42

Figura 4 - Fluxograma da implementação do algoritmo PTMC. As linhas tracejadas indicam os blocos simulados individualmente. . . . . . . . . . . . . . . 50

Figura 5 - Fluxograma de um passo de Monte Carlo. . . . . . . . . . . . . . . . . 53

Figura 6 - Diferentes valores de $r_{c}$ para os sistema (a) $\mathrm{LJ}_{13}$ e (b) $\mathrm{LJ}_{55} \ldots \ldots$. . . . . . 55

Figura 7 - Passos do algoritmo OE para obter os conjuntos de temperaturas para o sistema $\mathrm{LJ}_{38}$. Seguindo o algoritmo original, o número de passos de $\mathrm{MC}$ foi dobrado à cada passo do algoritmo $\mathrm{OE}$, partindo de $10^{7}$ passos. . . . . . . 59

Figura 8 - Passos do algoritmo OE para obter os conjuntos de temperaturas para o sistema $\mathrm{LJ}_{55}$. Seguindo o algoritmo original, o número de passos de $\mathrm{MC}$ foi dobrado à cada passo do algoritmo $\mathrm{OE}$, partindo de $10^{7}$ passos.

Figura 9 - Passos do algoritmo OE para obter os conjuntos de temperaturas para o sistema $\mathrm{LJ}_{38}$. O número de passos de $\mathrm{MC}$ foi aumentado em $20 \%$ a cada passo do algoritmo $\mathrm{OE}$, partindo no número inicial de $5 \times 10^{6}$ passos de $\mathrm{MC}$. Entre cada passo do OE, foi realizada uma termalização por $10^{7}$ passos de

Figura 10 - Passos do algoritmo OE para obter os conjuntos de temperaturas para o sistema $\mathrm{LJ}_{38}$. O número de passos de MC foi aumentado em $20 \%$ a cada passo do algoritmo OE, partindo no número inicial de $5 \times 10^{6}$ passos de MC. Entre cada passo do OE, foi realizada uma termalização por $10^{7}$ passos de MC . . . . . . . . . . . . . . . . . . . . . . . 62

Figura 11 - Curva de calor específico para os nanoclusters (a) $\mathrm{LJ}_{38}$ e (b) $\mathrm{LJ}_{55}$, calculadas utilizando o algoritmo MAPHPT e conjunto de temperaturas otimizado pelo algoritmo OE. 
Figura 12 - Conjuntos de temperaturas para os sistemas (a) $L J_{38}$ e (b) $L J_{55}$, obtidos com o algoritmo ACE.

Figura 13 - Curva de calor específico para os nanoclusters (a) $L J_{38}$ e (b) $L J_{55}$, calculadas utilizando o o algoritmo MAPHPT e conjunto de temperaturas otimizado pelo algoritmo ACE.

Figura 14 - Diferentes taxa de aceitação de Metropolis com algoritmos MTA e Percentual, para os nanoclusters (a) $L_{38}$ e (b) $L J_{55} \ldots$. . . . . . . . . . . . 66

Figura 15 - Diferentes critérios de convergência para a energia livre no algoritmo MAPHPT para o sistema $\mathrm{LJ}_{55}$.

Figura 16 - Curva de speedup para $10^{6}$ passos de PTMC considerando diferentes números de passos entre trocas $\left(N_{s w}\right)$, para os nanoclusters (a) $L J_{38}$ e (b) $L J_{147} \ldots 70$

Figura 17 - Curva de speedup para o nanocluster de $\mathrm{Pt}_{55}$ sendo o cálculo realizado com (a) $10^{6}$ passos e (b) $5 \times 10^{6}$ passos.

Figura 18 - Speedup obtido na execução do algoritmo MAPHPT. $N_{b i n s}$ indica o número de caixas utilizado na construção dos histogramas. . . . . . . . . . . . . 71

Figura 19 - Estruturas e grupo de simetria dos nanoclusters de LJ estudados. . . . . . 74

Figura 20 - Energia interna por átomo, $u$, e calor específico por átomo, $c_{v}$, dos nanoclusters $\mathrm{LJ}_{n}$ com $n=38,55,98$ e 147 . . . . . . . . . . . . . . . . . 75

Figura 21 - Calor específico e estruturas mais frequentes em temperaturas selecionadas para o nanocluster $\mathrm{LJ}_{38}$. . . . . . . . . . . . . . . . . . . . . . 77

Figura 22 - Calor específico e estruturas mais frequentes em temperaturas selecionadas para o nanocluster $\mathrm{LJ}_{55}$. . . . . . . . . . . . . . . . . . . . . . . . . . . . 78

Figura 23 - Calor específico e estruturas mais frequentes em temperaturas selecionadas para o nanocluster $\mathrm{LJ}_{98}$. . . . . . . . . . . . . . . . . . . . . . . . . . . . . 79

Figura 24 - Estruturas de diferentes composições das nanoligas ( $\mathrm{PtCo})_{55}$ e $(\mathrm{PtNi})_{55}$. . 80

Figura 25 - Energia de excesso $E_{\text {exc }}$ normalizada (veja texto) para as nanoligas (a) PtCo e (b) PtNi com 55 átomos. . . . . . . . . . . . . . . . . . . . . . 82

Figura 26 - Energia interna dos sistemas puros de $\mathrm{Pt}_{55}, \mathrm{Co}_{55}$ e $\mathrm{Ni}_{55}$, e nanoligas mais estáveis $\mathrm{Pt}_{30} \mathrm{Co}_{25}$ e $\mathrm{Pt}_{40} \mathrm{Ni}_{15} \ldots \ldots \ldots \ldots$. . . . . . . . . . . 83

Figura 27 - Calor específico e estruturas mais frequentes em temperaturas selecionadas para as nanoligas metálicas estudadas. . . . . . . . . . . . . . . . . . 84

Figura 28 - Gráfico pictórico ilustrando a SEP dos nanoclusters (a) $\mathrm{Pt}_{55}$ e (b) nanoclusters com mínimo global icosaédrico. . . . . . . . . . . . . . . . . 85

Figura 29 - Densidade de estados total ponderada (veja texto), e centro de banda dos nanoclusters estudadas. 


\section{Lista de abreviaturas e siglas}

\begin{tabular}{|c|c|}
\hline ACE & Algoritmo de Aumento Constante de Entropia \\
\hline AGG & Aproximação do Gradiente Generalizado \\
\hline Al & Algoritmo Amostragem Independente \\
\hline DFT & Teoria do Funcional da Densidade \\
\hline FHI-aims & Fritz Haber Institute ab initio molecular simulations \\
\hline GOTNano & Global Optimization and Thermodynamics of Nanoclusters \\
\hline HK & Hohenberg e Kohn \\
\hline HOMO & Highest Occupied Molecular Orbital \\
\hline KS & Kohn e Sham \\
\hline LJ & Lennard-Jones \\
\hline MAPHPT & Método de Análise Ponderada de Histograma para Parallel Tempering \\
\hline MC & Monte Carlo \\
\hline MTA & Método de Taxa de Aceitação \\
\hline NCE & Número de Coordenação Efetiva \\
\hline NP & Nanopartícula \\
\hline OE & Algoritmo Otimizado por Experiência \\
\hline PBE & Funcional de Perdew Burke e Ernzerhof \\
\hline PID & Algoritmo Par-ímpar Determinístico \\
\hline PIE & Algoritmo Par-ímpar Estocástico \\
\hline
\end{tabular}


PTMC Parallel Tempering Monte Carlo

RBHMC Revised Basin Hopping Monte Carlo

SEP Superfície de Energia Potencial 


\begin{tabular}{|c|c|}
\hline$T_{m}$ & Temperatura de fusão \\
\hline$C_{v}$ & Calor específico à volume constante \\
\hline$N$ & Número de átomos do sistema \\
\hline $\mathbb{U}$ & Energia potencial de interação \\
\hline $\mathbf{R}$ & Coordenadas atômicas \\
\hline$k$ & Constante de Boltzmann \\
\hline$T$ & Temperatura \\
\hline$\beta$ & Temperatura inversa dada por $1 / k T$ \\
\hline$N_{M C S}$ & Número de passos de Monte Carlo \\
\hline$M$ & Número de temperaturas no Parallel Tempering Monte Carlo \\
\hline$\delta$ & Deslocamento atômico máximo \\
\hline$U$ & Energia interna \\
\hline$d_{a v}$ & Comprimento de ligação ponderado médio \\
\hline$r_{i j}$ & Distância entre os átomos $i$ e $j$ \\
\hline$\Omega$ & Densidade de estados \\
\hline$\Delta$ & Critério de similaridade \\
\hline$P$ & Número de elétrons do sistema \\
\hline $\mathrm{LJ}_{n}$ & Nanocluster de Lennard-Jones com $n$ átomos \\
\hline$E_{e x c}$ & Energia de excesso \\
\hline
\end{tabular}





\section{Sumário}

INTRODUÇÃO . . . . . . . . . . . . . . . . 21

1.1 Motivação e justificativa . . . . . . . . . . . . . . . 21

1.2 Propriedades termodinâmicas de nanoclusters . . . . . . . . . . . . . 22

1.3 Objetivos e organização . . . . . . . . . . . . . . . . . . . . . . 24

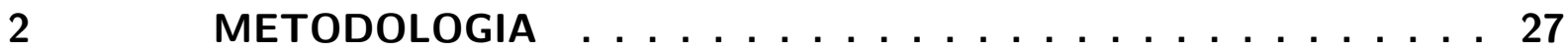

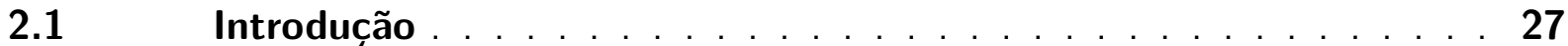

2.1.1 Valores esperados no ensemble canônico . . . . . . . . . . . . . . . . 27

2.1.2 Amostragem por importância . . . . . . . . . . . . . . . . . . . . . 28

$2.1 .3 \quad$ O algoritmo de Metropolis . . . . . . . . . . . . . . . . . . . . 29

2.1.4 Problemas com o Metropolis Monte Carlo . . . . . . . . . . . . . . . . . 30

$2.2 \quad$ Algoritmo Parallel Tempering Monte Carlo . . . . . . . . . . . . . . . 31

2.2.1 Derivação do Parallel Tempering Monte Carlo . . . . . . . . . . . . . . . . 31

2.2.2 Algoritmos de troca de réplicas . . . . . . . . . . . . . . . . . . . 33

2.2.3 Algoritmos de seleção de temperatura . . . . . . . . . . . . . . . . . 34

2.2.4 Algoritmos de otimização dos deslocamentos . . . . . . . . . . . . . 36

$2.3 \quad$ Propriedades . . . . . . . . . . . . . . . . . . . . . . . . . . 38

2.3.1 Propriedades termodinâmicas . . . . . . . . . . . . . . . . . 38

2.3.2 Propriedades estruturais . . . . . . . . . . . . . . . . . . . . . . . . . 41

$2.4 \quad$ Energia total . . . . . . . . . . . . . . . . . . . . . . . . . 43

2.4.1 Potenciais empíricos . . . . . . . . . . . . . . . . . 43

2.4.2 Potenciais de primeiros princípios . . . . . . . . . . . . . . 45

2.4.2.1 Aproximação de Born-Oppenheimer . . . . . . . . . . . . . . . . . . . 46

2.4.2.2 Teoria do funcional da densidade . . . . . . . . . . . . . . . . . . . 46

2.4.2.3 Energia de troca e correlação . . . . . . . . . . . . . . . . . . . . . . . 48

3 IMPLEMENTAÇÃO COMPUTACIONAL . . . . . . . . . . . 49

$3.1 \quad$ Introdução . . . . . . . . . . . . . . . . . . . 49

$3.2 \quad$ Estrutura de dados . . . . . . . . . . . . . . . . . . 51

$3.3 \quad$ Implementação de um passo de Monte Carlo . . . . . . . . . . . . . 53

$3.4 \quad$ Potencial de corte definindo o volume do nanocluster . . . . . . . . 54

3.5 Implementação das trocas de réplicas . . . . . . . . . . . . . . 55 
3.6 Inicialização, alocação de recursos e termalização . . . . . . . . 56

$3.7 \quad$ Otimização do conjunto de temperaturas . . . . . . . . . . . . . . 57

3.7.1 Algoritmo OE . . . . . . . . . . . . . . . . . 57

3.7.2 Algoritmo ACE . . . . . . . . . . . . . . . . . 61

$3.8 \quad$ Otimização do deslocamento máximo . . . . . . . . . . . . . . . 64

3.9 Cálculo das médias das propriedades . . . . . . . . . . . . . 65

3.10 Algoritmo para a determinação de frequência das estruturas por similaridade . . . . . . . . . . . . . . . . . . . . . . 67

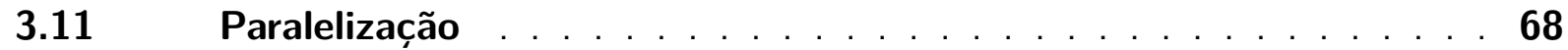

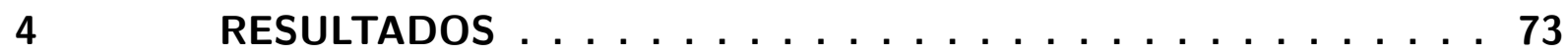

$4.1 \quad$ Nanoclusters de Lennard-Jones . . . . . . . . . . . . . . . . . . . . 73

4.1.1 Estruturas de mais baixa energia . . . . . . . . . . . . . . . . . . . 73

4.1.2 Propriedades termodinâmicas . . . . . . . . . . . . . . 74

$4.1 .3 \quad$ Análise estrutural . . . . . . . . . . . . . . . . . . . . . . . . 76

$4.2 \quad$ Nanoligas de metais de transição f . . . . . . . . . . . . . . . 78

4.2.1 Estruturas de mais baixa energia e avaliação do uso do potencial de Gupta para o estudo de nanoligas baseadas em $\mathrm{Pt}$. . . . . . . . . . . . . . . 79

4.2.2 Propriedades termodinâmicas e análise estrutural . . . . . . . . . . . . 82

4.2.3 Propriedades eletrônicas . . . . . . . . . . . . . . . . . . . . . . . . . 86

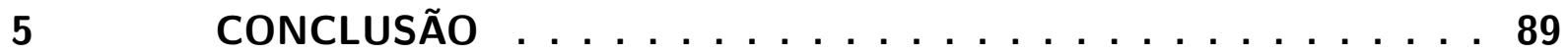

Referências . . . . . . . . . . . . . . . . . . . . 91 


\section{Capítulo 1}

\section{Introdução}

\subsection{Motivação e justificativa}

O estudo de nanomateriais como nanotubos, nanofios e nanopartículas, abriu portas para diversas aplicações tecnológicas, e impactou áreas como a catálise heterogênea (1) e a medicina, (2) na qual os nanomateriais são de grande importância no auxílio da detecção e tratamento de câncer. (3) Por exemplo, nanopartículas de ouro conjugadas à anticorpos podem ser utilizadas para a detecção de células cancerígenas, (4) e a utilização de nanopartículas de albumina (altamente solúveis em água) como invólucro para o Taxol (droga utilizada no tratamento quimioterápico de tumores), facilita o transporte da droga no organismo. (5)

Clusters, nanoclusters e nanopartículas (NPs) são definidos como um conjunto de átomos de uma ou mais espécies químicas que formam, por meio de ligações químicas, estruturas nanométricas. Essas partículas se diferenciam de moléculas por não terem uma composição fixa, e por possuírem diversos isômeros. Neste trabalho, baseando-se no diâmetro das estruturas a seguinte nomenclatura será utilizada: cluster para designar partículas de 0 a $1 \mathrm{~nm}$, nanocluster para partículas de 1 a $10 \mathrm{~nm}$, e nanopartícula para estruturas com diâmetro entre 10 e $100 \mathrm{~nm}$.

Esses nanomateriais possuem características peculiares, como propriedades que variam com o estado de carga, tamanho e/ou composição. Essas características em geral diferem das da forma bulk do material, e surgem de efeitos de confinamento quântico originados do tamanho e da grande razão superfície/volume que essas partículas possuem. A habilidade de se manipular propriedades magnéticas, $(6-8)$ catalíticas, $(1,9,10)$ óticas, $(11)$ eletrônicas $(12,13)$ e termodinâmicas $(14,15)$ alterando apenas o tamanho ou forma do material, desperta o interesse do uso dessas partículas em diversas aplicações.

Para a indústria química, por exemplo, há muito interesse no uso de nanoclusters e nanopartículas como catalisadores. (1) As propriedades catalíticas que variam com a composição, 
tamanho e forma, (16) permitem um ajuste que torna atraente o uso desses materiais. As aplicações, nesse caso, são diversas e vão desde de o uso de NPs de Au para a composiçao em tintas para reduzir os níveis de CO em ambientes, $(17,18)$ até o uso de NPs de Rh e Mn em nanotubos de carbono para uma maior eficiência na produção de etanol por fermentação de cana de açúcar ou milho. (19) Uma aplicação que se destaca por se tratar de uma fonte renovável de energia com alta eficiência, é o uso de nanoclusters como catalisadores na eletro-oxidação da mistura etanol-água, utilizada para a produção de hidrogênio em células combustíveis. $(20,21)$

Lord Kelvin se questionou, ainda durante o desenvolvimento da termodinâmica, sobre a influência do tamanho de uma partícula na sua temperatura de fusão. (22) Desde então, mais de um século se passou e hoje sabe-se que de uma maneira geral, a temperatura de fusão $T_{m}$ diminui com a diminuição do tamanho da partícula. (23) Contudo, estudos experimentais $(24,25)$ e teóricos (26) realizados nos últimos anos, mostram que graças às suas estruturas, clusters e nanoclusters de Ga podem apresentar temperatura de fusão superior à do bulk. Dessa maneira, fica claro que trabalhos envolvendo propriedades termodinâmicas e estruturais ainda são necessários para um entendimento completo do problema da fusão de nanomateriais.

Outra propriedade importante, observada tanto experimental, quanto teoricamente é o pré-derretimento. Para o caso de nanoclusters de Na com 139 e 147 átomos, por exemplo, o préderretimento é atribuído ao movimento anarmônico dos átomos, e leva à difusão das vacâncias no $\mathrm{Na}_{139}$, enquanto o pós-derretimento está ligado a manutenção de um núcleo de 13 átomos intacto no interior da estrutura icosaédrica do $\mathrm{Na}_{147}$. (27) Experimentalmente, nanoclusters de Al também apresentam pré-derretimento, (28) sendo este atribuído ao derretimento da casca dos nanoclusters ou mudanças estruturais, acarretando em uma mudança de fase sólido-sólido. O estudo das propriedades termodinâmicas de nanoclusters é, portanto, fundamental para o desenvolvimento de novos materiais, já que mudanças estruturais atribuídas às mudanças de fase podem impactar diretamente nas propriedades dos nanomateriais e, posteriormente suas aplicações.

\subsection{Propriedades termodinâmicas de nanoclusters}

Propriedades termodinâmicas de nanoclusters metálicos não suportados podem ser obtidas experimentalmente por meio de medidas do calor específico em função da temperatura. (14) Nesses estudos, nanoclusters de tamanho previamente selecionado por espectometria de massa, são termalizados em uma temperatura específica, para então serem transportados para um ambiente de alto vácuo, onde as medidas são realizadas. Tais medidas, que só podem ser realizadas em sistemas iônicos, utilizam a dissociação do nanocluster como referência para determinar a energia interna em função da temperatura. A energia interna é perturbada para a realização das medidas por meio de diferentes técnicas, que envolvem a absorção de fótons, (29) múltiplas colisões com átomos de gases raros (24) ou ainda colisões de átomos que se "grudam" 
ao nanocluster. (30) Com essas técnicas, o calor específico pode ser medido e, através dele, as mudanças de fase identificadas. Entretanto, limitações quanto à composição dos nanoclusters estudados e seu estado de carga, e quanto à possibilidade da medida de propriedades estruturais fazem com que estudos teóricos desses materiais sejam necessários para uma compreensão profunda dos mecanismos envolvidos nessas transições.

Computacionalmente, propriedades termodinâmicas, como o calor específico e energia interna, e propriedades estruturais podem ser obtidas por meio do uso de técnicas como dinâmica molecular ou Monte Carlo (MC). (31) A primeira delas, utiliza forças e equações de movimento para fazer a evolução temporal do sistema, simulando um ensemble com amostras que nos melhores casos, são obtidas após a simulação de alguns nanosegundos. Utilizando métodos de $\mathrm{MC}$, um ensemble estatístico no equilíbrio também é simulado. Nesse caso, através da amostragem aleatória de uma distribuição de probabilidades pertinente, o cálculo das integrais multi-dimensionais envolvidas na determinação dos valores esperados é simplificado. As duas técnicas têm sido utilizadas para realizar esse tipo de estudo, sendo ambas capazes de produzir resultados satisfatórios para as propriedades de nanoclusters e de determinar a temperatura de fusão do material.

Utilizando dinâmica molecular, uma série de estudos envolvendo nanoclusters de diferentes tamanhos e composições já foi realizada. Ercolessi, Andreoni e Tosatti(32) fizeram um dos primeiros estudos envolvendo nanoclusters de $\mathrm{Au}$ e, com a utilização de potenciais empíricos, encontraram evidência de pré-derretimento causado pela difusividade dos átomos. Também utilizando potenciais empíricos, Sankaranarayanan, Bhethanabotla e Joseph(33) estudaram nanoligas de Pt-Pd e observaram o derretimento da superfície antes do derretimento completo do núcleo, favorecendo a difusão de átomos de Pt do interior para a superfície do nanocluster. Dinâmica molecular com potenciais de primeiros princípios foi utilizada por Steenbergen e Gaston(26) que, empregando dinâmica molecular de Born-Oppenheimer (BOMD) juntamente com Parallel Tempering, estudaram clusters de Ga com até 12 átomos, encontrando temperatura de fusão maior que a bulk para os nanoclusters com 9,10 e 11 átomos, além de não observarem a fusão dos sistemas com 7 e 8 átomos. Nanoclusters de Al também foram alvo de diversos estudos com BOMD, como os de Aguado e López(34) que, além de observarem mudanças na $T_{m}$ dos nanoclusters com a mudança do estado de carga (também observada por Starace et al.(35)), também encontraram uma fase termodinâmica intermediária entre as fases sólida e líquida.

O uso de métodos de $\mathrm{MC}$, por outro lado, está tipicamente restrito à sistemas modelo, como é o caso dos nanoclusters de Lennard-Jones (LJ). Talvez a primeira tentativa da utilização de MC para o cálculo de propriedades de nanoclusters tenha sido feita por Lee, Barker e Abraham. (36) Nesse trabalho de 1973, as primeiras ideias da construção de um algoritmo de $\mathrm{MC}$ para o estudo das propriedades de nanoclusters, como a definição de um potencial de corte definindo o nanocluster, foram implementadas e testadas em nanoclusters 
de Ar. Muito foi desenvolvido desde então, e o surgimento de técnicas de ensemble estendido, além de outros algoritmos que exploram ao máximo os dados amostrados, como os algoritmos multi-histograma, $(37,38)$ aumentaram significativamente a eficiência desse tipo de simulação.

Empregando o algoritmo Parallel Temperting Monte Carlo (PTMC), (39) nanoclusters de LJ com até algumas centenas de átomos já foram estudados. (40) Dentre esses nanoclusters, se destacam os que possuem uma estrutura de mais baixa energia não icosaédrica, como o $\mathrm{LJ}_{38}$, alvo de muitos estudos envolvendo desde a sua fusão até o pré-derretimento que decorre de uma mudança de fase sólido-sólido, onde a transição da estrutura de mínimo global para a estrutura de icosaedro incompleto é observada. $(41,42)$ Além desse, tem-se que o $L_{75}$, que possui um decaedro como mínimo global e exibe uma transição sólido-sólido para a estrutura icosaédrica pré-derretimento, (43) e o $\mathrm{LJ}_{309}$, que exibe um pré-derretimento devido às transformações estruturais das camadas da estrutura icosaédrica, (44) foram alvos de estudos específicos. Em todos esses casos, o PTMC mostrou-se uma técnica eficaz, capaz de superar as barreiras de energia e amostrar o espaço de forma ergódica.

O atrativo de aproximações possíveis à dinâmica molecular de primeiros princípios, como a dinâmica molecular de Car-Parrinelo, (45) e a disponibilidade comercial de códigos que utilizam dinâmica molecular (tanto nos níveis empírico, semi-empírico como de primeiros princípios), fazem com que esse método seja amplamente utilizado para o cálculo de propriedades termodinâmicas de nanoclusters e NPs. Contudo, a utilização dessa técnica em diversos estudos não implica, necessariamente, que a mesma é a mais adequada. Assim como MC, a dinâmica molecular pode sofrer com problemas originados da dificuldade de exploração do espaço configuracional, de modo que, para minimizar esse problemas, o uso de técnicas como a Replica Exchange (46) (que facilita a superação de barreiras de energia) pode ser necessária.

Os diversos estudos utilizando técnicas de MC sobre sistemas modelo apontam que esses algoritmos são capazes de amostrar com eficiência mesmo nos casos onde a convergência é dificultada, como para os nanoclusters $\mathrm{LJ}_{38}$ e $\mathrm{LJ}_{75}$. Além disso, estudos comparativos para amostragem conformacional de hexano líquido, já mostraram que técnicas de MC podem ser até 3.8 vezes mais rápidas que dinâmica molecular. (47) Esses fatos fazem a hipótese do uso de algoritmos de MC para o cálculo de propriedades de nanoclusters de materiais reais ao menos plausível, devendo essa ser avaliada.

\subsection{Objetivos e organização}

Este trabalho tem o objetivo de verificar a viabilidade do uso de métodos de MC para o estudo de propriedades termodinâmicas e estruturais de clusters e nanopartículas de materiais reais. Buscando alcançar esse objetivo e avaliar o seu sucesso, essa dissertação foi dividida em três partes: 
- Implementação do método PTMC para o estudo de propriedades termodinâmicas de clusters, nanoclusters e NPs;

- Validação da implementação do algoritmo, por meio do estudo de nanoclusters de LJ;

- Estudo das propriedades de nanoligas de metais de transição.

Nos capítulos 2 e 3, a fundamentação teórica e os detalhes de implementação do método utilizado são, respectivamente, apresentados. $O$ capítulo 4 contém os resultados utilizados para a validação do algoritmo, assim como os resultados obtidos no estudo de nanoligas de $(\mathrm{PtCo})_{55}$ e $(\mathrm{PtNi})_{55}$. Finalmente, no capítulo 5 as conclusões obtidas com esse estudo são apresentadas. 



\section{Capítulo 2}

\section{Metodologia}

\subsection{Introdução}

Os métodos de MC são utilizados para o cálculo de integrais através de amostragem estatística. Esses métodos são extremamente eficientes e podem ser aplicados no estudo de diversos problemas dentro da física estatística. (48) $\mathrm{O}$ algoritmo de Metropolis realiza uma amostragem por importância, selecionando as amostras por meio da distribuição de Boltzmann. Esse algoritmo, apesar de ter sido previamente utilizado para estudos de propriedades de nanoclusters, (37) sofre com problemas relativos a relaxação lenta e a manutenção da ergodicidade. Esses problemas são minimizados com o uso de técnicas de ensemble estendido, como por exemplo o PTMC, que utiliza diversas réplicas em diferentes temperaturas para construir um novo ensemble onde tentativas de troca entre réplicas em diferentes temperaturas são realizadas.

\subsubsection{Valores esperados no ensemble canônico}

O ensemble canônico é um ensemble utilizado para representar os estados de um sistema em equilíbrio com um reservatório térmico. Por considerar número de partículas $(N)$, o volume $(V)$, e a temperatura $(T)$ constantes, esse ensemble também é conhecido como ensemble $N V T$, e é um dos ensembles que pode ser utilizado para calcular as propriedades termodinâmicas de nanoclusters e NPs.

Sendo $\mathbb{H}\left(\mathbf{R}^{N}, \mathbf{P}^{N}\right)$ o Hamiltoniano de um sistema de especificado pelas posições atômicas $\mathbf{R}^{N}=\left\{\mathbf{R}_{1}, \mathbf{R}_{2}, \ldots, \mathbf{R}_{\mathbf{N}}\right\}$ e momentos $\mathbf{P}^{N}=\left\{\mathbf{P}_{\mathbf{1}}, \mathbf{P}_{\mathbf{2}}, \ldots, \mathbf{P}_{\mathbf{N}}\right\}$, a função de partição canônica pode ser escrita como

$$
\mathcal{Q} \sim \iint \cdots \int \exp \left[-\beta \mathbb{H}\left(\mathbf{R}^{N}, \mathbf{P}^{N}\right)\right] d \mathbf{P}^{N} d \mathbf{R}^{N},
$$

sendo $\beta=1 / k T$ a temperatura inversa. Assim, o valor esperado de uma propriedade $A^{\prime}$, pode 
ser obtido nesse ensemble por meio da solução da equação:

$$
\left\langle A^{\prime}\right\rangle=\frac{\iint \cdots \int d \mathbf{P}^{N} d \mathbf{R}^{N} A^{\prime}\left(\mathbf{R}^{N}, \mathbf{P}^{N}\right) \exp \left[-\beta \mathbb{H}\left(\mathbf{R}^{N}, \mathbf{P}^{N}\right)\right]}{\iint \cdots \int d \mathbf{P}^{N} d \mathbf{R}^{N} \exp \left[-\beta \mathbb{H}\left(\mathbf{R}^{N}, \mathbf{P}^{N}\right)\right]} .
$$

Entretanto, na maioria dos casos a energia potencial de interação $\mathbb{U}\left(\mathbf{R}^{N}\right)$ não depende dos momentos, de modo que pode-se separar o Hamiltoniano em uma parte dependente apenas do momento e outra dependente apenas da posição $\left(\mathbb{H}\left(\mathbf{R}^{N}, \mathbf{P}^{N}\right)=\mathbb{K}\left(\mathbf{P}^{N}\right)+\mathbb{U}\left(\mathbf{R}^{N}\right)\right.$, com $\left.\mathbb{K}=\sum_{i=1}^{N} \frac{P_{i}^{2}}{2 M_{i}}\right)$. Assim, se a propriedade também puder ser separada dessa maneira $\left(A^{\prime}\left(\mathbf{R}^{N}, \mathbf{P}^{N}\right)=A_{p}\left(\mathbf{P}^{N}\right)+A\left(\mathbf{R}^{N}\right)\right)$, a equação 2.2 pode ser reescrita como:

$$
\left\langle A^{\prime}\right\rangle=\frac{\iint \cdots \int d \mathbf{P}^{N} A_{p}\left(\mathbf{P}^{N}\right) \exp \left[-\beta \mathbb{K}\left(\mathbf{P}^{N}\right)\right]}{\iint \cdots \int d \mathbf{P}^{N} \exp \left[-\beta \mathbb{K}\left(\mathbf{P}^{N}\right)\right]}+\frac{\iint \cdots \int d \mathbf{R}^{N} A\left(\mathbf{R}^{N}\right) \exp \left[-\beta \mathbb{U}\left(\mathbf{R}^{N}\right)\right]}{\iint \cdots \int d \mathbf{R}^{N} \exp \left[-\beta \mathbb{U}\left(\mathbf{R}^{N}\right)\right]} .
$$

Para o cálculo de médias de energia, ${ }^{*}$ a integral dependente do momento da equação 2.3 é conhecida como a solução do gás ideal no ensemble canônico, e pode ser obtida analiticamente (veja por exemplo a referência 49). Por esse motivo, o interesse da utilização desses método está somente para solução da integral

$$
\langle A\rangle=\frac{\iint \cdots \int d \mathbf{R}^{N} A\left(\mathbf{R}^{N}\right) \exp \left[-\beta \mathbb{U}\left(\mathbf{R}^{N}\right)\right]}{\mathcal{Z}},
$$

onde $\mathcal{Z}$ é a função de partição configuracional, dada por

$$
\mathcal{Z} \equiv \iint \cdots \int d \mathbf{R}^{N} \exp \left[-\beta \mathbb{U}\left(\mathbf{R}^{N}\right)\right]
$$

A solução da integral da equação 2.4 para o cálculo de propriedades termodinâmicas de aglomerados atômicos não é trivial, e somente pode ser realizada numericamente. Ainda assim, algoritmos tradicionais de integração, como o método do trapézio ou de Simpson, costumam sofrer com grandes erros numéricos no cálculo de integrais multi-dimensionais. Neste trabalho, as integrais dadas pelas equações 2.4 e 2.5 são calculadas através da utilização de técnicas de MC.

\subsubsection{Amostragem por importância}

A qualidade dos resultados obtidos com simulações de MC está diretamente relacionada à forma como é feita a amostragem. Para sistemas onde o espectro de energia é contínuo ou o número de estados do sistema é muito grande, é computacionalmente impossível amostrar todos os possíveis pontos no domínio de integração. Uma das alternativas para a solução desse problema, é a utilização da técnica de amostragem por importância, onde os pontos são amostrados segundo uma distribuição de probabilidades.

\footnotetext{
* Como o da energia interna, utilizada neste trabalho por permitir o estudo de mudanças de fase.
} 
Para sistemas em equilíbrio térmico com um reservatório na temperatura inversa $\beta$ é conhecido* que os microestados $\mu$ são distribuídos pela distribuição de Boltzmann:

$$
p_{\mu}^{\beta} \equiv \frac{\exp \left[-\beta \mathbb{U}_{\mu}\right]}{\sum_{\nu} \exp \left[-\beta \mathbb{U}_{\nu}\right]},
$$

onde $\mathbb{U}_{\mu}$ representa a energia total do sistema no estado $\mu$.

Um algoritmo capaz de amostrar estados com essa distribuição, fazendo uma amostragem por importância, pode simplificar de maneira considerável o cálculo da integral da equação 2.4 , já que essa é a distribuição dos pesos dos estados. Se $N_{M C S}$ amostras são obtidas seguindo a equação 2.6, o estimador do valor esperado de uma propriedade no ensemble canônico é dado por uma simples somatória:

$$
\langle A\rangle_{N_{M C S}}=\frac{1}{N_{M C S}} \sum_{i=1}^{N_{M C S}} A\left(\mathbf{R}_{i}^{N}\right) .
$$

Para simplificar a notação, o subíndice de $\langle A\rangle_{N_{M C S}}$ será omitido ao longo do texto, de modo que as referências à $\langle A\rangle$, na verdade se referirão o estimador da equação 2.7 .

\subsubsection{O algoritmo de Metropolis}

O algoritmo de Metropolis ${ }^{\dagger}$ é um método de Monte Carlo de cadeia de Markov, que faz a amostragem de estados aleatoriamente, conforme a distribuição de Boltzmann. Partindo de um estado identificado por $o$ (especificado pelo conjunto de posições $\left\{\mathbf{R}_{o}^{N}\right\}$ ), a probabilidade de transição para um estado $n$ (representando $\left\{\mathbf{R}_{n}^{N}\right\}$ ) é dada por $\pi(o \rightarrow n)$. Essa probabilidade pode ser decomposta como

$$
\pi(o \rightarrow n)=\alpha(o \rightarrow n) \times a c c(o \rightarrow n)
$$

onde $\alpha(o \rightarrow n)$ dá a probabilidade de ocorrer um processo que mude o sistema do estado $o$ para $n$, e $\operatorname{acc}(o \rightarrow n)$ representa a probabilidade de aceitação de tal processo. Para a amostragem ser feita baseada na distribuição de Boltzmann, a probabilidade de aceitação $\operatorname{acc}(o \rightarrow n)$ deve ser escolhida de forma pertinente.

Essa escolha no entanto deve ser feita de modo que a condição de balanço detalhado seja obedecida. Essa condição garante que o sistema permanece em equilíbrio impondo que cada processo deve ser equilibrado pelo seu processo reverso. Para processos de Markov o balanço detalhado é obedecido se a geração dos estados obedecerem a equação

$$
p_{o}^{\beta} \pi(o \rightarrow n)=p_{n}^{\beta} \pi(n \rightarrow o) .
$$

\footnotetext{
* Conforme o formulado por Ludwig Boltzmann em 1896, e posteriormente investigado por Josiah Gibbs em 1902 no seu trabalho pioneiro pai da mecânica estatística moderna.

† Também conhecido como algoritmo de Metropolis-Hastings, por ter sido generalizado por Hastings(50) em 1970.
} 
Considerando que não há preferência quanto a direção* tem-se que $\alpha(o \rightarrow n)=\alpha(n \rightarrow$ $o$ ), e assim pode-se usar a equação 2.8 no balanço detalhado para simplificar a condição para

$$
\frac{\operatorname{acc}(o \rightarrow n)}{\operatorname{acc}(n \rightarrow o)}=\frac{p_{n}^{\beta}}{p_{o}^{\beta}}=\exp \left[-\beta\left(\mathbb{U}_{n}-\mathbb{U}_{o}\right)\right]
$$

onde o lado direito da igualdade é obtido substituindo as probabilidades $p_{o}^{\beta}$ e $p_{n}^{\beta}$ com a probabilidade dada pela equação 2.6. A condição proposta por Metropolis e seus colaboradores que satisfaz a equação 2.10 , e também o fato de que a probabilidade $\operatorname{acc}(o \rightarrow n) \leq 1$, é dada por:

$$
\operatorname{acc}(o \rightarrow n)= \begin{cases}\frac{p_{n}^{\beta}}{p_{o}^{\beta}} & \text { se } p_{n}^{\beta}<p_{o}^{\beta} \\ 1 & \text { se } p_{n}^{\beta} \geq p_{o}^{\beta}\end{cases}
$$

que é o chamado "critério de Metropolis". Esse critério é verificado antes da aceitação de qualquer estado, sendo que quando um estado é rejeitado pelo critério, o anterior é mantido e sua contribuição para as médias é contada novamente. A importância da recontagem dos estados antigos no caso de uma rejeição pelo critério de Metropolis é para que as probabilidades de transição sejam normalizadas. (31) Os detalhes práticos da utilização do algoritmo são discutidos na seção 3.3 .

\subsubsection{Problemas com o Metropolis Monte Carlo}

$\mathrm{O}$ algoritmo de Metropolis e os métodos tradicionais de MC podem enfrentar dificuldades ao tentar manter a ergodicidade em alguns sistemas. A condição de ergodicidade diz que todos os estados do sistema devem ser acessíveis a partir de qualquer outro estado, através de um número finito de passos. (51) Em princípio, se os estados são gerados de uma maneira que essa condição é obedecida, a condição de ergodicidade é válida com o critério de Metropolis. Entretanto, essa condição pode ser quebrada quando se encontra o problema de relaxamento lento, (52) por exemplo próximo à transições de fase. Nesses casos, o número efetivo de amostras é reduzido pois o sistema perde muitos passos de $M C$ descorrelacionando os estados. Uma consequência desse fato são resultados que podem ser dependentes das condições iniciais.

O relaxamento lento também pode ser observado durante a amostragem de sistemas que possuem superfície de energia potencial (SEP) rugosa. (52) Sistemas complexos com vários graus de liberdade, como é o caso de nanoclusters e NPs, costumam possuir um SEP com um número de mínimos locais da ordem de $e^{N}$, o que dificulta a exploração do espaço de fase. Nesses casos, os estados amostrados costumam corresponder apenas a uma pequena região do espaço de fase, pois a temperatura necessária para se escapar dos mínimos pode

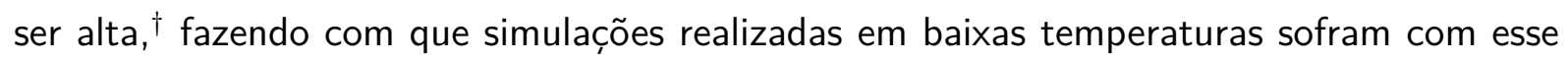

\footnotetext{
* Ou seja, considerando que a probabilidade de partindo do estado o o estado $n$ seja gerado, é igual a probabilidade do processo reverso.

$\dagger$ Note que para uma temperatura infinita, $\beta \rightarrow 0$ e portanto os estados são sempre aceitos conforme o critério da equação 2.11
} 
problema. O desafio na amostragem de estados para a simulação de nanoclusters e NPs se dá justamente pelas características da sua SEP, de modo que para o estudo das propriedades desse tipo de sistema, a utilização de algoritmos que vão além do tradicional método de Metropolis é necessária.

\subsection{Algoritmo Parallel Tempering Monte Carlo}

Diversos algoritmos foram e vem sendo propostos como alternativas aos métodos clássicos de MC. Dentre esses algoritmos se destacam os algoritmos de ensemble expandido (53) e têmpera simulada, (54) MC multi-canônico, (55) e também o PTMC. (39) Esse último, que também possui uma versão para dinâmica molecular, vêm sendo aplicado com sucesso no estudo de nanoclusters de LJ, conforme mostrado no capítulo 1. Baseado na observação de que a temperatura na qual o sistema é simulado pode afetar a exploração do espaço de fase, Swendsen e Wang(56) propuseram em 1986 um método que utilizava diversas réplicas em diferentes temperaturas, e misturava as configurações após passos de MC. Esse método conhecido como Replica Monte Carlo, foi posteriormente aprimorado por Hukushima e Nemoto(39), e se tornou o PTMC da forma hoje conhecida.

\subsubsection{Derivação do Parallel Tempering Monte Carlo}

A ideia do PTMC baseia-se na construção de um ensemble com $M$ diferentes simulações (utilizando o algoritmo de Metropolis) não interagentes, ${ }^{*}$ cada uma delas em contato térmico com um reservatório em uma temperatura $\beta_{m}$ diferente. Essas simulações são realizadas simultaneamente (em paralelo), e tentativas de troca entre configurações em temperaturas diferentes são feitas periodicamente. Um esquema ilustrando um passo de PTMC é apresentado na figura 1 , onde fica clara a ideia das trocas com os passos independentes de MC.

Atribuindo a cada réplica uma temperatura $\beta_{m}$, e por convenção adotando que $\beta_{m}<$ $\beta_{m+1}$, pode-se então de um modo análogo ao feito na subseção 2.1.3, encontrar a condição para que ocorram as trocas e o sistema continue em equilíbrio. Pela distribuição de Boltzmann, tem-se que a distribuição de probabilidade $p_{\mu_{m}}^{\beta_{m}}$ de se encontrar um sistema em um estado $\mu_{m}$ em uma temperatura inversa $\beta_{m}$ é dada pela equação 2.6. Desse modo, a distribuição de estados com a qual a amostragem deve ser feita envolve a distribuição de probabilidades das $M$ réplicas

$$
P_{\mu}^{\beta}=\prod_{m=1}^{M} p_{\mu_{m}}^{\beta_{m}} .
$$

Novamente, para garantir que o novo ensemble esteja em equilíbrio, a condição do

\footnotetext{
* No sentido de cada uma poder ser tratada como um ensemble independente.
} 
Figura 1 - Esquema do $i$-ésimo passo de PTMC.

\section{i-ésimo passo de Monte Carlo}

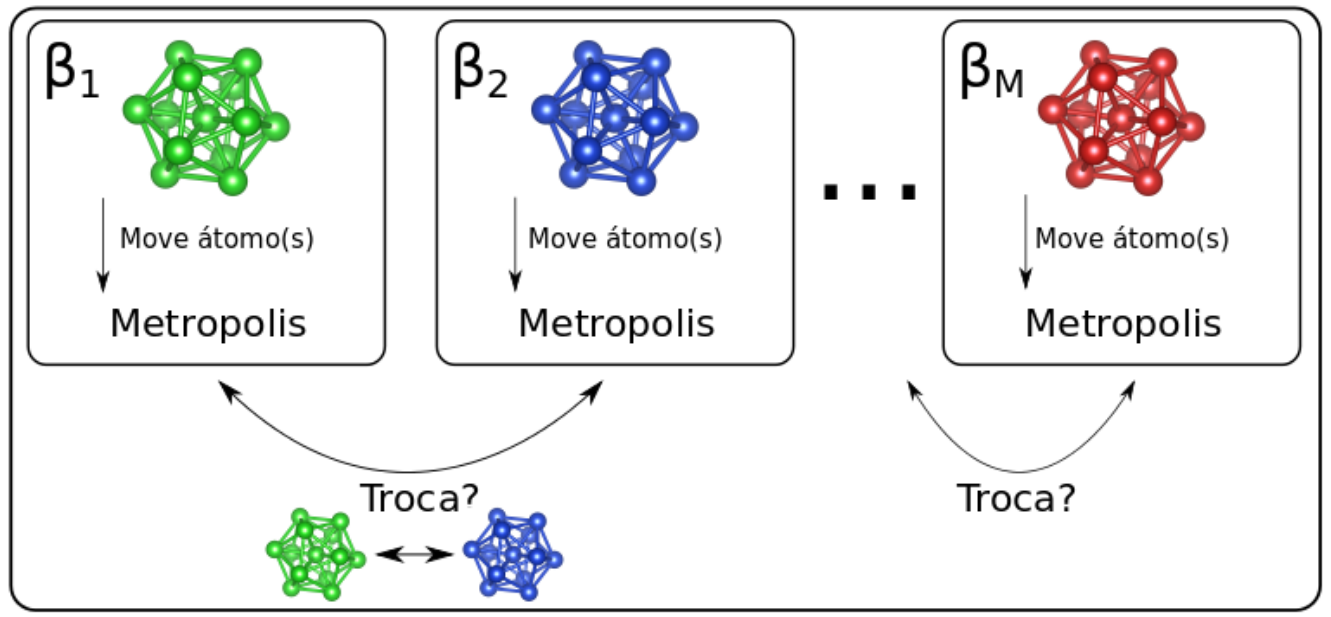

Fonte: Elaborada pelo autor.

balanço detalhado é exigida. A transição de estados para qual quer-se encontrar a probabilidade de transição, troca as configurações associadas a um par de temperaturas, mudando o estado do ensemble de $\mu$ para um novo estado $\nu$ onde todos os pares de temperatura e estado continuam os mesmos exceto para duas temperaturas $\beta_{m}$ e $\beta_{n}$, onde os estados são trocados. A condição do balanço detalhado nessas condições é então dada por:

$$
\left(\cdots \times p_{\mu_{m}}^{\beta_{m}} \times \cdots \times p_{\mu_{n}}^{\beta_{n}} \times \ldots\right) \pi(\mu \rightarrow \nu)=\left(\cdots \times p_{\mu_{n}}^{\beta_{m}} \times \cdots \times p_{\mu_{m}}^{\beta_{n}} \times \ldots\right) \pi(\nu \rightarrow \mu),
$$

onde $\pi(\mu \rightarrow \nu)$ representa a probabilidade de transição, que é composta por

$$
\pi(\mu \rightarrow \nu)=\alpha(\mu \rightarrow \nu) \operatorname{acc}(\mu \rightarrow \nu)
$$

ou seja, a probabilidade de ocorrer o processo $\alpha(\mu \rightarrow \nu)$ vezes a sua probabilidade de aceitação.

Considerando novamente que $\alpha(\mu \rightarrow \nu)=\alpha(\nu \rightarrow \mu)$, onde não há favorecimento na direção dos processos, tem-se que a aceitação é dada pela substituição da equação 2.6 na equação 2.12:

$$
\begin{aligned}
\frac{\operatorname{acc}(\mu \rightarrow \nu)}{\operatorname{acc}(\nu \rightarrow \mu)} & =\frac{p_{\mu_{1}}^{\beta_{1}} \cdot p_{\mu_{n}}^{\beta_{m}} \cdot-p_{\mu_{m}}^{\beta_{n}} \cdots p_{\mu_{M}}^{\beta_{M}}}{p_{\mu_{1}}^{\beta_{1}} \cdot p_{\mu_{m}}^{\beta_{m}} \cdot p_{\mu_{n}}^{\beta_{n}} \cdots p_{\mu_{M}}^{\beta_{M}}} \\
& =\exp \left[-\beta_{m} \mathbb{U}\left(\mathbf{R}_{n}^{N}\right)-\beta_{n} \mathbb{U}\left(\mathbf{R}_{m}^{N}\right)+\beta_{m} \mathbb{U}\left(\mathbf{R}_{m}^{N}\right)+\beta_{n} \mathbb{U}\left(\mathbf{R}_{n}^{N}\right)\right] \\
& =\exp \left\{\left(\beta_{m}-\beta_{n}\right)\left[\mathbb{U}\left(\mathbf{R}_{m}^{N}\right)-\mathbb{U}\left(\mathbf{R}_{n}^{N}\right)\right]\right\} .
\end{aligned}
$$

A probabilidade de aceitação na equação 2.15 é similar à da equação 2.10, e por esse motivo, pode-se escolher novamente o critério de Metropolis para que a amostragem seja feita com a distribuição correta, garantindo o equilíbrio termodinâmico:

$$
\operatorname{acc}(\mu \rightarrow \nu)= \begin{cases}\exp (\Delta) & \text { se } \Delta<0 \\ 1 & \text { se } \Delta \geq 0\end{cases}
$$


onde $\Delta=\left(\beta_{m}-\beta_{n}\right)\left[\mathbb{U}\left(\mathbf{R}_{m}^{N}\right)-\mathbb{U}\left(\mathbf{R}_{n}^{N}\right)\right]$.

Esse critério, define portanto a probabilidade de aceitação das trocas no método PTMC. Contudo, os algoritmos utilizados para a troca de réplicas, seleção de temperatura, entre outros, não são especificados pelo método. Essa liberdade abre um leque de possibilidades, fazendo com que um conjunto de algoritmos possa ser mais adequado ao estudo de cada problema. Os algoritmos estudados e utilizados nessa dissertação, serão apresentados nas próximas subseções, sendo os detalhes referentes à implementação e a comparação entre esses métodos deixadas para o capítulo 3 .

\subsubsection{Algoritmos de troca de réplicas}

O sucesso do método PTMC depende em grande parte dos algoritmos utilizados para a troca das réplicas. A eficiência da amostragem mais eficiente do espaço de fase, e a facilidade com a qual barreiras de energia podem ser superadas, estão diretamente ligadas a esses protocolos. (57) Existem em geral na literatura dois tipos de protocolos utilizados para a seleção das réplicas candidatas a troca. (57-59) Os mais simples deles tratam-se de protocolos de trocas entre primeiros vizinhos, ${ }^{*}$ e exploram o fato de que para vizinhos além dos primeiros as taxas de aceitação das trocas são em geral pequenas. Por outro lado, a segunda classe de protocolos tenta explorar algoritmos que propõe trocas entre todos os pares, buscando maximizar as possibilidades de troca. Neste trabalho mencionarei três algoritmos para a troca de réplicas, sendo dois deles algoritmos de trocas entre primeiros vizinhos e outro para trocas entre vizinhos não adjacentes.

Os algoritmos par-ímpar estocástico e par-ímpar determinístico (57) (siglas PIE e PID) são similares, e aparecem como uma alternativa simples e eficiente para a troca aos pares entre primeiros vizinhos. Esses algoritmos se baseiam na divisão do conjunto de temperaturas em duas diferentes listas: uma contendo pares de índices iniciados com um índice par, e representada por $\mathcal{P}=(2 j, 2 j+1) \in \mathcal{N}$, e outra com pares de índices iniciados com índices ímpares, representada por $\mathcal{I}=(2 j-1,2 j) \in \mathcal{N}$. O conjunto $\mathcal{N}$ contém todos os possíveis pares de índices adjacentes das $M$ temperaturas, e é dado por $\mathcal{N}=\{(i, i+1) \mid i=1,2, \ldots, M-1\}$. Por exemplo, a lista dos pares de índices pares é iniciada pela temperatura de índice 2, de modo que os pares são $(2,3),(4,5),(6,7)$ e assim sucessivamente. Já os pares da lista dos pares iniciados com índice ímpar é iniciada pela temperatura de índice 1 , formando os pares $(1,2),(3,4),(5,6)$ etc. Essas listas são representadas na figura 2(a) por meio das setas de cores preta e vermelha, onde os círculos pretos representam as réplicas de uma temperatura simulada no ensemble.

A diferença entre os dois algoritmos é sutil, e se dá na forma como essas listas são escolhidas a cada passo de troca. O algoritmo PIE consiste de a cada passo de troca, selecionar $\mathcal{P}$ ou $\mathcal{I}$ aleatoriamente (com probabilidade $\frac{1}{2}$ cada uma) e realizar as tentativas de troca

\footnotetext{
* Entendendo como vizinhos nesse caso, temperaturas vizinhas na lista das M temperaturas.
} 
Figura 2 - Ilustração dos esquemas (a) PID e PIE e (b) Al, utilizados para a troca de réplicas no PTMC.

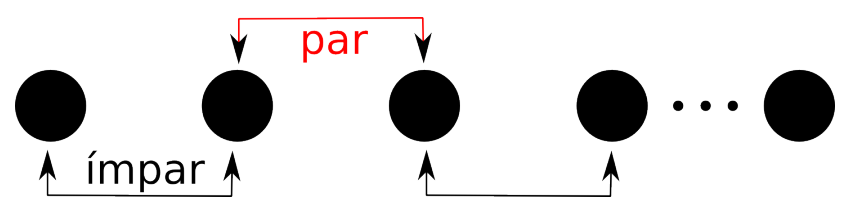

(a) PID e PIE

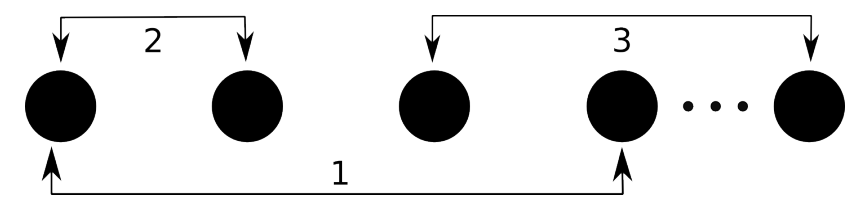

(b) $\mathrm{Al}$

Fonte: Elaborada pelo autor.

entre todos os pares de réplicas pertencentes à lista selecionada. $\mathrm{O}$ algoritmo PID, por outro lado, seleciona $\mathcal{P}$ e $\mathcal{I}$ alternadamente, e também tenta as trocas em todos os pares da lista selecionada. Apesar da similaridade entre os algoritmos, a referência 57 apresenta resultados que mostram que o algoritmo PID (quando comparado ao PIE) demonstra maiores taxas de ida-volta, ou seja, o algoritmo gasta menos tempo para fazer uma estrutura sair da temperatura mais baixa, ir até a mais alta, e voltar.

Já na classe de algoritmos que realizam as tentativas de trocas não somente entre vizinhos, tem-se o algoritmo de amostragem independente (59) ( $\mathrm{Al}$ ). A ideia por trás do algoritmo está baseada no embaralhar de cartas, onde para $N$ cartas, $N \ln N$ movimentos são o suficiente para deixar o baralho em uma configuração completamente aleatória. Contudo, dado que a troca entre replicas ocorre com uma probabilidade dada pela equação 2.16 (que em geral é menor que 1), um número maior de tentativas de troca deve ser feita para alcançar um número próximo a $M \ln M$ trocas aceitas, e assim, obter um conjunto de réplicas embaralhadas entre as temperaturas. $\mathrm{O}$ algoritmo Al seleciona então $M^{3}$ pares de temperaturas, dentre os quais ocorrem as tentativas de troca. Esses pares são indicados pelos números $1,2,3, \ldots$ da figura 2(b), onde uma ilustração do método é apresentada.

\subsubsection{Algoritmos de seleção de temperatura}

Do mesmo modo que há vários algoritmos disponíveis na literatura para a troca de réplicas, há também diversos algoritmos que definem as temperaturas nas quais cada réplica será simulada. (39, 58, 60-62) Dado que a aceitação das trocas depende da diferença de temperaturas conforme mostra a equação 2.16 , o número de temperaturas $M$, e a temperatura na qual cada réplica é simulada, são largamente responsáveis pela taxa de aceitação das trocas em uma simulação de PTMC, e por consequência também são responsáveis pela eficiência da amostragem. Dentre os algoritmos existentes para realizar a seleção de temperaturas em uma 
simulação de PTMC, estão os algoritmos de distribuição geométrica, otimizado por experiência $(\mathrm{OE})$ e o algoritmo de aumento constante de entropia (ACE).

O algoritmo mais simples para gerar essas temperaturas, é o que geras as temperaturas de acordo com uma progressão geométrica. (63) Nesse caso, a distribuição de temperaturas é feita definindo as temperaturas máxima $\left(T_{\max }\right)$ e mínima $\left(T_{\min }\right)$, e utilizando a equação

$$
T_{i}=T_{\min } \lambda^{i-1}
$$

onde $i=1,2, \ldots, M$ e $\lambda=\left(T_{\max } / T_{\min }\right)^{1 /(M-1)}$. A simplicidade desse algoritmo, além do fato de ele proporcionar o conjunto ótimo de temperaturas quando o $C_{v}$ é aproximadamente constante, (60) faz com que essa distribuição seja frequentemente utilizada como uma distribuição inicial para outros algoritmos que requerem informações do sistema, como será o caso dos algoritmos OE e ACE mencionados mais à frente nessa seção.

O algoritmo OE, (61) utiliza informações da difusão das réplicas entre as temperaturas para atingir auto-consistentemente o conjunto de temperaturas otimizado, onde o tempo de ida-volta* é minimizado. Para medir a difusão, é atribuído a cada estrutura uma etiqueta que pode conter "subindo" ou "descendo", de modo que as estruturas que visitaram mais recentemente $T_{\min }$ possuem "subindo", enquanto as que visitaram mais recentemente $T_{\max }$ recebem "descendo". Fazendo então uma breve simulação com $N_{O E}$ passos, pode-se obter uma estimativa da fração de réplicas que oriunda de uma das temperaturas extremas, e assim medir a difusão das réplicas entre as temperaturas. É utilizada a informação da situação das réplicas presentes nas temperaturas em cada passo do PTMC, de modo que em uma certa temperatura $T_{i}$, a fração de réplicas que visitou mais recentemente a temperatura mais baixa seja dada por

$$
f\left(T_{i}\right)=\frac{n_{\text {subindo }}\left(T_{i}\right)}{n_{\text {subindo }}\left(T_{i}\right)+n_{\text {descendo }}\left(T_{i}\right)},
$$

onde $n_{\text {subindo }}$ e $n_{\text {descendo }}$ representam o número de réplicas com as etiquetas "subindo" e "descendo" que passaram pela temperatura $T_{i}$.

O fluxo de réplicas entre as temperaturas extremas forma uma corrente estacionária. Através da fração dada pela equação 2.18 , e assumindo $T$ como uma variável contínua, é possível determinar essa corrente de réplicas através das temperaturas:

$$
j=D(T) \eta(T) \frac{d f}{d T},
$$

onde $D(T)$ é difusividade local, $\frac{d f}{d T}$ é encontrada por meio de uma regressão linear na equação 2.18 e $\eta(T)$ indica a probabilidade de uma réplica estar na temperatura $T$ e é aproximada por $\eta(T)=C / \Delta T$, com $\Delta T=T_{i+1}-T_{i}$ e $C$ uma constante de normalização escolhida tal que a integral de $\eta(T)$ entre as temperaturas máxima e mínima seja 1.

\footnotetext{
* Número de passos utilizados para que a estrutura saia de $T_{\min }$, vá até $T_{\max }$ e volte para $T_{\min }$
} 
Assim, é possível mostrar (61) que o conjunto de temperaturas que maximiza a corrente de réplicas pode ser obtido iterativamente por meio de medidas da fração de réplicas, gerando em cada passo um novo conjunto de temperaturas encontrado por

$$
\int_{T_{1}^{\prime}}^{T_{k}^{\prime}} \eta^{\prime}(T) d T=\int_{T_{1}^{\prime}}^{T_{k}^{\prime}} C^{\prime} \sqrt{\frac{1}{\Delta T} \frac{d f}{d T}} d T=\frac{k}{M},
$$

até que a convergência seja atingida. Para garantir uma melhor convergência, o número de passos $N_{O E}$ é dobrado em cada passo do algoritmo, o que faz com que o custo computacional do algoritmo OE seja relativamente alto, restringindo sua aplicação à sistemas onde o cálculo de energia é barato computacionalmente.

Uma alternativa ao algoritmo OE é o algoritmo ACE (62) que também otimiza o conjunto de temperaturas, mas nesse caso, não de forma auto-consistente. O objetivo do algoritmo ACE é uniformizar o aumento de entropia entre temperaturas, e assim obter o conjunto de temperaturas otimizado. A ideia baseia-se no fato de a probabilidade de aceitação da troca entre as réplicas estar ligada às diferenças de entropia. (64) Para garantir que o aumento de entropia seja constate, o conjunto de temperaturas deve satisfazer

$$
\int_{T_{m}}^{T_{m+1}} \frac{C_{v}(T)}{T} d T=\frac{\Delta S}{M-1},
$$

onde $m=1,2, \ldots, M-1, \Delta S$ é a diferença de entropia entre as temperaturas máximas $T_{M}=T_{m a x}$ e mínima $T_{1}=T_{m i n}$, e $C_{v}(T)$ é o calor específico à volume constante em função da temperatura.

Assim como para algoritmo OE, é necessária uma simulação prévia exploratória para estimar as grandezas utilizadas pelo algoritmo, já que a equação 2.21 depende do $C_{v}(T)$ e $\Delta S$, que a princípio não são conhecidos. Por esse motivo uma simulação de PTMC preliminar é realizada, e após uma breve termalização o calor específico é estimado. Contudo, dado que uma integral envolvendo $C_{v}(T)$ (equação 2.21) é calculada, os valores de $C_{v}(T)$ devem ser conhecidos de forma praticamente contínua (para diversos valores de $T$ ). ${ }^{*}$ Realizar uma simulação de PTMC com centenas ou milhares de temperaturas é inviável e, por isso, tipicamente recorre-se a métodos de histograma para o cálculo do valor da propriedade em qualquer temperatura. $\mathrm{O}$ método de histograma aqui utilizado será discutino na subseção 2.3.1.

\subsubsection{Algoritmos de otimização dos deslocamentos}

Um dos mais importantes pontos nas simulações de $M C$ (não se restringindo somente ao PTMC nesse caso) é o mecanismo utilizado para gerar os novos estados. Esses estados são

\footnotetext{
* Não necessariamente uma forma analítica de $C_{v}$ deve ser conhecida, já que a integração é feita de forma numérica.
} 
gerados à partir do estado anterior do sistema, e à princípio não devem conter "memória" dos estados amostrados em passos anteriores. $\mathrm{O}$ exato mecanismo ou algoritmo para gerar esses estados é dependente do sistema estudado. Por exemplo, para o modelo de Ising, um novo estado é gerado pela troca de um ou mais spins na rede. Para sistemas que não estão em uma rede, como é o caso dos nanoclusters e NPs, os estados são gerados à partir de uma variação na posição dos componentes do sistema. Utilizando coordenadas cartesianas, a posição $x, y$ e $z$ de um ou mais átomos selecionados aleatoriamente no sistema é alterada com um deslocamento $\Delta \mathbf{R}=\delta\left([-1,+1]_{x} \hat{x}+[-1,+1]_{y} \hat{y}+[-1,+1]_{z} \hat{z}\right)$, onde $\delta$ é o deslocamento máximo em cada coordenada, e $[-1,+1]$ representa um número aleatório obtido de uma distribuição uniforme.

Um controle no tamanho dos deslocamentos é necessário, pois os estados gerados devem possuir uma energia comparável ao estado anterior e assim garantir que a taxa de aceitação pelo critério de Metropolis não seja excessivamente baixa. Se a taxa de aceitação for sempre próxima de 1 (todos os estados são sempre aceitos), não está sendo feita uma amostragem por importância, enquanto se a taxa for 0 ou próxima disso a amostragem é feita em uma região muito restrita do espaço de fase, exigindo um número proibitivamente grande de passos ou violando a condição de ergodicidade. O valor ótimo da taxa de aceitação é dependente do sistema, contudo uma regra geral é o uso de uma taxa de aceitação de $50 \%$ para casos onde o ótimo não é conhecido.

Em 1992, Bouzida, Kumar e Swendsen(65) propuseram um método para o ajuste dinâmico do deslocamento máximo $\delta$. Esse método, mais tarde revisado por Swendsen(66), é chamado de método da taxa de aceitação (MTA), e ajusta adaptativamente $\delta$ baseado em uma taxa de aceitação "ideal" fornecida pelo usuário. Nesse algoritmo, o novo deslocamento máximo é obtido pela equação

$$
\delta_{\text {novo }}=\delta_{\text {antigo }} \frac{\ln \left(a P_{\text {ideal }}+b\right)}{\ln \left(a P_{\text {antigo }}+b\right)},
$$

onde $P_{\text {ideal }}$ é a taxa de aceitação desejada, $P_{\text {antigo a taxa de aceitação no momento da }}$ atualização, $\delta_{\text {antigo }}$ o deslocamento máximo no momento da atualização, e $a$ e $b$ são obtidos previamente pela solução iterativa das equações:

$$
\begin{gathered}
c \leftarrow\left(a P_{\text {ideal }}+b\right)^{\alpha}, \\
a \leftarrow\left(a P_{\text {ideal }}+b\right)^{1 / \alpha}-c, \\
b \leftarrow c,
\end{gathered}
$$

e tem como objetivo lidar com os casos onde $P_{\text {antigo }}=1$ e $P_{\text {antigo }}=0$. Nesses casos, os valores de $a$ e $b$ garantem que os novos deslocamentos serão $\delta_{\text {novo }}=\alpha \delta_{\text {antigo }}$ e $\delta_{\text {novo }}=\delta_{\text {antigo }} / \alpha$, respectivamente, sendo $\alpha$ uma constante.

Além do algoritmo MTA, algumas outras propostas para algoritmos de ajuste de deslocamento podem ser encontradas na literatura. Uma delas, e mais simples, pode ser encontrada na referência 67 . Nesse algoritmo, o valor de $\delta$ é ajustado percentualmente quando 
a taxa de aceitação sai do intervalo $\left[a c c_{\max }, a c c_{\min }\right]$ determinado. Nesses casos, o valor de $\delta_{\text {novo }}$ é obtido por meio da expressão:

$$
\delta_{\text {novo }}=\delta_{\text {antigo }}\left(1+\frac{a c c_{\max }-a c c_{\min }}{\alpha}\right),
$$

onde $a c c_{\max }$ e $a c c_{\min }$ dão respectivamente o valor máximo e mínimo aceito pela taxa de aceitação, e $\alpha$ é uma constante utilizada para controlar o percentual variado.

A frequência na qual ocorrem as atualizações podem afetar a incerteza dos valores esperados. Em sistemas com uma superfície de energia com mais de um mínimo local profundo, onde se encaixam os nanoclusters, o viés introduzido pelas atualizações tem um erro menor que o erro intrínseco do MC quando (66)

$$
t_{\text {atualização }} \geq \sqrt{t_{\text {total }}}
$$

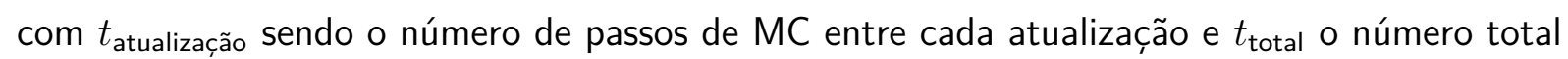
de passos de MC. Com esse critério, tem-se uma regra geral para determinar a frequência com a qual o valor de $\delta$ é ajustado.

\subsection{Propriedades}

Utilizando o PTMC, propriedades termodinâmicas como a energia interna e calor específico podem ser facilmente calculadas. Além disso, o uso de técnicas como a análise de similaridade, permitem uma análise das estruturas obtidas nas mudanças de fase.

\subsubsection{Propriedades termodinâmicas}

Para determinar as mudanças de fase dos nanoclusters estudados, são utilizadas informações obtidas da energia interna e calor específico dos sistemas. Aumentos na inclinação da curva da energia interna pela temperatura, indicam um ganho de calor latente, associado às mudanças de fase. Essa mudança na inclinação pode ser facilmente observada por meio do calor específico, que apresenta um pico ao redor das transições.

A energia interna e o calor específico são obtidas por meio de médias dos valores de energia amostrados ao decorrer da simulação de PTMC. A energia interna está diretamente ligada à energia média, tendo somente um termo cinético* somado à média da energia, de modo que, sendo $E=\mathbb{U}\left(\mathbf{R}^{N}\right)$, sua expressão é dada por:

$$
U=\frac{3}{2} N k T+\langle E\rangle
$$

Já o calor específico é obtido com a derivação da energia interna com relação à temperatura. Essa derivação dá que o calor específico possui um termo proporcional à variância

\footnotetext{
* Originado da integral dos momentos da equação 2.3.
} 
da energia, de modo que para uma simulação de PTMC, a forma conveniente de se obter o valor dessa propriedade é por meio da expressão:

$$
C_{v}=\frac{3}{2} N k+k \beta^{2}\left(\left\langle E^{2}\right\rangle-\langle E\rangle^{2}\right)
$$

Entretanto, o cálculo das propriedades termodinâmicas por meio de médias como as da equação 2.7 , permite somente obter resultados para as temperaturas simuladas. Para extrapolar os dados simulados nessas temperaturas para temperaturas próximas, e para utilizar toda a informação disponível no ensemble, métodos de análise com histograma são frequentemente utilizados. Nessa classe de métodos estão incluídos os algoritmos de um único histograma, (51) e os métodos de multi-histograma. $(38,51,68,69)$ O algoritmo de um único histograma utiliza dados de apenas uma temperatura, e extrapola o valor da propriedade para temperaturas próximas utilizando um histograma das energias amostradas. Os métodos de multi-histograma por outro lado, utilizam da informação amostrada em diversas temperaturas para extrapolar o dado para uma temperatura próxima não calculada, ou até mesmo obter um valor médio mais preciso em um ponto já calculado.

Os algoritmos tradicionalmente utilizados nos métodos multi-histograma foram elaborados considerando simulações independentes em cada temperatura e medidas independentes das propriedades em cada passo. Entretanto, em uma simulação de PTMC as trocas entre réplicas, e as amostras obtidas com o algoritmo de Metropolis, introduzem uma correlação temporal nos dados que não deve ser negligenciada. Essa correlação reduz o número efetivo de amostras que podem ser utilizadas nos métodos de histograma, fazendo necessária uma correção dos algoritmos tradicionais para esse caso. Para lidar com esse problema, o método de análise ponderada de histograma para parallel tempering (MAPHPT) (69) foi proposto. Esse algoritmo se trata de uma modificação do algoritmo MAPH original, (68) onde é introduzida a "ineficiência estatística", que utiliza a correlação temporal das medidas para obter o número efetivo de amostras.

Para se calcular o valor esperado de qualquer propriedade em uma determinada temperatura $\beta$, o MAPHPT utiliza-se de uma modificação da equação 2.4 , onde por meio do conhecimento a função densidade de probabilidade é possível escrever o valor médio como uma integral da energia:

$$
\langle A\rangle_{\beta}=\frac{\int \Omega(E) e^{-\beta E} A(E) d E}{\int \Omega(E) e^{-\beta E} d E},
$$

onde $\Omega(E)$ é a densidade de estados e $A(E)$ é a média da propriedade $A$ sobre todas as configurações com energia $E$. Essa equação pode ainda ser aproximada para o caso discreto, onde o valor da densidade de estados é considerado constante em um intervalo $\Delta E$. Se a densidade de estados nesse intervalo for dada por $\Omega_{m}=\Omega\left(E_{m}\right)$, a aproximação pode ser 
escrita como:

$$
\langle A\rangle_{\beta} \approx \frac{\sum_{m=1}^{M} \Omega_{m} e^{-\beta E_{m}} A_{m} \Delta E}{\sum_{m=1}^{M} \Omega_{m} e^{-\beta E_{m}} \Delta E},
$$

onde $A_{m}$ representa o valor médio da propriedade sobre as configurações com energia no intervalo $\Delta E$. Desse modo, o conhecimento da densidade de estados pode ser utilizado para obter valores estimados da propriedade em qualquer temperatura.

Um estimador da densidade de estados $\Omega$ pode ser obtido utilizando dados coletados em cada temperatura ao decorrer da simulação. Esse estimador é obtido através da construção de histogramas de energia, utilizados para se estimar a função de densidade de probabilidade e por conseguinte $\Omega$. Assim, sendo $H_{m k}$ a frequência das energias medidas na réplica $k$ que caem na caixa $m$ (correspondente à energia $E_{m}$ do centro da caixa), tem-se que para a réplica $k$ o estimador de $\Omega$ é dado por (69)

$$
\hat{\Omega}_{m k}=\frac{H_{m k}}{N_{k} \Delta E \exp \left[f_{k}-\beta_{k} E_{m}\right]},
$$

onde $N_{k}$ é o número total de amostras obtidas pela réplica $k$, e $f_{k}$ é a energia livre adimensional dada por

$$
f_{k}=-\ln Z\left(\beta_{k}\right) \approx-\ln \sum_{m=1}^{M} \Omega_{m} e^{-\beta E_{m}} \Delta E
$$

Entretanto, dado que a densidade de estados não depende da temperatura, é possível utilizar o estimador das diferentes réplicas (dados pela equação 2.32) para construir um estimador ótimo comum. Para isso, são calculados os tempos de correlação $(\tau)$ entre as medidas amostradas e a ineficiência estatística $(g)$. Sendo $\left\{x_{n}\right\}_{n=1}^{N}$ uma série temporal de $N$ medidas de uma certa grandeza $X$, é possível mostrar (69) que

$$
\begin{gathered}
\tau=\sum_{t=1}^{N-1}\left(1-\frac{t}{N}\right) C_{t}, \\
g \equiv 1+2 \tau
\end{gathered}
$$

onde $C_{t}$ é a função de autocorrelação definida por:

$$
C_{t} \equiv \frac{\left\langle x_{n} x_{n+t}\right\rangle-\left\langle x_{n}\right\rangle^{2}}{\left\langle x_{n}^{2}\right\rangle-\left\langle x_{n}\right\rangle^{2}}
$$

Através de $g$ pode-se então encontrar o estimador comum ótimo $\hat{\Omega}_{m}$ que leva em consideração a correlação entre as medidas. Esse estimador é dado por (69)

$$
\hat{\Omega}_{m}=\frac{\sum_{k=1}^{K} g_{m k}^{-1} H_{m k}}{\sum_{k=1}^{K} g_{m k}^{-1} N_{k} \Delta E \exp \left[f_{k}-\beta_{k} E_{m}\right]},
$$


onde $g_{m k}$ é a ineficiência estatística da série das $N_{k}$ medidas na réplica $k$ com respectiva à caixa $m$ do histograma, e novamente $f_{k}$ é dado pela equação 2.33 . Nota-se que a equação 2.33 depende da densidade de estados $\hat{\Omega}_{m}$, assim como a equação 2.37 depende da energia livre $f_{k}$. Por esse motivo, essas equações devem ser resolvidas auto-consistentemente, partindo de um valor inicial para $f_{k}$ como $f_{k}=0$.

Finalmente, conhecido o estimador da densidade de estados $\hat{\Omega}_{m}$ é possível calcular o valor médio das propriedades por meio da equação 2.31. Para isso um estimador de $A_{m}$ é calculado, utilizando valores das simulações em todas temperaturas nos passos cuja energia cai na caixa $m$ do histograma. Desse modo, é possível simplificar a equação 2.31 para que o estimador do valor esperado $\langle A\rangle_{\beta}$ seja dado por

$$
\hat{A}(\beta)=\frac{\sum_{k=1}^{K} \sum_{n=1}^{N_{k}} w_{k n}(\beta) A_{k n}}{\sum_{k=1}^{K} \sum_{n=1}^{N_{k}} w_{k n}(\beta)},
$$

onde $A_{k n}$ representa a medida da propriedade $A$ feita em $k$ no passo $n$ e $w_{k n}$ o peso dessa medida para a propriedade na temperatura $\beta$, dado por

$$
w_{k n}=\sum_{m=1}^{M} \psi_{m k n} H_{m}^{-1} \hat{\Omega}_{m} e^{-\beta E_{m}},
$$

sendo $\psi_{m k n}$ uma função que é igual a 1 se a medida de energia da réplica $k$ feita no passo $n$ pertencer a caixa $m$, e igual a 0 caso contrário, e $H_{m}=\sum_{k=1}^{K} H_{m k}$ é a soma das frequências dos histogramas de cada réplica na caixa $m$.

\subsubsection{Propriedades estruturais}

O número de amostras geradas em cada temperatura durante uma simulação de PTMC pode chegar à casa de bilhões. Essas amostras trazem consigo informações estruturais importantes sobre as mudanças de fase, e permitem a caracterização das mesmas. Uma das abordagens possíveis para a análise desses dados, proposta neste trabalho, é o uso de uma análise de similaridade para investigar as estruturas mais frequentes amostradas em cada temperatura.

Gehrke e Reuter(70) utilizaram em seu trabalho uma métrica euclideana, capaz de atribuir uma distância, $\Delta S_{A B}$, entre duas estruturas $A$ e $B$ diferentes. Essa métrica, entretanto, não permite a comparação da distância entre estruturas com mais de uma espécie química, pois nela isômeros com a mesma forma, mas com átomos de diferentes espécies em posições distintas, são consideradas equivalentes. Por esse motivo, neste trabalho essa métrica foi modificada, atendendo assim a necessidade do estudo de nanoligas.

Considerando dois nanoclusters com $N^{\alpha}$ átomos de uma espécie química e $N^{\beta}$ átomos de uma espécie diferente, as distâncias, $d_{A, i}$ e $d_{B, i}$, entre o $i$-ésimo átomo das estruturas $A$ e 
Figura 3 - Esquema mostrando as listas, separadas por espécie, contendo as distâncias atômicas ordenadas da estrutura $A$.
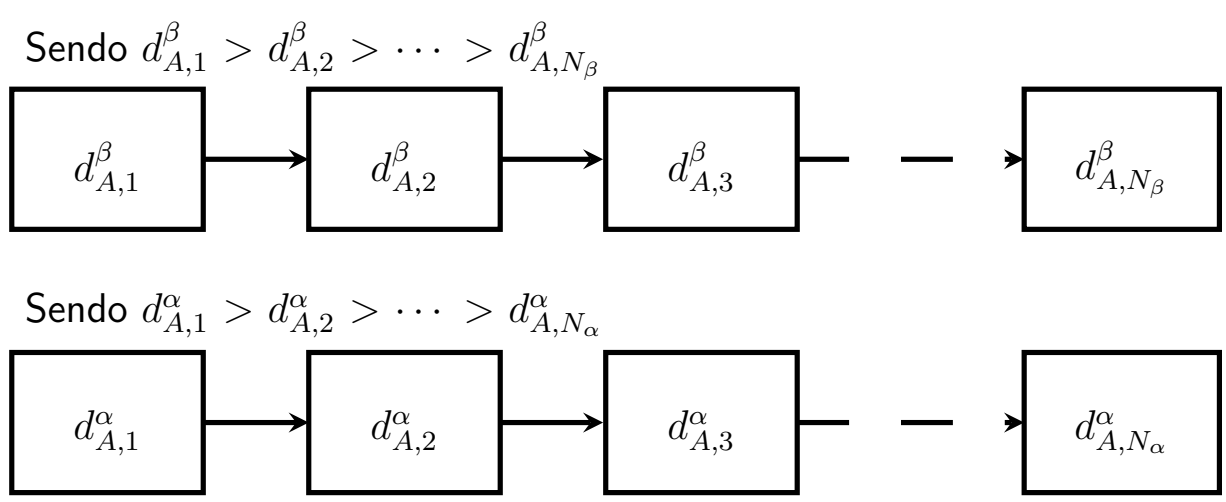

Fonte: Elaborada pelo autor.

$B$ e o centro de massa são medidas. Essas distâncias são dividias em duas listas (no caso de duas espécies químicas) e ordenadas, conforme mostrado na figura 3.

Com o auxilio dessas listas, as distâncias atômicas entre os átomos dos dois nanoclusters são comparadas. Essa comparação é feita somando o quadrado da diferença das distâncias de mesmo índice das duas estruturas, de modo que o valor ainda é normalizado para gerar o número adimensional $\Delta S_{A B}$ :

$$
\Delta S_{A B}=\frac{\sum_{i=1}^{N^{\alpha}}\left(d_{A, i}^{\alpha}-d_{B, i}^{\alpha}\right)^{2}+\sum_{i=1}^{N^{\beta}}\left(d_{A, i}^{\beta}-d_{B, i}^{\beta}\right)^{2}}{\sum_{i=1}^{N} d_{A, i}^{2}+d_{B, i}^{2}}
$$

Assim, se um critério $\Delta$ para indicar a mínima distância para duas estruturas serem consideradas diferentes é definido, pode-se classificar pares de estrutura como similares se $\Delta S_{A B}<\Delta$.

Além da similaridade, outras propriedades estruturais podem ser estudadas. O número de coordenação efetiva (NCE) médio representa o número de ligações químicas feitas pelos átomos do sistema. (71-73) Através do NCE, é possível identificar ou diferenciar diferentes estruturas cristalinas, já que essas possuem um valor típico associado à sua forma. Além disso, devido ao menor número de ligações realizadas pelos átomos da superfície, o valor dessa propriedade pode ser útil para estimar o número de átomos na superfície do nanocluster.

Essa propriedade, que é similar ao número de coordenação, tem a vantagem de ser mais sensível, e poder ser obtida sem a definição arbitrária de uma distância de corte para indicar o comprimento das ligações atômicas. Para determinar a distância de corte, o NCE utiliza um comprimento de ligação ponderado médio, $d_{a v}^{i}$, que atribui pesos diferentes à cada distância $r_{i j}$ (distância entre os átomos $i$ e $j$ ). Os pesos utilizados para o cálculo do NCE foram baseados em exponenciais e na potência seis, de modo que para o $i$-ésimo átomo, o $d_{a v}^{i}$ 
pode ser obtido por:

$$
d_{a v}^{i}=\frac{\sum_{j} r_{i j} \exp \left[1-\left(\frac{r_{i j}}{d_{a v}^{i}}\right)^{6}\right]}{\sum_{j} \exp \left[1-\left(\frac{r_{i j}}{d_{a v}^{i}}\right)^{6}\right]} .
$$

Vale notar que essa expressão depende do próprio $d_{a v}^{i}$, de modo que uma solução auto-consistente da equação é necessária.

O NCE para o átomo $i$ é obtido por meio da soma de todo os pesos, e pode portanto (diferentemente do número de coordenação), exibir valores não inteiros. A expressão utilizada para encontrar NCE de cada átomo, utiliza então os valores de $d_{a v}^{i}$, e é dada por:

$$
\mathrm{NCE}_{i}=\sum_{j} \exp \left[1-\left(\frac{r_{i j}}{d_{a v}^{i}}\right)^{6}\right] \text {. }
$$

Para obter o NCE médio, uma média sobre as contribuições de cada átomo é realizada $\left(\mathrm{NCE}=1 / N \sum_{i} \mathrm{NCE}_{i}\right)$.

\subsection{Energia total}

Uma simulação de PTMC pode requerer de $10^{7}$ a $10^{9}$ cálculos de energia antes de atingir o equilíbrio e obter os valores das propriedades. Isso torna inviável, ao menos em um primeiro momento, o uso de métodos de primeiros princípios como a teoria do funcional da densidade (DFT) para o cálculo de energia de tais simulações. Desse modo, por possuírem um baixo custo computacional, o uso de potenciais empíricos é justificado, especialmente para sistemas com algumas centenas de átomos. Neste trabalho, o potencial empírico de LJ é utilizado como modelo de teste da implementação do algoritmo, e o potencial de Gupta (74) é utilizado para a descrição dos metais de transição. Através da comparação das estruturas obtidas com o potencial de Gupta e estruturas obtidas com a DFT, é mostrado no capítulo 4 que a utilização desse potencial empírico é justificada.

\subsubsection{Potenciais empíricos}

Utilizando a descrição clássica da interação entre partículas, a energia de interação de um conjunto de $N$ átomos é dada como uma função de $3 N$ coordenadas, $\mathbf{R}^{N}$, de modo que a equação que define a energia total pode ser escrita como (75)

$$
\mathbb{U}\left(\mathbf{R}^{N}\right)=\sum_{i=1}^{N} V_{1}\left(\mathbf{R}_{i}\right)+\sum_{i=1}^{N} \sum_{j>i}^{N} V_{2}\left(\mathbf{R}_{i}, \mathbf{R}_{j}\right)+\sum_{i=1}^{N} \sum_{j>i}^{N} \sum_{k>j}^{N} V_{3}\left(\mathbf{R}_{i}, \mathbf{R}_{j}, \mathbf{R}_{k}\right)+\cdots,
$$

onde $V_{1}$ representa forças externas que atuam no sistema, $V_{2}$ dá a interação entre dois átomos*, $V_{3}$ a interação entre três átomos, e assim sucessivamente. Considerando o potencial externo

\footnotetext{
*A mais importante colaboração a energia de interação.
} 
$V_{1}$ como nulo e truncando a expansão dada pela equação 2.43 , pode-se obter aproximações para a energia de interação interatômica. Essas aproximações, como as mostradas a seguir, dependem de parâmetros que devem ser ajustados para a descrição dos sistemas estudados.

A aproximação mais simples é constituída apenas da interação de pares $V_{2}$, e pode ser utilizada para descrever de maneira precisa a interação de sistemas como gases nobres. (67) Nessa classe de potenciais se encontra o potencial de Lennard-Jones, (76) um potencial de forma analítica simples e apenas dois parâmetros, que contém um termo de repulsão (elevado a potência 12) e outro de atração (elevado a potência 6). A expressão desse potencial é dada por

$$
\mathbb{U}_{L J}\left(\mathbf{R}^{N}\right)=\frac{1}{2} \sum_{\substack{i=1 \\ j \neq i}}^{N} \sum_{\substack{j=1 \\ j \neq i}}^{N}\left[\left(\frac{\sigma^{\alpha \beta}}{r_{i j}}\right)^{12}-\left(\frac{\sigma^{\alpha \beta}}{r_{i j}}\right)^{6}\right]
$$

onde $\epsilon^{\alpha \beta}$ dá a escala de energia e a profundidade da energia mínima, e $\sigma^{\alpha \beta}$ dá a escala de distância e a distância na qual a energia de interação é nula. Tipicamente, para sistemas com átomos de apenas uma espécie atômica, os índices referentes às espécies químicas são omitidos, de modo que $\epsilon^{\alpha \beta}=\epsilon$ e $\sigma^{\alpha \beta}=\sigma$. Para o estudo dos sistemas chamados de clusters de LJ, os resultados são expressos em função desses parâmetros, nas unidades chamadas de unidades reduzidas, onde $\epsilon=\sigma=1$.

Uma descrição mais precisa da interação interatômica pode ser obtida com potenciais construídos considerando interações além da interação de pares, ou ainda, partindo de aproximações como a de elétrons fortemente ligados (tight binding em inglês). O potencial de Gupta foi construído partindo da aproximação de elétrons fortemente ligados, e tem como objetivo a descrição da relaxação entre camadas em superfícies de metais. Esse potencial descreve com sucesso metais de transição, e já foi parametrizado para descrever a fase bulk dos mesmos. (77) A forma analítica do potencial de Gupta é dada por

$$
\mathbb{U}_{\text {Gupta }}\left(\mathbf{R}^{N}\right)=\frac{1}{2} \sum_{\substack{i=1 \\ j \neq i}}^{N} \sum_{\substack{j=1 \\ j \neq i}}^{N} V_{i j}-\sum_{i=1}^{N} \sqrt{\rho_{i}}
$$

onde

$$
\begin{gathered}
V_{i j}=A^{\alpha \beta} e^{-p^{\alpha \beta}\left(r_{i j} / r_{0}^{\alpha \beta}-1\right)}, \\
\rho_{i}=\sum_{j=1}^{N}\left(\xi^{\alpha \beta}\right)^{2} e^{-2 q^{\alpha \beta}\left(r_{i j} / r_{0}^{\alpha \beta}-1\right)},
\end{gathered}
$$

e sendo $A^{\alpha \beta}, \xi^{\alpha \beta}, p^{\alpha \beta}, q^{\alpha \beta}$ e $r_{0}^{\alpha \beta}$ os parâmetros a serem otimizados para a descrição de cada sistema. Esses parâmetros são tipicamente otimizados para sistemas com apenas uma espécie química, sendo necessário o uso de regras de combinação como as de Lorentz(78) e Berthelot(79) que dão as combinações $A^{\alpha \beta}=\sqrt{A^{\alpha \alpha} A^{\beta \beta}}, \xi^{\alpha \beta}=\sqrt{\xi^{\alpha \alpha} \xi^{\beta \beta}}, p^{\alpha \beta}=\frac{p^{\alpha \alpha}+p^{\beta \beta}}{2}$, $q^{\alpha \beta}=\frac{q^{\alpha \alpha}+q^{\beta \beta}}{2}$ e $r_{0}^{\alpha \beta}=\frac{r_{0}^{\alpha \alpha}+r_{0}^{\beta \beta}}{2}$. 
Um dos grandes problemas na utilização de potenciais empíricos é justamente a determinação dos parâmetros dos potenciais. Esses parâmetros podem ser obtidos através da parametrização de resultados de cálculos quânticos, ou ainda da parametrização de resultados experimentais. Para o potencial de Gupta, foram utilizados os parâmetros obtidos por Cleri e Rosato, (77) parametrizados para descrever dados experimentais de bulks.

\subsubsection{Potenciais de primeiros princípios}

Devido a escala de tamanho dos sistemas e a efeitos de confinamento, a descrição mais apropriada da interação entre os átomos dos clusters e nanoclusters é dada pela mecânica quântica. Utilizando a mecânica quântica para a solução de um problema de $P$ elétrons e $N$ núcleos, pode-se encontrar o espectro de energia do sistema através da solução da equação de Schrödinger, que em sua forma não relativística e independente do tempo é dada por

$$
\hat{H} \Psi\left(\mathbf{r}^{P}, \mathbf{R}^{N}\right)=E \Psi\left(\mathbf{r}^{P}, \mathbf{R}^{N}\right)
$$

onde $\hat{H}$ é o Hamiltoniano, $\Psi\left(\mathbf{r}^{P}, \mathbf{R}^{N}\right)$ a função de onda dada, respectivamente, em função das coordenadas eletrônicas e nucleares, e $E$ é a energia do auto-estado dado por $\Psi\left(\mathbf{r}^{P}, \mathbf{R}^{N}\right)$.

O Hamiltoniano para esse problema de muitos corpos, inclui, além das energias cinéticas dos elétrons e núcleos, as interações elétron-elétron, núcleo-elétron e núcleo-núcleo, de modo que sua expressão é dada por:*

$$
\hat{H}\left(\mathbf{r}^{P}, \mathbf{R}^{N}\right)=\hat{K}_{n}\left(\mathbf{R}^{N}\right)+\hat{K}_{e}\left(\mathbf{r}^{P}\right)+\hat{V}_{n e}\left(\mathbf{r}^{P}, \mathbf{R}^{N}\right)+\hat{V}_{e e}\left(\mathbf{r}^{P}\right)+\hat{V}_{n n}\left(\mathbf{R}^{N}\right) .
$$

Os dois primeiros termos da equação 2.49 representam a energia cinética dos núcleos e elétrons respectivamente. Sendo $\mathbf{R}_{\alpha}$ a posição do núcleo $\alpha$ e o Laplaciano $\nabla_{\mathbf{R}_{\alpha}}^{2}$ tomado nessas coordenadas, o termo referente a energia cinética núcleo é dado por

$$
\hat{K}_{n}\left(\mathbf{R}^{N}\right)=-\sum_{\alpha=1}^{N} \frac{1}{2 M_{\alpha}} \nabla_{\mathbf{R}_{\alpha}}^{2},
$$

onde $M_{\alpha}$ dá a massa do respectivo núcleo. De maneira análoga, a energia cinética dos elétrons é dada por

$$
\hat{K}_{e}\left(\mathbf{r}^{P}\right)=-\sum_{i=1}^{P} \frac{1}{2} \nabla_{\mathbf{r}_{i}}^{2},
$$

sendo $\nabla_{\mathbf{r}_{i}}^{2}$ o Laplaciano tomado referente às coordenadas $\mathbf{r}_{i}$ do $i$-ésimo elétron.

\footnotetext{
* Neste trabalho será utilizada unidades atômicas e gaussianas. Nesses sistemas de unidade tem-se que $\hbar=1$, $|e|=1, m_{e}=1$ e $4 \pi \epsilon_{0}=1$.
} 
Os outros três termos são devidos à energia potencial da interação eletrostática, e em unidades do sistema gaussiano são dados por:

$$
\begin{gathered}
\hat{V}_{n e}\left(\mathbf{r}^{P}, \mathbf{R}^{N}\right)=-\sum_{\alpha=1}^{N} \sum_{i=1}^{P} \frac{Z_{\alpha}}{\left|\mathbf{R}_{\alpha}-\mathbf{r}_{i}\right|}, \\
\hat{V}_{e e}\left(\mathbf{r}^{P}, \mathbf{R}^{N}\right)=\frac{1}{2} \sum_{\substack{i=1 \\
j}}^{P} \sum_{\substack{j=1 \\
j \neq i}} \frac{1}{\left|\mathbf{r}_{j}-\mathbf{r}_{i}\right|}, \\
\hat{V}_{n n}\left(\mathbf{R}^{N}\right)=\frac{1}{2} \sum_{\alpha=1}^{N} \sum_{\beta=1}^{N} \frac{Z_{\alpha} Z_{\beta}}{\left|\mathbf{R}_{\beta}-\mathbf{R}_{\alpha}\right|}
\end{gathered}
$$

onde $Z_{\alpha}$ e $Z_{\beta}$ são os números atômicos dos núcleos $\alpha$ e $\beta$.

\subsubsection{Aproximação de Born-Oppenheimer}

A primeira aproximação feita para possibilitar solução da equação 2.48 é a aproximação de Born-Oppenheimer. Essa aproximação, válida nos casos onde o acoplamento vibrônico (entre os movimentos eletrônicos e vibracionais) pode ser desprezado, admite que é possível se desacoplar as partes eletrônicas e nucleares da equação 2.48 , fazendo $\Psi\left(\mathbf{r}^{P}, \mathbf{R}^{N}\right)=$ $\psi\left(\mathbf{r}^{P} ;\left\{\mathbf{R}^{N}\right\}\right) \chi\left(\mathbf{R}^{N}\right)$. Isso é razoável dado que o núcleo mais massivo que o elétron, permitindo então a aproximação de núcleos aparentemente fixos com respeito ao movimento dos elétrons. Esse desacoplamento faz com que o problema se reduza a dois: a solução da equação com o Hamiltoniano eletrônico e a solução para o Hamiltoniano nuclear.

Para o caso eletrônico, a equação após a separação de variáveis é dada por

$$
\hat{H}_{e} \psi\left(\mathbf{r}^{P} ;\left\{\mathbf{R}^{N}\right\}\right)=E_{e} \psi\left(\mathbf{r}^{P} ;\left\{\mathbf{R}^{N}\right\}\right),
$$

onde $\{\mathbf{R}\}$ indica uma dependência paramétrica com as posições dos núcleos, e sendo

$$
\hat{H}_{e}=\hat{K}_{e}\left(\mathbf{r}^{P}\right)+\hat{V}_{n e}\left(\mathbf{r}^{P} ;\left\{\mathbf{R}^{N}\right\}\right)+\hat{V}_{e e}\left(\mathbf{r}^{P}\right) .
$$

Já para o Hamiltoniano nuclear, a aproximação de Born-Oppenheimer dá

$$
\hat{H}_{n} \chi\left(\mathbf{R}^{N}\right)=E_{n} \chi\left(\mathbf{R}^{N}\right)
$$

onde

$$
\hat{H}_{n}=\hat{K}_{n}\left(\mathbf{R}^{N}\right)+\hat{V}_{n n}\left(\mathbf{R}^{N}\right)+E_{e}\left(\left\{\mathbf{R}^{N}\right\}\right),
$$

sendo a energia $E_{e}\left(\left\{\mathbf{R}^{N}\right\}\right)$ o potencial eletrônico sentido pelos núcleos.

\subsubsection{Teoria do funcional da densidade}

A solução da equação 2.55 para o problema de muitos corpos não é uma tarefa trivial. Graças ao termo de interação elétron-elétron, o problema somente possui solução exata para 
$P=1$. Por esse motivo, o estudo de soluções numéricas e aproximadas desse tipo de problema é de grande interesse.

A DFT é uma teoria que teve seu início com os teoremas de Hohenberg e Kohn (HK), (80) que possibilitaram a redução de um problema de $3 P$ variáveis para o problema de apenas 3, envolvendo a densidade eletrônica. Nos seus teoremas HK demonstram que qualquer observável, incluindo a energia, podem ser calculados à partir da densidade $n(\mathbf{r})$. Além disso, eles também demonstram que partindo do método variacional é possível se obter a densidade eletrônica, de modo que a densidade que minimiza a energia total é a densidade do estado fundamental. Esses teoremas permitem então a descrição de todo o sistema por meio da densidade, não sendo necessária a obtenção da função de onda. Entretanto, os teoremas não mostravam de maneira clara, como esse conhecimento poderia ser utilizado de maneira prática.

Somente no ano seguinte que Kohn e Sham (KS) particionaram a energia total como um funcional da densidade, e de maneira na qual pudesse ser utilizada em cálculos computacionais. (81) Para isso, KS simplificaram o problema utilizando a energia cinética de elétrons não interagentes, com a densidade eletrônica sendo a mesma do sistema interagente. A energia total foi então particionada como

$$
E_{e}[n(\mathbf{r})]=K_{0}[n(\mathbf{r})]+V_{n e}[n(\mathbf{r})]+V_{e e}[n(\mathbf{r})]+E_{x c}[n(\mathbf{r})]
$$

onde $K_{0}[n(\mathbf{r})]$ é a energia cinética do sistema não interagente, $V_{n e}[n(\mathbf{r})]$ a energia da interação elétron-núcleo e $V_{e e}[n(\mathbf{r})]$ é a energia eletrostática da interação elétron-elétron. O termo $E_{x c}[n(\mathbf{r})]$ é o funcional de troca e correlação, que além das energias de troca e correlação, inclui também a correção da energia cinética e da auto interação eletrônica presente em $V_{e e}[n(\mathbf{r})]$. Dessa maneira se o termo $E_{x c}[n(\mathbf{r})]$ for conhecido exatamente, a energia da equação 2.59 é exata.

Para a solução do problema, são então consideradas as funções de onda do sistema de elétrons não interagentes $\phi_{i}^{K S}\left(\mathbf{r}^{P}\right)$, conhecidas como orbitais de Kohn-Sham. Através desses orbitais é possível se obter a densidade eletrônica

$$
n(\mathbf{r})=\sum_{i}^{N}\left|\phi_{i}^{K S}(\mathbf{r})\right|^{2} .
$$

Esses orbitais são encontrados na solução das Equações de Kohn-Sham, que tem a forma

$$
\hat{h} \phi_{i}^{K S}(\mathbf{r})=\epsilon_{i}^{K S} \phi_{i}^{K S}(\mathbf{r})
$$

onde o Hamiltoniano $\hat{h}$ é dado por

$$
\hat{h}=-\frac{1}{2} \nabla_{i}^{2}+V_{e f f}(\mathbf{r})
$$

sendo

$$
V_{e f f}[n(\mathbf{r})]=V_{n e}[n(\mathbf{r})]+V_{e e}[n(\mathbf{r})]+\frac{\delta E_{x c}[n(\mathbf{r})]}{\delta n(\mathbf{r})}
$$


Portanto, sendo o potencial efetivo $V_{e f f}[n(\mathbf{r})]$ um funcional da densidade, a solução das equações deve ser feita de maneira auto-consistente. Na prática, se inicia a solução com uma densidade eletrônica inicial sujeita ao vínculo $P=\int d \mathbf{r} n(\mathbf{r})$, e após a obtenção do potencial $V_{\text {eff }}[n(\mathbf{r})]$ inicial a equação 2.61 é resolvida, dando novos orbitais de $\mathrm{KS}$ utilizados na construção de uma nova densidade. A nova densidade é misturada à densidade anterior, e esse processo é repetido até que a convergência desejada seja alcançada. Com a convergência a energia do estado fundamental dos elétrons pode ser encontrada, utilizando-se a equação

$$
E_{e}[n(\mathbf{r})]=\sum_{i=1}^{P} \epsilon_{i}^{K S}-\frac{1}{2} \iint d \mathbf{r} d \mathbf{r}^{\prime} \frac{n(\mathbf{r}) n\left(\mathbf{r}^{\prime}\right)}{\left|\mathbf{r}-\mathbf{r}^{\prime}\right|}+E_{x c}[n(\mathbf{r})]-\int d \mathbf{r} n(\mathbf{r}) V_{x c}[n(\mathbf{r})] .
$$

Finalmente com a energia fundamental do estado eletrônico da equação 2.64 e considerando os núcleos fixos, somos capazes de obter a energia total, que inclui além da energia dos elétrons a energia de interação dos núcleos

$$
E_{t o t}\left(\mathbf{R}^{N}\right)=\frac{1}{2} \sum_{\substack{\alpha=1 \\ \alpha \neq \beta}}^{N} \sum_{\substack{\alpha=1 \\\left|\mathbf{R}_{\beta}-\mathbf{R}_{\alpha}\right|}} \frac{Z_{\alpha} Z_{\beta}}{\left.\mid\left\{\mathbf{R}^{N}\right\}\right)} .
$$

\subsubsection{Energia de troca e correlação}

A aproximação feita nos cálculos de DFT encontra-se somente no funcional de troca e correlação $E_{x c}[n(\mathbf{r})]$. Como essa energia não é conhecida de forma exata, tipicamente se separa essa energia como $E_{x c}[n(\mathbf{r})]=E_{x}[n(\mathbf{r})]+E_{c}[n(\mathbf{r})]$, e seguindo alguns vínculos conhecidos, aproximações para cada termo são propostas.

Historicamente, a primeira aproximação proposta foi a aproximação da densidade local, que aproxima a densidade eletrônica localmente como constante, dada pela densidade do gás de elétrons homogêneo. Essa aproximação dá resultados insatisfatórios em muitos casos, exigindo então correções. A aproximação do gradiente generalizado (AGG), que inclui correções semi-locais ao funcional, vem sendo utilizada com grande sucesso nas ultimas décadas. A AGG utiliza além da densidade, o gradiente da mesma e tem como sua forma geral

$$
E_{x c}^{A G G}[n(\mathbf{r})]=\int d \mathbf{r} \epsilon_{x c}[n(\mathbf{r}), \vec{\nabla} n(\mathbf{r})] n(\mathbf{r}) .
$$

A função $\epsilon_{x c}[n(\mathbf{r}), \vec{\nabla} n(\mathbf{r})]$ presente na equação 2.66 varia de acordo com os diferentes funcionais $A G G$ existentes. Um dos funcionais mais populares nessa classe é o funcional de Perdew, Burke e Ernzerhof, conhecido como funcional PBE. (82) Esse funcional é construído com uma função $\epsilon_{x c}[n(\mathbf{r}), \vec{\nabla} n(\mathbf{r})]$ derivada de primeiros princípios, e possui uma boa relação entre precisão e custo computacional. Por esse motivo e por ser um funcional já muito bem estabelecido, o funcional PBE foi o escolhido para ser utilizado nesse trabalho. 


\section{Capítulo 3}

\section{Implementação computacional}

\subsection{Introdução}

A implementação computacional do método PTMC foi feita utilizando a linguagem de programação C. Essa escolha se dá pelo excelente desempenho computacional da linguagem, pela possibilidade da criação e utilização de estruturas de dados adequadas, e pela possibilidade de paralelização com diferentes APIs (do inglês, Application Programming Interface). Além disso, a implementação pôde dessa maneira, ser integrada ao código GOTNano (Global Optimization and Thermodynamics of Nanoclusters), desenvolvido em nosso grupo de pesquisa. O GOTNano contém além da implementação do PTMC, a implementação do algoritmo Revised Basin Hopping Monte Carlo $(83,84)$ (RBHMC), e do algoritmo genético para a otimização de estruturas de nanoclusters.

Na figura 4 é mostrado um fluxograma da organização da implementação do método de PTMC no código GOTNano. Os parâmetros de entrada são lidos à partir dos arquivos "input", "input_atoms" e "input_temperatures", por meio da utilização de palavras-chave. Esses arquivos permitem entrada do conjunto inicial de informações utilizado pelo código, como as posições dos átomos nos nanoclusters, as temperaturas, entre outras. Após a leitura dos parâmetros, as variáveis e vetores são alocados conforme a necessidade da simulação.

A simulação PTMC é realizada em blocos ou etapas, sendo essas: inicialização, termalização, otimização do conjunto de temperaturas, fixação de um valor ótimo de $\delta$ e o cálculo das médias das propriedades. Esses blocos são identificados na figura 4 com os retângulos tracejados, e são simulados individualmente. Cada um deles possui uma função específica, e pode ser omitido conforme o desejo do usuário. 
Figura 4 - Fluxograma da implementação do algoritmo PTMC. As linhas tracejadas indicam os blocos simulados individualmente.

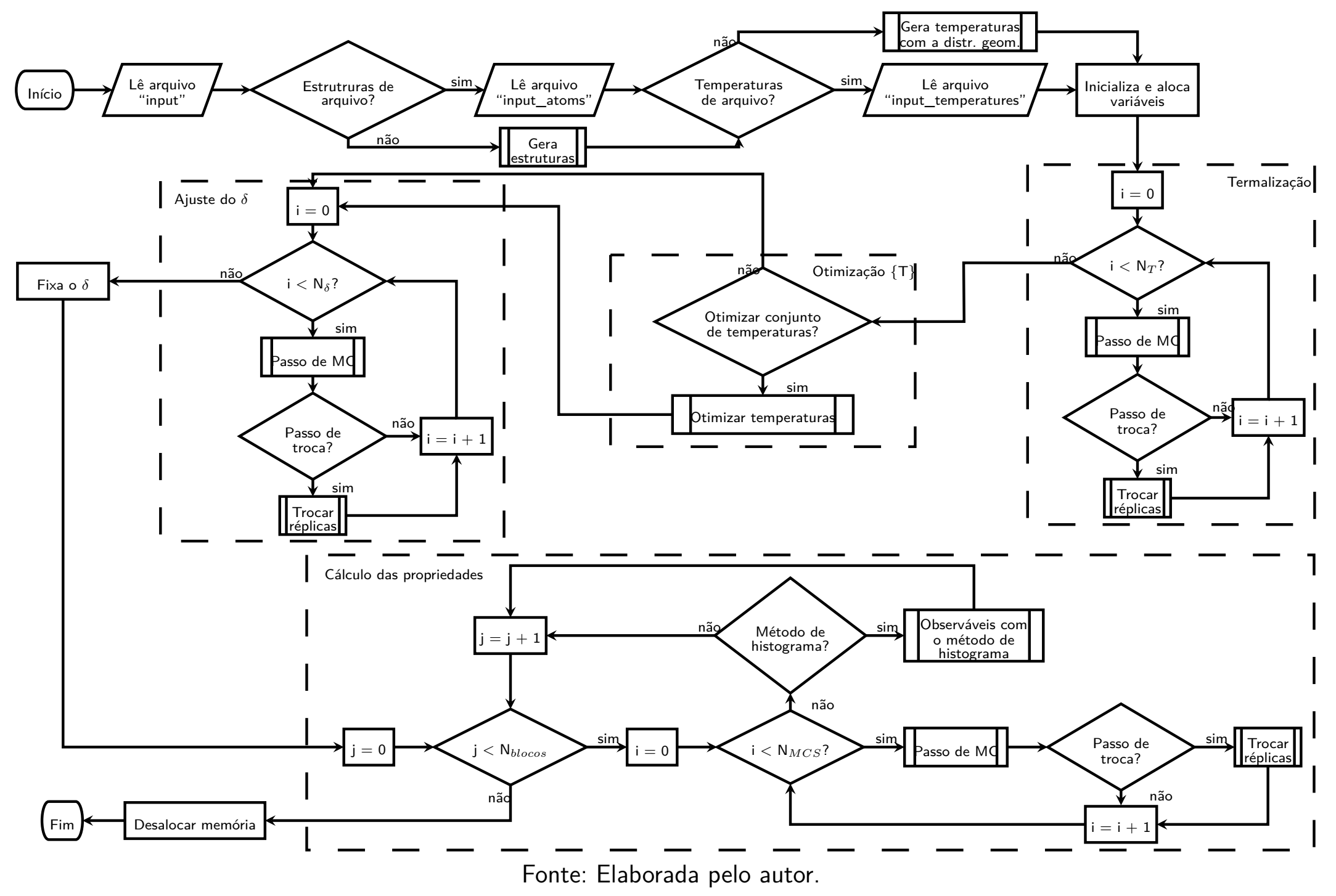




\subsection{Estrutura de dados}

A estrutura de dados do GOTNano é feita utilizando de estruturas struct, agrupando os dados relevantes para a simulação em cada temperatura através de um novo tipo de dado. Sendo as temperaturas simuladas de forma independente*, é conveniente introduzir uma estrutura que contenha as variáveis necessárias para a simulação de uma temperatura específica. Construindo então uma lista (vetor) com um membro dessa estrutura para cada temperatura, tem-se a representação completa do ensemble a ser simulado. A implementação desse tipo de dados que contém as informações necessárias para uma simulação de Metropolis MC é composta basicamente de:

\section{Tipo de dados \#1: variáveis para uma simulação de Metropolis MC}

- Uma variável de ponto flutuante para armazenar a temperatura

- Um ponteiro para a posição da memória contendo estrutura com as coordenadas dos átomos do nanocluster (tipo de dado \#2)

- Variáveis inteiras que contem os passos de MC, número de aceitações e rejeições, número de trocas realizadas e aceitas e número de rejeições pelo potencial de corte

- Variáveis de ponto flutuante para o acumulo e armazenamento das médias de grandezas fundamentais como a energia e o quadrado da energia

entre outras variáveis que servem para controle do programa e seus arquivos de saída. Essa estrutura de dados também é conveniente na implementação da paralelização, conforme será discutido na seção 3.11 .

Além dessa estrutura básica, um outro tipo de dado contendo informações sobre as estruturas do nanocluster é definido. Esse tipo de dado é utilizado por todo o GOTNano, e por esse motivo, contém variáveis utilizadas somente em outros algoritmos, como é o caso das forças, que somente são utilizadas no RBHMC e algoritmo genético. Nesse tipo de dados são armazenados:

\section{Tipo de dados \#2: estrutura do nanocluster}

- Lista com estrutura dos átomos do nanocluster, contendo espécie, coordenadas e distância do centro de gravidade

- Uma matriz de distância de pontos flutuantes, contendo as distâncias entre cada átomo do nanocluster

\footnotetext{
* Interagindo somente no momento em que a troca das estruturas entre réplicas é realizada.
} 
- Vetores com as componentes $x, y$ e $z$ das forças sentidas por cada átomo

- Raio do nanocluster

- Centro de gravidade da estrutura

- Matrizes auxiliares que armazenam, por exemplo, os elemento $V_{i j}$ da equação 2.46 .

Na figura 1 apresentada no capítulo 2, a estrutura de dados utilizada é mostrada de uma maneira pictórica. Cada um dos quadrados corresponde a uma variável do tipo de dados \#1, e os clusters representam variáveis do tipo de dados \#2. Já o retângulo exterior, representa a lista contendo todas as variáveis do tipo \#1 em diferentes temperaturas.

O cálculo de energia é implementado com o auxílio de duas matrizes auxiliares, como mencionadas no tipo de dados \#2, de forma que os termos utilizados nas somas são armazenados na memória. Essa representação é útil para economizar tempo computacional, já que o movimento de um átomo somente modifica uma linha/coluna na matriz de distâncias, de modo que não é necessário o cálculo de todos os termos a cada passo. Mantendo os termos na memória, a energia total do potencial de Gupta é computada somando os termos repulsivos e atrativos da equação 2.45. O lado negativo dessa implementação seria o uso de memória, e uma possível diminuição na localidade de dados, que devido à falta de conteúdo na memória cache (cache miss), pode acarretar em uma queda de desempenho. Entretanto, isso somente deve se tornar um problema para NPs com um grande número de átomos.

Utilizando a matriz de distâncias, a energia total com o potencial de LJ, dada pela equação 2.44, é diretamente calculada utilizando produtos dos termos $\sigma / r$. A utilização de produtos, ao invés da função potência disponível nas bibliotecas padrões, é devido ao desempenho superior dos produtos, já que nesse caso, o termo repulsivo é o quadrado do termo atrativo.

As energias e propriedades calculadas em cada passo são armazenadas em memória quando os valores esperados são calculados utilizando o método MAPHPT. Nesse caso, vetores são alocados na memória para armazenar o valor da energia e propriedades em cada passo. Como tipicamente centenas de milhões de passos são realizados, armazenar esse número de variáveis de ponto flutuante se torna inviável em computadores comuns, mas por outro lado, o uso de disco também não é uma opção, já que esses valores são acessados diversas vezes durante o cálculo, tornando essa solução computacionalmente ineficiente. Uma solução para esse problema é apresentada na seção 3.9, quando a implementação do método de histograma é discutida. 
Figura 5 - Fluxograma de um passo de Monte Carlo.

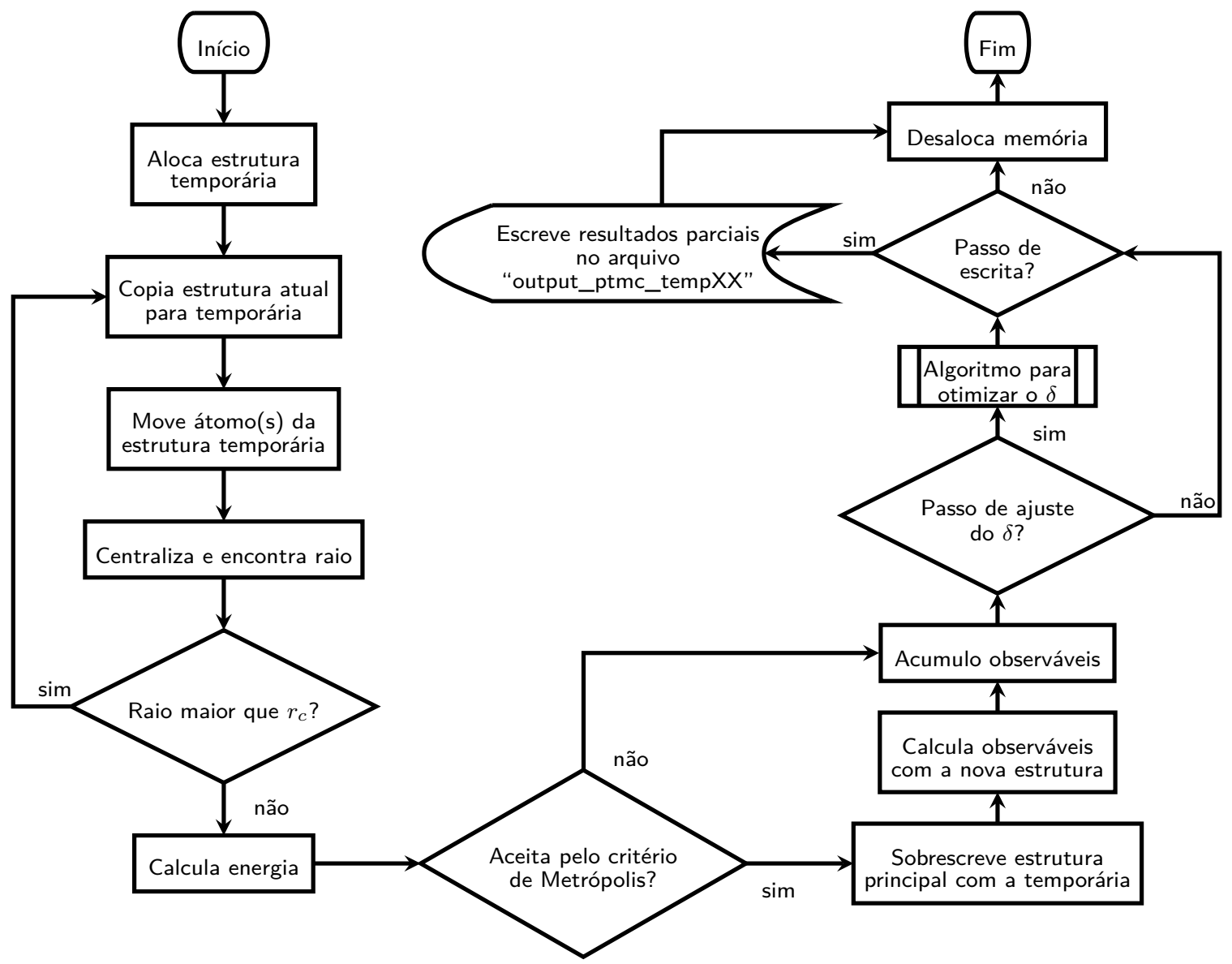

Fonte: Elaborada pelo autor.

\subsection{Implementação de um passo de Monte Carlo}

O algoritmo executado pela subrotina "Passo de MC" presente nos blocos da figura 4 é detalhado no fluxograma da figura 5. Basicamente, cada passo de MC é iniciado realizando uma cópia da estrutura atual, na qual será feita um deslocamento na posição dos átomos. Esse deslocamento é feito conforme descrito na subseção 2.2.4, ou seja, sorteando três números aleatórios (um para cada coordenada cartesiana), e adicionando o produto do $\delta$ com esses números à cada coordenada de um átomo selecionado aleatoriamente.

A qualidade do gerador de números aleatórios é fundamental para que os estados gerados não possuam memória dos estados anteriores. Por esse motivo, foi utilizado o gerador de números aleatórios MT19937, criado por Matsumoto e Nishimura(85) e implementado na biblioteca GNU Scientific Library (GSL). Esse gerador possui um período de aproximadamente $10^{600}$, e passou em testes padrões utilizados para a verificação da qualidade de números aleatórios (como o teste DIEHARD).

Após o novo estado ser gerado, sua energia total é calculada, e o critério de Metropolis é aplicado para verificar se o estado gerado deve ser aceito. Na aplicação do critério, um 
número aleatório $p$ no intervalo $[0,1]$ é obtido com o gerador MT19337 e utilizado para o sorteio da probabilidade de aceitação no caso de $p_{n}^{\beta}<p_{o}^{\beta}$. Quando o passo é aceito pelo critério de Metropolis, a estrutura atual* é sobrescrita com a temporária. Logo após, os valores das propriedades calculadas são acumulados em suas respectivas variáveis.

É importante notar que mesmo no caso onde a nova configuração é rejeitada a amostragem é feita, mas nesse caso utilizando a configuração antiga como ponto amostral. Essas amostras "repetidas" são acumuladas e utilizadas nas médias, e isso é importante pois garante que as probabilidades de transição sejam normalizadas. $\mathrm{O}$ código segue fazendo o ajuste do $\delta$ e a escrita em disco dos resultados parciais quando necessário.

\subsection{Potencial de corte definindo o volume do nanocluster}

O deslocamento feito no átomo para gerar o novo estado e a estrutura temporária, não é feito de forma livre, pois uma restrição quanto à máxima distância que o átomo pode estar do centro geométrico do cluster é utilizada. Essa restrição é baseada na ideia de Lee, Barker e Abraham(36) e serve para a definição do que é um nanocluster na simulação PTMC, fixando um limite para a distância de um átomo considerado "evaporado".

Na prática, o que ocorre é que quando um novo estado é gerado, é verificado se o átomo não excede a distância máxima permitida ao centro do cluster. Quando essa distância é excedida essa amostra é descartada, e uma nova amostra é gerada selecionando um novo átomo aleatoriamente e fazendo o deslocamento. Essa restrição, equivale ao uso de um potencial de corte de esfera dura:

$$
\mathbb{U}_{c}(r)= \begin{cases}0 & \text { se } r<r_{c} \\ \infty & \text { se } r \geq r_{c}\end{cases}
$$

que é adicionado ao potencial de interação.

Diversos trabalhos empregam essa definição e esse potencial de corte (como por exemplo as referências 40 e 86), que também servem para a definição de um volume $V$ a ser mantido constante em uma simulação no ensemble canônico. Entretanto, essa definição introduz um novo parâmetro ao código $\left(r_{c}\right)$, que pode afetar diretamente os resultados.

Na figura 6 é mostrado como diferentes valores de $r_{c}$ afetam os valores esperados do calor específico $C_{v}$ para os sistemas $\mathrm{LJ}_{13}$ e $\mathrm{LJ}_{55}$. Os diferentes valores de $r_{c}$, são escritos como variações percentuais do raio da estrutura de mais baixa energia $\left(r_{0}\right)$, portanto, tomando como exemplo a curva $1.15 r_{0}$, o valor utilizado de $r_{c}$ é $15 \%$ maior que $r_{0}$. Para as curvas do nanocluster $L J_{13}$ da figura $6(\mathrm{a})$, fica clara a tendência de um pico mais proeminente quanto maior o valor de $r_{c}$. Isso se dá pela alta razão superfície-volume do sistema, já que os átomos de superfície podem evaporar com facilidade, e portanto, a definição do tamanho da esfera

\footnotetext{
*Uma variável do tipo de dados \#2 apresentado na seção 3.2.
} 
Figura 6 - Diferentes valores de $r_{c}$ para os sistema (a) $L J_{13}$ e (b) $L J_{55}$.

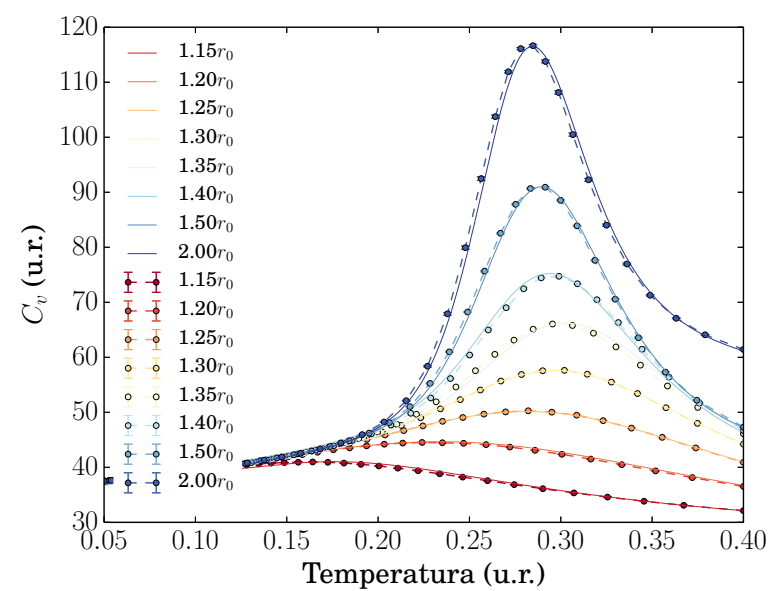

(a) $\mathrm{LJ}_{13}$

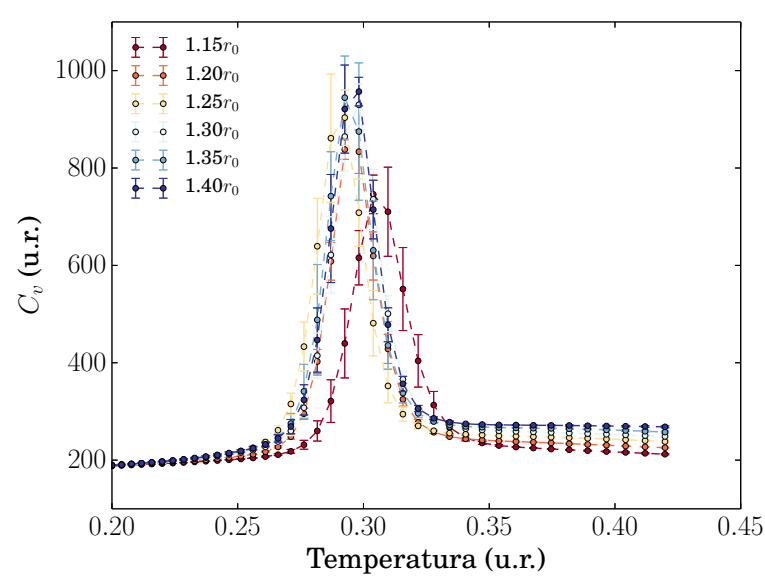

(b) $\mathrm{LJ}_{55}$

Fonte: Elaborada pelo autor.

restritora define o quão disperso os átomos podem estar e ainda definir um nanocluster. Para os menores valores de $r_{c}$, o pico no calor específico é praticamente inexistente devido à pressão exercida pela esfera restritora, de modo que a transição existente é suprimida ao menos nesse intervalo de temperaturas. As linhas contínuas do gráfico foram obtidas utilizando o método MAPHPT, e coincidem muito bem com os pontos calculados com médias simples nesse caso, confirmando então que nenhuma informação extra da simulação é perdida com as médias simples.

Contrastando com o caso do $\mathrm{LJ}_{13}$, tem-se na figura $6(\mathrm{~b})$ as curvas obtidas com diferentes valores de $r_{c}$ para o nanocluster $\mathrm{LJ}_{55}$. Nesse caso, o tamanho da esfera não afeta drasticamente o resultado quando o valor de $r_{c}$ é ao menos $20 \%$ maior que $r_{0}$. Para $r_{c}$ apenas $15 \%$ maior que $r_{0}$, a esfera exerce uma pressão no nanocluster, o que afeta diretamente as suas propriedades e ponto de fusão. Os efeitos do uso de um valor de $r_{c}$ que exerça pressão no sistema, assim como efeitos potenciais constritores diferentes do expresso pela equação 3.1 já foram explorados na literatura para casos como o do $\mathrm{LJ}_{38}$. (87)

Esses resultados, indicam que um cuidado deve ser tomado para a escolha de $r_{c}$ no estudo de clusters pequenos como o $\mathrm{LJ}_{13}$. Entretanto, é observado que para o $\mathrm{LJ}_{55} \circ$ valor de $r_{c}$ tem um papel menos crítico, sugerindo que para nanoclusters maiores, essa escolha não desempenhe um papel tão fundamental nos resultados.

\subsection{Implementação das trocas de réplicas}

A implementação dos algoritmos descritos na subseção 2.2.2 para a troca de réplicas, utilizou de características da estrutura de dados do programa. A troca das estruturas, na 
verdade consiste na mudança da posição de memória apontada pelos ponteiros no tipo de dados \#1. Dessa maneira, a implementação da troca consiste apenas na seleção das réplicas a serem trocadas (utilizando os algoritmo PID, PIE ou AI), e da aplicação do critério de Metropolis para a aceitação ou não da mesma.

Pelo fato de não existir um critério padrão definido para a análise de performance de algoritmos de troca, e nenhum trabalho reunir todas as possíveis possibilidades e algoritmos existentes, a escolha de algoritmo depende da aplicação, ${ }^{*}$ e deve ser feita considerando além da performance o custo computacional.

À princípio, fazendo uma breve análise qualitativa, o algoritmo Al deve mostrar uma melhor performance, dada suas características que buscam maximizar a mistura das replicas. Entretanto o seu custo computacional é maior que o dos algoritmos PID e PIE por exemplo, pois $M^{3}$ tentativas de trocas são realizadas. Por esse motivo o algoritmo Al pode ser usado como referência, mas a sua utilização prática se torna pouco interessante, já que com a utilização de algoritmos como o PID pode-se obter resultados satisfatórios com um custo consideravelmente menor.

\subsection{Inicialização, alocação de recursos e termalização}

O primeiro passo após a leitura dos arquivos de entrada, é a alocação de recursos e criação dos arquivos de saída. É alocada nessa etapa a memória referente à simulação a ser realizada, por exemplo, caso o método de histograma não seja utilizado, os vetores e estruturas usados pelo método não são alocados. Comum à todos os tipos de possíveis simulações com o algoritmo PTMC, estão as estruturas descritas na seção 3.2, que são alocadas em todos os casos. O tamanho das listas e vetores são compatíveis com os números de temperaturas e passos a serem simulados.

Uma parte importante da inicialização está na obtenção das estruturas dos aglomerados. Quando as estruturas não são lidas do arquivo, um algoritmo que gera as estruturas de forma aleatória é utilizado. Neste caso, as posições dos átomos são geradas aleatoriamente dentro de uma esfera de raio fornecido pelo usuário. Esse raio deve obrigatoriamente ser maior que $r_{c}$, evitando assim que o sistema seja inicializado com um átomo já evaporado.

Na inicialização também é verificada a consistência dos dados de entrada fornecidos pelo usuário, como o número de passos que deve ser positivo, e o intervalo de temperaturas, que deve ser maior que zero por se tratar de temperaturas absolutas. À partir desse intervalo que o primeiro conjunto de temperaturas é gerado. Conforme a entrada do usuário, é possível gerar um conjunto distribuído geometricamente entre um intervalo de temperaturas (conforme a equação 2.17), ou ainda uma distribuição uniforme no intervalo. Esse conjunto é o utilizado

\footnotetext{
* Tanto do sistema quanto da propriedade a ser estudada.
} 
na simulação durante o processo de termalização do sistema.

Após a inicialização, o bloco de termalização é iniciado. Durante os passos dessa etapa, a única propriedade calculada é a energia, já que apenas ela é necessária no critério de Metropolis. A termalização é importante pois permite que a estrutura saia do mínimo em que foi inicializada e vá para a região a ser explorada. Dessa maneira, se as estruturas iniciais forem, por exemplo, completamente aleatórias e iniciarem com uma configuração de muito alta energia (que possuem um peso pequeno na distribuição de Boltzmann), essa energia é reduzida de modo a explorar a região pertinente do espaço de configurações. O número de passos, $N_{T}$, necessário para alcançar a termalização é dependente do sistema e configuração inicial, e por esse motivo, fica como parâmetro de entrada do código.

\subsection{Otimização do conjunto de temperaturas}

Quando o bloco de termalização é completo, o usuário tem a opção de otimizar o conjunto de temperaturas. Esse bloco é opcional pois para sistemas e intervalos de temperatura onde o calor específico é aproximadamente constante, o conjunto de temperaturas inicial gerado na inicialização (obedecendo a progressão geométrica) é o conjunto ótimo. Além disso, quando o número de temperaturas $M$ é grande e o intervalo de temperatura pequeno, as temperaturas são alocadas próximas umas as outras, produzindo altas taxas de aceitação de trocas e resultados que não são quase afetados pelo conjunto de temperatura. Entretanto, como esses casos se tratam de casos específicos, os algoritmos de otimização do conjunto de temperaturas descritos na subseção 2.2.3 foram implementados.

\subsubsection{Algoritmo OE}

A implementação da rotina de otimização das temperaturas é feita selecionando primeiramente o algoritmo a ser utilizado. No caso do algoritmo OE, simulações feitas utilizando um bloco similar ao da termalização, são necessárias para possibilitar a medida da corrente de réplicas através da fração dada pela equação 2.18.* O número de passos utilizados nessas simulações é inicialmente informado pelo usuário, sendo esse multiplicado por um fator maior que um (tipicamente dois) a cada passo.

A implementação do método $\mathrm{OE}$, foi feita ligeiramente diferente da proposta no trabalho original de Katzgraber et al.(61) Como na derivação do método é assumida uma corrente de réplicas estacionárias, passos de termalização foram inseridos entre cada passo do algoritmo OE. Essa adição ao algoritmo pode ser importante pois, ao menos nos primeiros passos, o conjunto de temperaturas se altera bastante, fazendo com que os deslocamentos $\delta$ e a própria

\footnotetext{
* A derivada dessa fração com respeito à temperatura, é obtida por meio de uma regressão linear de três pontos.
} 
estrutura não estejam otimizados para a nova temperatura. Dessa maneira, a inclusão dos passos de termalização pode solucionar esse eventual problema, e a opção da utilização do método original pode ser feita utilizando um número de passos de termalização entre os passos do OE igual a zero.

Nas figuras 7 e 8 são exibidos passos do algoritmo OE para a otimização do conjunto de temperaturas dos sistemas $\mathrm{LJ}_{38}$ e $\mathrm{LJ}_{55}$, respectivamente, utilizando uma implementação conforme a descrita no trabalho original. É possível ver para o caso do $\mathrm{LJ}_{38}$ que mesmo após 9 passos com o algoritmo OE (sendo necessários $2.55 \times 10^{9}$ passos de $\mathrm{MC}$ ) o conjunto de temperaturas não convergiu completamente. Entretanto, os conjuntos dos passos 7 e 8 diferem de forma mínima (um desvio médio das diferenças absolutas de 0.001297), e podem ser considerados como convergidos dependendo do critério utilizado. Para a $\mathrm{LJ}_{55}$, tem-se que a segunda temperatura do conjunto oscila entre os passos do $\mathrm{OE}$, resultando também em um conjunto que não converge totalmente mesmo após 9 passos, apesar de novamente entre os passos 7 e 8 , o desvido médio das diferenças absolutas ser de apenas 0.000289 .

As modificações introduzidas pela implementação do algoritmo OE no GOTNano, permitem uma maior flexibilidade e ajuste da convergência. Utilizando a mesma quantidade de tempo computacional* foram realizados testes para verificar se é possível alcançar a convergência do conjunto de temperaturas variando o fator multiplicativo do número de passos e introduzindo a termalização entre passos do OE. Conforme exibido nas figuras 9 e 10, nessas condições é possível realizar um maior número de passos do OE com o mesmo custo computacional. Nesse caso é possível observar o comportamento oscilatório dos conjuntos de temperaturas para ambos os casos, com períodos que podem incluir mais de dois passos como o caso do $\mathrm{LJ}_{38}$ exibido na figura 9 . Esse comportamento oscilatório se dá pela variação do $f$, que leva a um ajuste maior do que o necessário para algumas temperaturas, de modo que o algoritmo tenta corrigir essa imprecisão da fração $f$ a cada passo. Ainda no caso da $\mathrm{LJ}_{38}$, é interessante notar que no sétimo passo as temperaturas foram uniformemente distribuídas no intervalo. Isso é resultado da segunda temperatura do conjunto no passo anterior, que por estar distante da temperatura mínima, não favoreceu a difusão dos identificadores "subindo", e assim fazendo com que o algoritmo tivesse uma estimativa ruim da derivada $\frac{d f}{d T}$, gerando um $\eta^{\prime}(T)$ (dado pela equação 2.20) constante.

Tanto para o algoritmo original quanto para o com os parâmetros modificados, notamos que a maior característica do algoritmo é um grande acúmulo de temperaturas ao redor da temperatura onde ocorre a mudança de fase. Isso se dá pela baixa taxa de aceitação das trocas de réplicas ao redor dessa temperatura, que faz com que haja nesse ponto um "gargalo", que deve ser compensado com o acumulo de mais temperaturas na região, facilitando o fluxo das réplicas entre as temperaturas extremas. Entretanto, essa característica faz com que próximas

* Todos os cálculos para o OE foram realizados utilizando 8 núcleos de processamento, por um tempo total de 72 horas. 
Figura 7 - Passos do algoritmo OE para obter os conjuntos de temperaturas para o sistema $\mathrm{LJ}_{38}$. Seguindo o algoritmo original, o número de passos de $\mathrm{MC}$ foi dobrado à cada passo do algoritmo $\mathrm{OE}$, partindo de $10^{7}$ passos.

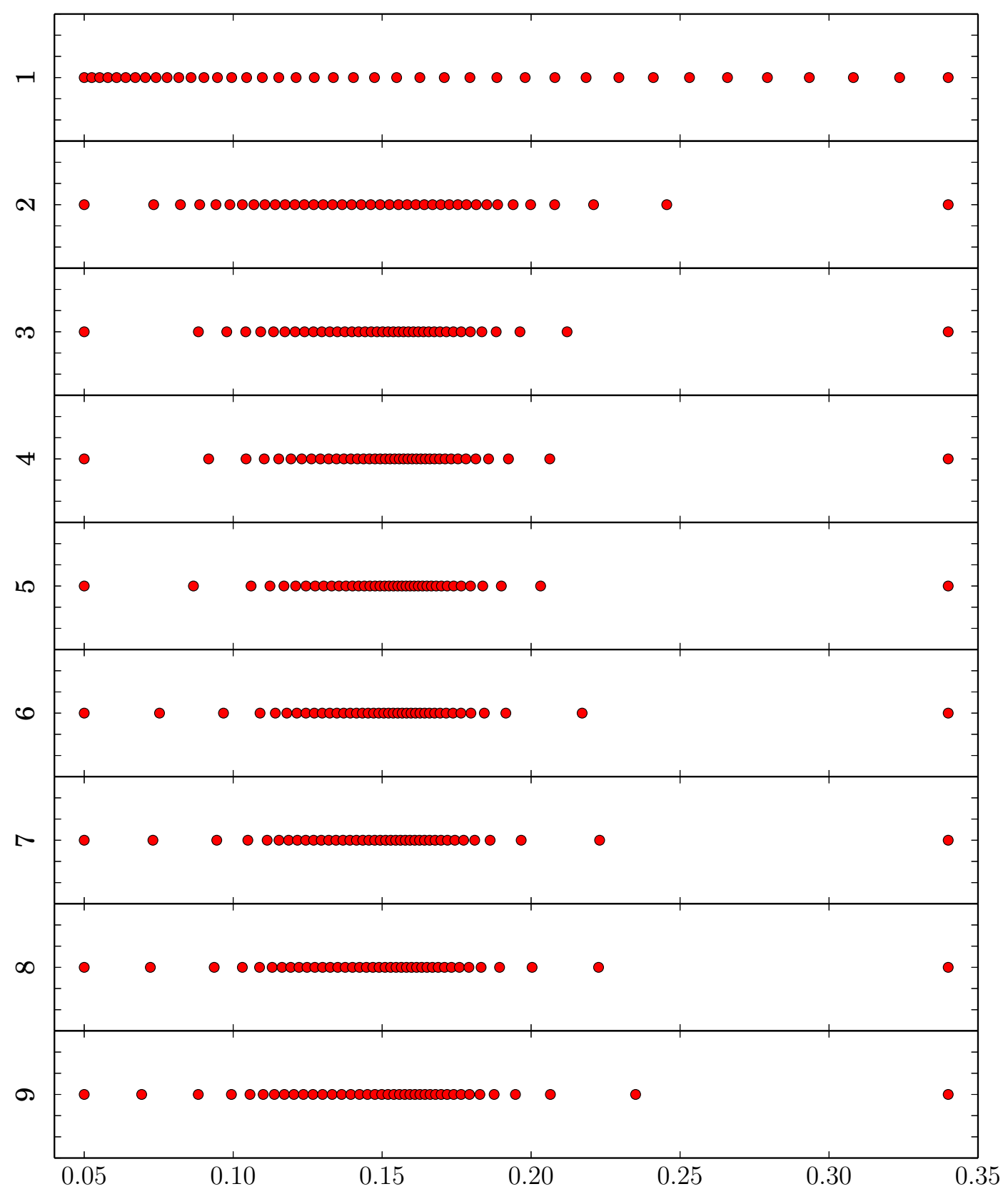

Fonte: Elaborada pelo autor.

às temperaturas extremas, o número de temperaturas seja reduzido, o que pode se tornar um problema em alguns casos.

Para o cálculo das médias das propriedades com o algoritmo MAPHPT, o conjunto de temperaturas gerado pelo OE pode não ser adequado. Conforme mostrado na figura 11 , o valor médio das propriedades calculados como uma média simples no ensemble e com o MAPHPT diferem consideravelmente nos casos apresentados. O espaçamento das temperaturas 
Figura 8 - Passos do algoritmo OE para obter os conjuntos de temperaturas para o sistema $\mathrm{LJ}_{55}$. Seguindo o algoritmo original, o número de passos de $\mathrm{MC}$ foi dobrado à cada passo do algoritmo $\mathrm{OE}$, partindo de $10^{7}$ passos.

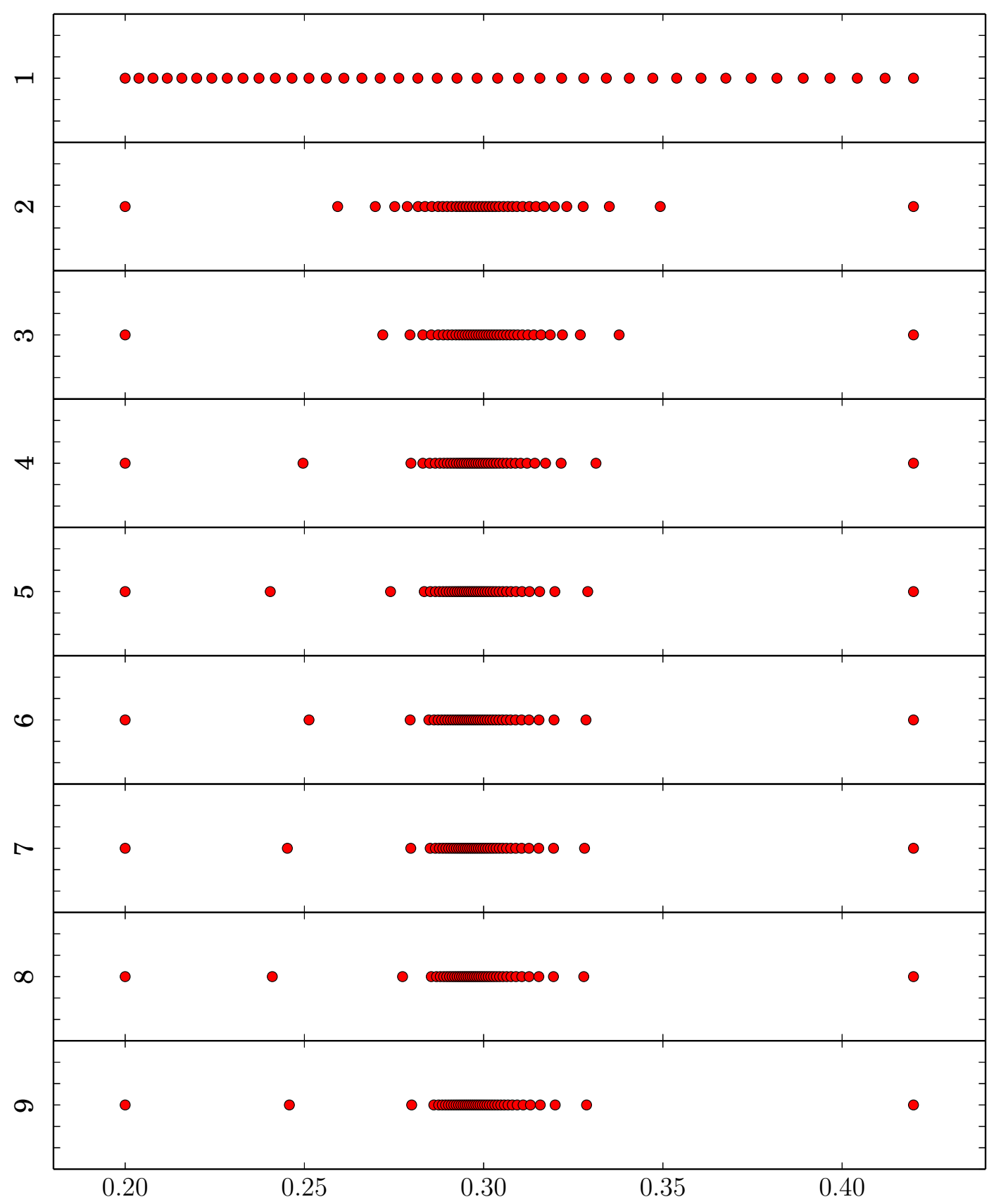

Fonte: Elaborada pelo autor.

próximos aos extremos faz com que a sobreposição dos histogramas seja pequena, ou até nula, próxima aos extremos, introduzindo efeitos espúrios às médias. Esse efeito ocorre para ambos nanoclusters, sendo mais acentuado para a $\mathrm{LJ}_{38}$, onde além dos grandes picos que não são exibidos nas médias simples (próximos aos extremos), a transição sólido-sólido que deveria ocorrer próxima a 0.12 u.r. não tem sua forma evidenciada como ocorre em simulações utilizando outros conjuntos de temperatura. 
Figura 9 - Passos do algoritmo OE para obter os conjuntos de temperaturas para o sistema $\mathrm{LJ}_{38}$. O número de passos de $\mathrm{MC}$ foi aumentado em $20 \%$ a cada passo do algoritmo $\mathrm{OE}$, partindo no número inicial de $5 \times 10^{6}$ passos de $\mathrm{MC}$. Entre cada passo do OE, foi realizada uma termalização por $10^{7}$ passos de MC.

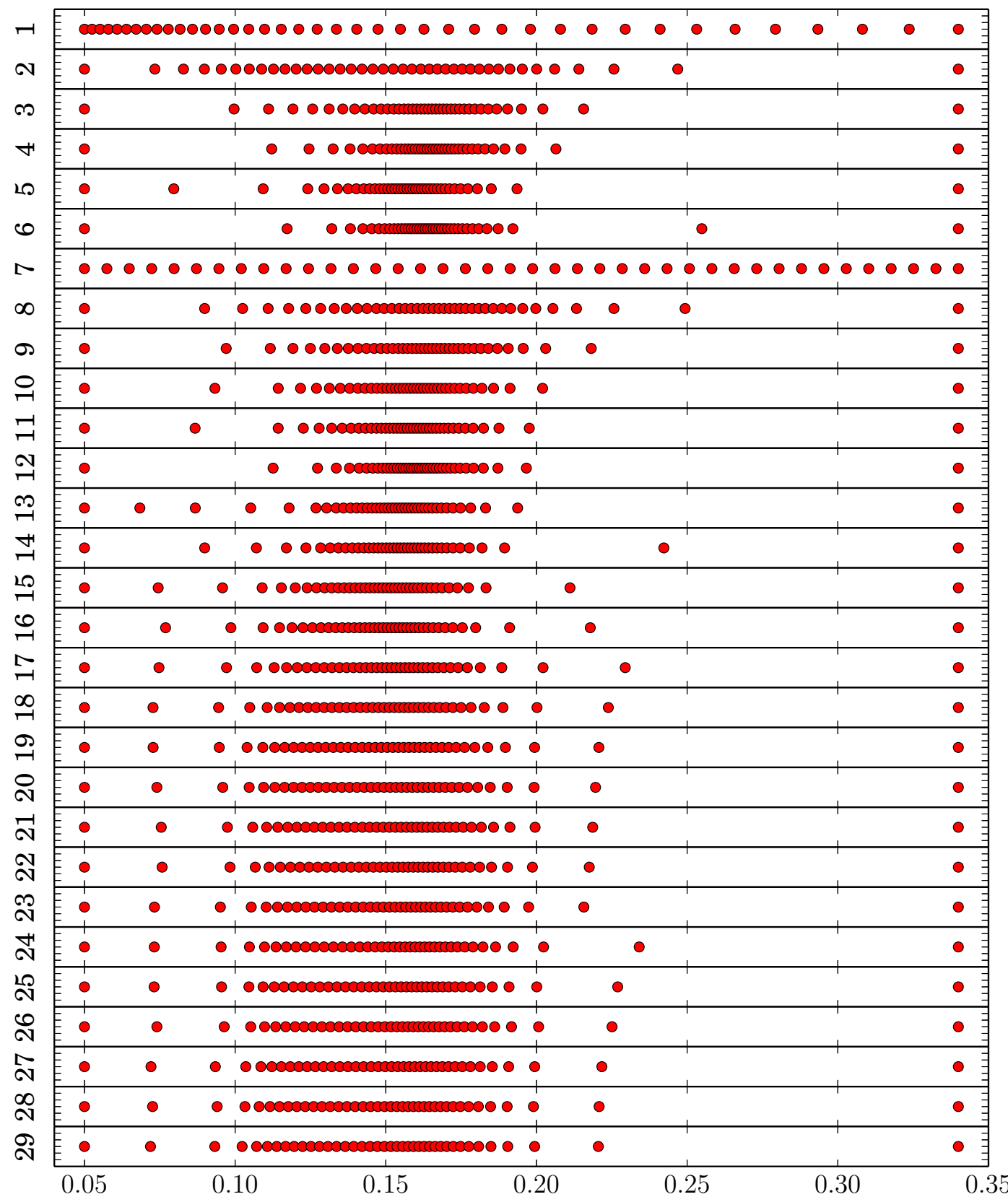

Fonte: Elaborada pelo autor.

\subsubsection{Algoritmo ACE}

O algoritmo ACE também utiliza-se de um bloco de passos de MC realizados previamente, mas nesse caso, para estimar o calor específico utilizado pelo método. Para isso, o algoritmo de histograma é automaticamente utilizado, já que o processo de integração numérica da 
Figura 10 - Passos do algoritmo OE para obter os conjuntos de temperaturas para o sistema $\mathrm{LJ}_{38}$. O número de passos de MC foi aumentado em $20 \%$ a cada passo do algoritmo $\mathrm{OE}$, partindo no número inicial de $5 \times 10^{6}$ passos de MC. Entre cada passo do $\mathrm{OE}$, foi realizada uma termalização por $10^{7}$ passos de $\mathrm{MC}$.



Fonte: Elaborada pelo autor.

equação 2.21 com o método dos trapézios requer o conhecimento do calor específico em diversas temperaturas. A utilização do método do histograma pelo ACE, não implica necessariamente que as propriedades calculadas no bloco de cálculo das médias serão feitos utilizando o método do histograma.

Na figura 12 são mostrados os conjuntos de temperaturas iniciais (utilizando a distribui- 
Figura 11 - Curva de calor específico para os nanoclusters (a) $L_{38}$ e (b) $L J_{55}$, calculadas utilizando o algoritmo MAPHPT e conjunto de temperaturas otimizado pelo algoritmo OE.

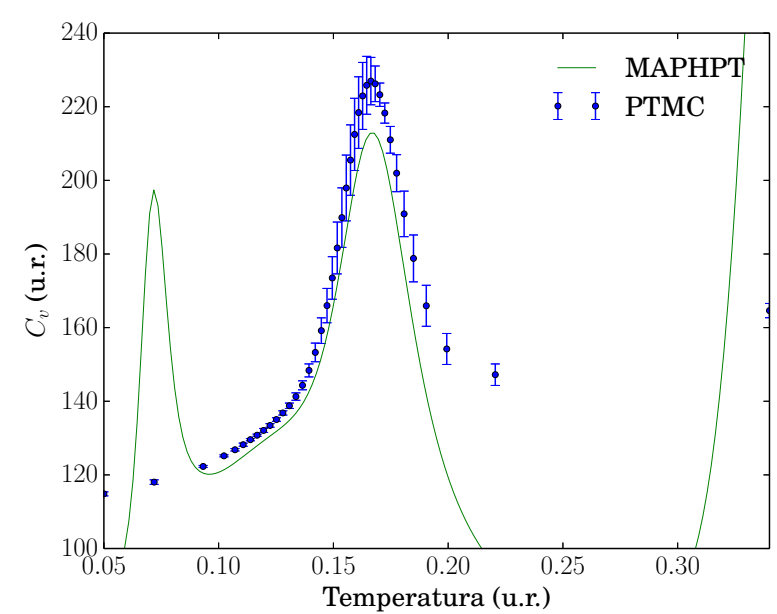

(a) $\mathrm{LJ}_{38}$



(b) $\mathrm{LJ}_{55}$

Fonte: Elaborada pelo autor.

ção geométrica) e otimizados para os nanoclusters $\mathrm{LJ}_{38}$ e $\mathrm{LJ}_{55}$. Para estimar o calor específico, após uma simulação com $2 \times 10^{7}$ de passos de MC, o algoritmo MAPHPT é utilizado para obter o valor de $C_{v}$ em temperaturas espaçadas em 0.0001 unidades reduzidas. O resultado é um conjunto de temperaturas no qual, assim como no conjunto gerado pelo OE, concentra um número maior de temperaturas ao redor da temperatura de mudança de fase. Entretanto, nesse caso o número de temperaturas alocadas ao redor dessa temperatura é menor, gerando um conjunto de temperaturas mais uniformemente distribuído no intervalo. Comparando com a distribuição geométrica, também é possível perceber que o conjunto otimizado com o ACE preserva um pouco da distribuição inicial. De um modo geral, a troco de um número menor de temperaturas próximas à $T_{\text {min }}$, a otimização das temperaturas com o ACE resolve um dos maiores problemas enfrentado pela distribuição geométrica: a queda na taxa de aceitação ao redor da temperatura de transição, que dificulta a difusão das réplicas entre as temperaturas extremas.

O conjunto de temperaturas gerado pelo ACE, é tipicamente mais adequado que o conjunto gerado pelo OE para o uso de algoritmos de histograma. Na figura 13, são exibidos o calor específico do $\mathrm{LJ}_{38}$ e $\mathrm{LJ}_{55}$ calculados com o conjunto otimizado pelo ACE. Diferentemente do caso do $\mathrm{OE}$, nesse caso o novo conjunto de temperaturas gera uma grande superposição dos histogramas do MAPHPT, e por esse motivo, tem-se resultados com comportamentos que se assemelham aos do cálculo das propriedades com média simples. Vale observar na figura 13(b) que o maior número de temperaturas estão alocadas imediatamente após o pico do $C_{v}$. Isso ocorre pois ao estimar o calor específico utilizado pelo $A C E$, a posição exata do pico não é determinada, ${ }^{*}$ sendo esse um pouco deslocado de sua posição real. Dessa maneira, o

\footnotetext{
* Para determinar com uma maior precisão, um número maior de passos de MC deveria ser realizado, para
} 
Figura 12 - Conjuntos de temperaturas para os sistemas (a) $\mathrm{LJ}_{38}$ e (b) $\mathrm{LJ}_{55}$, obtidos com o algoritmo ACE.

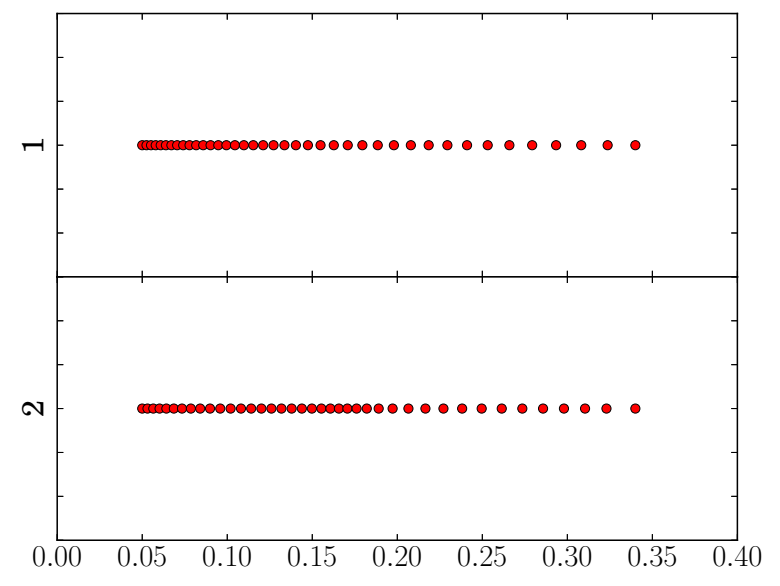

(a) $\mathrm{LJ}_{38}$

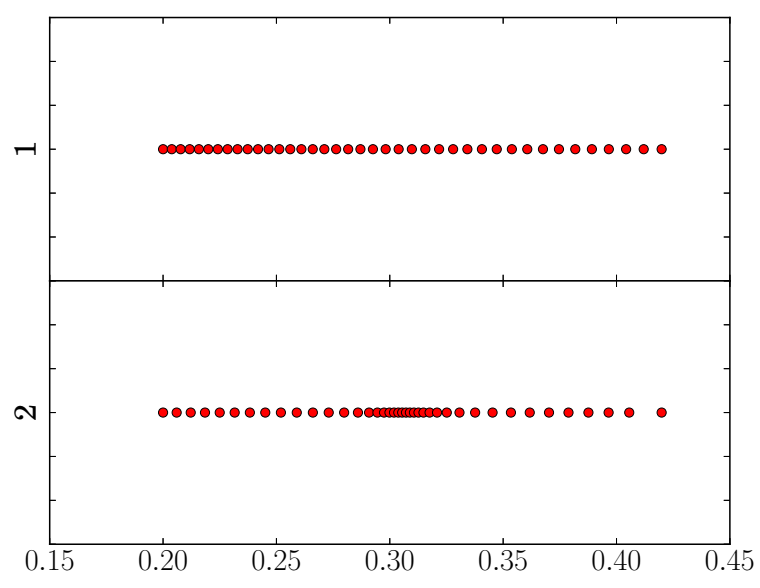

(b) $\mathrm{LJ}_{55}$

Fonte: Elaborada pelo autor.

Figura 13 - Curva de calor específico para os nanoclusters (a) $L J_{38}$ e (b) $L J_{55}$, calculadas utilizando o o algoritmo MAPHPT e conjunto de temperaturas otimizado pelo algoritmo ACE.

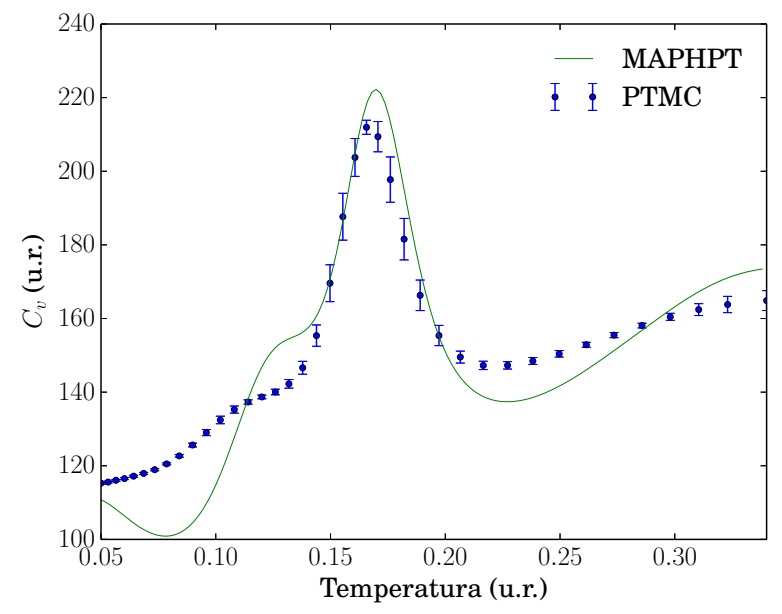

(a) $\mathrm{LJ}_{38}$

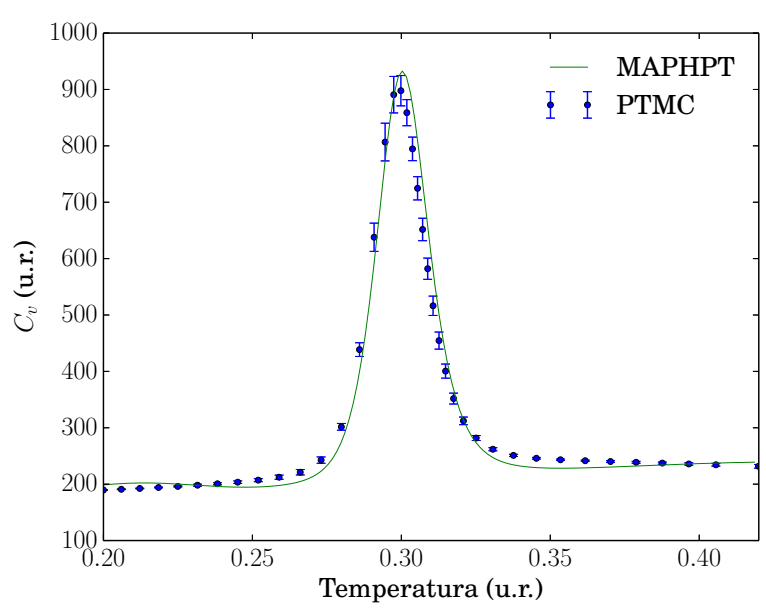

(b) $L J_{55}$

Fonte: Elaborada pelo autor.

conjunto gerado pelo algoritmo busca otimizar as temperaturas para o $C_{v}$ com o pico deslocado, acumulando na região do pico um maior número de temperaturas.

\subsection{Otimização do deslocamento máximo}

Imediatamente após o conjunto de temperaturas ser otimizado, as estruturas presentes em cada temperatura não necessariamente representam a região "correta" a ser explorada.

\footnotetext{
* assim obter o verdadeiro conjunto de temperaturas que proporciona um aumento constante de entropia.
} 
Também como consequência da mudança das temperaturas, o valor de $\delta$ associado à cada réplica pode não ser o ótimo. Por esse motivo, é feita a simulação de um novo bloco, que tem a finalidade de fazer uma nova termalização, e otimizar o valor do máximo deslocamento $\delta$.

Esse bloco é feito de maneira similar ao bloco de termalização, realizando os passos de MC calculando apenas a energia. A diferença fundamental nesse caso é que após a realização dos $N_{\delta}$ passos (número fornecido pelo usuário), o valor de $\delta$ é mantido fixo. Essa decisão foi tomada pois mesmo realizando as atualizações a cada $t_{\text {atualização passos, as incertezas e }}$ amostragem podem ser afetadas.

A implementação dos algoritmos é feita dentro do passo de $M C$, conforme mostrado na figura 5. Para fazer com que o valor de $\delta$ seja mantido fixo após o término do bloco de otimização, uma variável do tipo booleana é adicionada à condição que verifica a otimização, sendo esta feita inativa ao término do bloco.

As diferenças entre os algoritmos e diferentes taxa de aceitação podem ser observadas na figura 14 , onde são apresentadas as curvas de calor específico para o $L_{38}$ e $L_{55}$. As simulações para cada nanocluster foram feitas com a mesma "seed" do gerador de números aleatórios, de modo que a única diferença entre as curvas das figuras 14(a) e 14(b) se dá pela taxa de aceitação do algoritmo de Metropolis e algoritmo de ajuste do $\delta$. Para o $\mathrm{LJ}_{38}$ a forma da transição sólido-sólido, representada pelo pequeno "ombro" antes do pico, é afetada tanto pelo algoritmo quanto pela taxa de aceitação utilizada. Não é possível entretanto, definir qual a melhor taxa de aceitação ou algoritmo nesse caso, e por esse motivo o teste apenas identifica a dependência das propriedades com o algoritmo e taxa utilizados. Já para o $\mathrm{LJ}_{55}$ observa-se que a taxa de aceitação e algoritmo não afetam drasticamente o calor específico, contudo, caso o objetivo da simulação seja determinar com precisão a temperatura na qual ocorre o derretimento do nanocluster, o algoritmo e taxa utilizados podem ser relevantes.

\subsection{Cálculo das médias das propriedades}

A etapa de cálculo das propriedades difere consideravelmente das etapas anteriores. Esse bloco é dividido em sub-blocos, os quais são constituídos de passos do algoritmo PTMC. Essa divisão ocorre para viabilizar simulações com bilhões de passos utilizando o método de histograma, que devido à necessidade de se armazenar em memória os valores das propriedades, pode consumir dezenas de gigabytes de memória facilmente. Assim, com o esquema de blocos é possível dividir um grande número de passos em pequenos blocos e obter o valor esperado final fazendo uma média entre os valores obtidos em cada um deles. $\mathrm{O}$ número de blocos, e o número de passos realizado em cada um deles é dado pelo usuário.

As propriedades que podem ser calculadas com o código são descritas na subseção 2.3.1. Por dependerem somente de momentos estatísticos da energia, a energia interna e calor 
Figura 14 - Diferentes taxa de aceitação de Metropolis com algoritmos MTA e Percentual, para os nanoclusters (a) $\mathrm{LJ}_{38}$ e (b) $L J_{55}$.

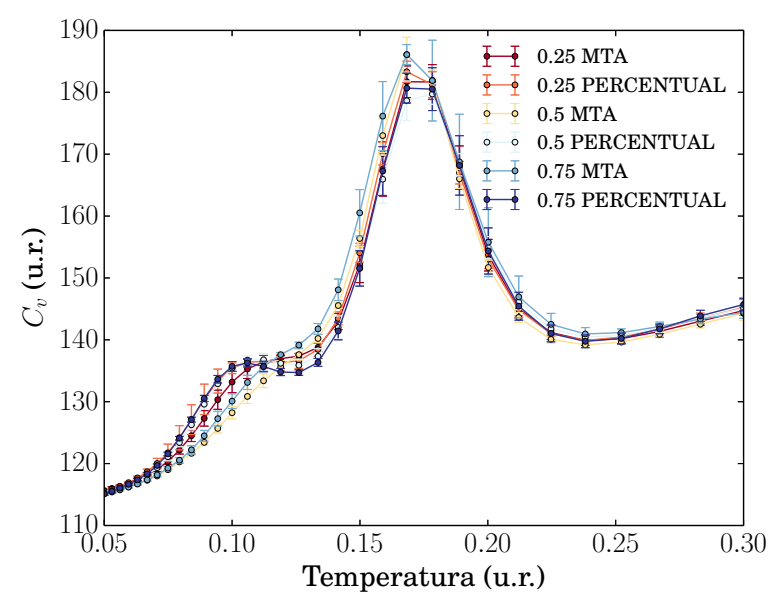

(a) $\mathrm{LJ}_{38}$

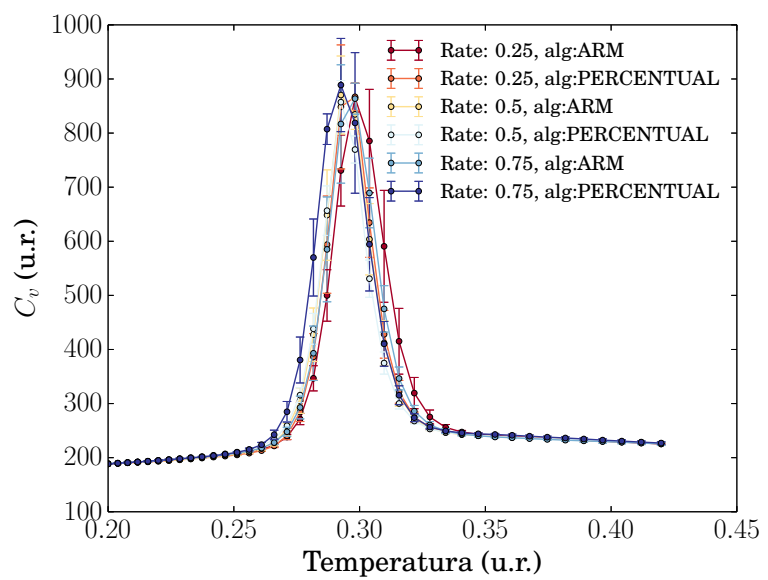

(b) $\mathrm{LJ}_{55}$

Fonte: Elaborada pelo autor.

específico são calculados em toda simulação, já que o custo computacional do cálculo dessas propriedades é baixo. * Por outro lado, o cálculo do número de coordenação efetiva é comprimento de ligação médio introduzem um custo extra à simulação, e por isso são deixados como opcionais conforme o desejo do usuário.

O modo padrão do cálculo das médias é por meio do acumulo dos valores das propriedades ao decorrer do passos de MC. À princípio os valores da energia e das propriedades em cada passo não são armazenados e somente acumulados, já que o grande volume de dados gerado exigiria uma grande quantidade de memória disponível. Essa estratégia permite o cálculo dos valores médios facilmente, somente sendo necessária a divisão pelo número de passos para a obtenção do valor médio final. Entretanto, o método de histograma descrito na subseção 2.3.1 exige que esse histórico (valor das propriedades em cada passo) seja mantido, aumentando drasticamente o consumo de memória pelo código. A alternativa, que seria o uso do disco rígido para o armazenamento dessas informações, se torna inviável, já que as informações são utilizadas com frequência na execução do algoritmo.

A implementação do método do histograma não é trivial devido à problemas numéricos relacionados a soma de exponenciais. Por ter um rápido crescimento e descrescimento, um overflow ou underflow podem ocorrer ao se calcular somas durante o cálculo da densidade de estados $\hat{\Omega}_{m}$, convergência da energia livre $f_{k}$ e cálculo dos pesos $w_{k n}(\beta)$ dados, respectivamente, pelas equações 2.37, 2.33 e 2.39. A magnitude dos elementos da somatória podem ser tão grandes, que nem mesmo o uso de variáveis de precisão dupla garantem que a precisão seja excedida.

\footnotetext{
*A energia é calculada em todo passo para ser utilizada no critério de Metropolis, e por isso não apresenta um custo extra.
} 
Esse problema das somas com exponencial, pode ser resolvido se realizarmos o logaritmo da soma. Como a função logarítmica cresce de forma muito lenta para valores grande do argumento, a sua utilização para controle de overflows é muito conveniente. Sendo $a_{0}>$ $a_{1}, a_{2}, \ldots, a_{n}>0$, é possível escrever o logaritmo de uma soma como

$$
\ln \sum_{i=0}^{n} a_{i}=\ln a_{0}+\ln \left(1+\sum_{i=1}^{n} e^{\left(\ln a_{i}-\ln a_{0}\right)}\right)
$$

e assim garantir um melhor controle do crescimento dos valores nas somas. Vale notar que $e^{\left(\ln a_{i}-\ln a_{0}\right)}$ deve ser um valor pequeno, já que $a_{0}>a_{i}$ garantindo um valor negativo para o argumento. Após o cálculo da soma com os logaritmos, é possível de se obter facilmente o valor da soma, pela exponenciação do resultado da equação 3.2.

Como mencionado na subseção 2.3.1, o cálculo da energia livre e densidade de estados requer uma solução auto-consistente. Para isso, as energias internas são inicializadas como nulas, e o estimador da densidade de estados é calculado. À partir dessa densidade de estados, é possível calcular um novo valor de $f_{k}$, utilizado para obter novamente $\hat{\Omega}_{m}$. Esse processo é repetido até que a maior diferença $\left|f_{k}-f_{k}^{\prime}\right|$ (sendo $f_{k}^{\prime}$ a energia livre do passo auto-consistente anterior) seja menor que um valor limite fixado pelo usuário. Quando a convergência é atingida, o valor final de $\hat{\Omega}_{m}$ pode ser então utilizado para o cálculo dos pesos e finalmente das médias das propriedades. Na figura 15 são apresentados os efeitos de diferentes critérios de convergência nos valores do calor específico do $\mathrm{LJ}_{55}$, onde é mostrado que se a convergência não for atingida, o valor obtido para a propriedade é totalmente impreciso. Entretanto, após atingir a convergência, o valor esperado da propriedade (ou ao menos do calor específico nesse caso) não varia muito, não sendo então necessário o gasto de tempo computacional para obter-se a energia livre de maneira exageradamente precisa.

\subsection{Algoritmo para a determinação de frequência das estruturas por similaridade}

Utilizando a distância euclideana apresentada na subseção 2.3.2, foi implementado um algoritmo capaz de obter, à partir de um conjunto de estruturas, aquelas que menos se assemelham. Esse algoritmo é geral, e pode ser feito como uma análise pós simulação, fazendo com que dados de simulação de dinâmica molecular, por exemplo, possam ser utilizados.

O algoritmo é iniciado, atribuindo um índice (número inteiro) a cada estrutura do conjunto total. À partir daí, a comparação entre a estrutura número 1 e todas as outras estruturas do conjunto, é feita utilizando o critério definido na equação 2.40. As estruturas similares são descartadas, de modo que ao término das comparações da estrutura número 1 com todas as outras, somente restam no conjunto as estruturas com $\Delta S_{A B}$ maior que o critério definido. 
Figura 15 - Diferentes critérios de convergência para a energia livre no algoritmo MAPHPT para o sistema $\mathrm{LJ}_{55}$.

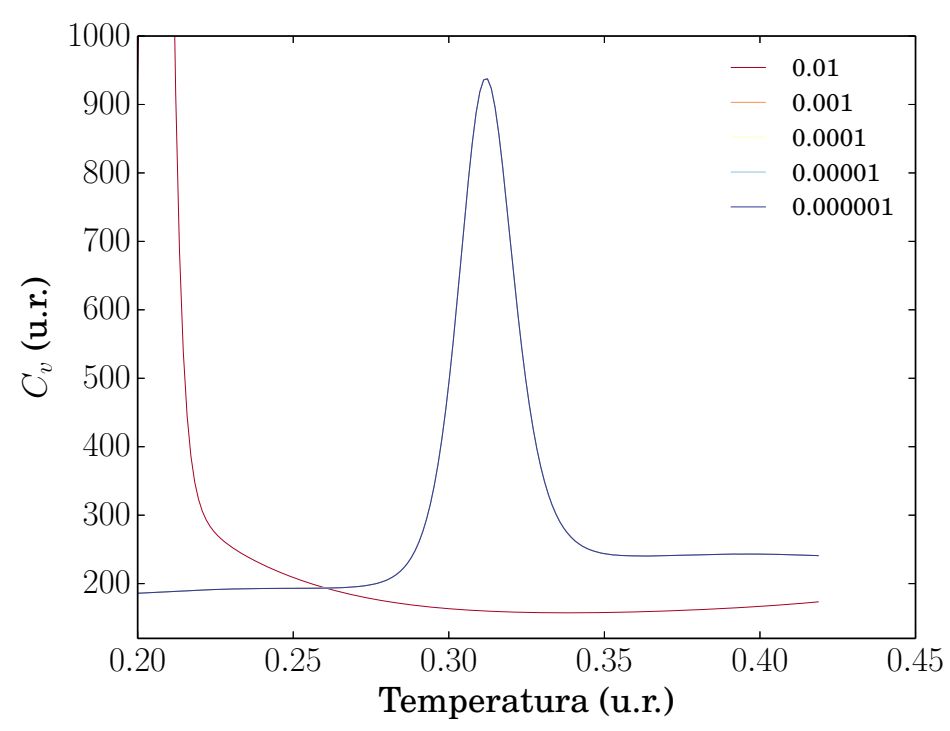

Fonte: Elaborada pelo autor.

Após isso, uma nova rodada de comparações é iniciada, utilizando como referência a estrutura com menor índice (diferente de 1, que já foi utilizado) do conjunto. As comparações são feitas da mesma maneira, considerando todas as estruturas que ainda não foram eliminadas do conjunto. Ao final dessa outra rodada, a próxima estrutura com o menor índice é selecionada, e esse processo é repetido até que não hajam mais estruturas para serem comparadas. No final, as estruturas remanescentes são as que, dado o critério $\Delta$ escolhido, melhor representam as diferenças do conjunto.

\subsection{Paralelização}

Devido a natureza intrinsecamente paralela do método PTMC, o uso de técnicas de paralelização e o desenvolvimento de um código paralelo surge de forma natural. Para realizar esse tipo de implementação, existem algumas APIs que podem ser utilizadas, podendo essas serem classificadas em dois modelos: passagem de mensagens ou memória compartilhada, sendo dentro dessa última possível a implementação com unidades de processamento gráfico. Neste trabalho, a implementação da paralelização foi realizada em memória compartilhada, utilizando a API do OpenMP. (88)

A escolha do OpenMP é devida principalmente à facilidade da implementação. Dada a estrutura do código GOTNano, onde o cálculo da energia é feito de forma serial, a paralelização pode ser feita de maneira quase imediata, fazendo a divisão do conjunto de temperaturas entre as threads. Essa divisão pode ser considerada balanceada, já que a carga de trabalho é igual para todas as temperaturas. As threads são criadas no início de cada bloco de simulação sendo 
as outras etapas, como a inicialização por exemplo, seriais. Como garantia de segurança de thread, um gerador de números aleatórios é alocado para cada thread.

Durante os passos de MC a sincronização das threads somente é necessária antes da troca das replicas. Sendo assim, cada thread executa $N_{s w}$ passos de MC para cada uma das temperaturas atribuídas a si, para então haver uma sincronização da execução e a sub-rotina de trocar de réplicas ser executada. Isso faz com que a eficiência da paralelização seja então dependente do parâmetro $N_{s w}$, além de outros fatores como o tamanho do sistema, e tempo gasto no cálculo de energia.

Para verificar a eficiência da paralelização, curvas de speedup foram construídas para diferentes casos. Utilizando simulações com diferentes parâmetros e sistemas, o tempo de execução dos passos de PTMC foi computado. Uma curva de speedup para a paralelização do método de histograma MAPHPT também foi obtida separadamente, já que o cálculo das propriedades com esse algoritmo é opcional no código. Como a ideia é apenas estimar essas curvas, somente uma simulação para cada caso foi realizada, e sendo essa realizada com poucos passos $\left(10^{6}\right.$ passos para todos os casos exceto o segundo caso da $\left.\mathrm{Pt}_{55}\right)$. As curvas foram obtidas em uma máquina com dois processadores Intel(R) Xeon(R) CPU E5-2670 v2 @ $2.50 \mathrm{GHz}$, e 64GB de memória RAM.

Para a medida do speedup nos passos de PTMC foram escolhidos três sistemas, buscando formar o conjunto mais variado possível. Para cada um desses sistemas, foram realizados testes com três diferentes valores de $N_{s w}$, já que como mencionado, esse valor afeta diretamente a necessidade de sincronização das threads. Primeiramente, foram obtidas as curvas de speedup para nanoclusters descritas com o potencial de LJ em dois diferentes tamanhos: 38 e 147 átomos. Como o tempo gasto para o cálculo da energia é afetado pelo número de átomos do nanocluster, e por sua vez, o tempo computacional gasto em cada passo de MC ser em grande parte devido ao cálculo de energia, é esperado que esse conjunto represente grande parte das situações possíveis encontradas pelo código.

Os resultados obtidos nesse caso são exibidos na figura 16. É possível verificar que claramente a paralelização se comporta melhor no caso do $\mathrm{LJ}_{38}$, e ainda assim nesse caso, o speedup obtido é longe do ideal para um número de núcleos maior que 5 . Conforme o esperado, também é verificado que speedups menores são obtidos para baixos valores de $N_{s w}$, contudo, essa diferença não é tão grande para nanocluster de 147 átomos, conforme mostrado na figura 16(b). Isso se deve muito provavelmente à quantidade de vezes em que o conteúdo sendo operado no momento não se encontra na memória cache, que acaba se tornando o fator dominante em sistemas maiores, que possuem maiores matrizes para armazenar as matrizes interatômicas, e em simulações com mais núcleos, já que o cache é compartilhado. Por esse motivo, simulações utilizando mais do que 10 núcleos com o GOTNano devem ser evitadas.

Outro fator que pode afetar diretamente o speedup é o potencial interatômico utilizado. O cálculo da energia total utilizando o potencial de Gupta é mais custoso, e também pode 
Figura 16 - Curva de speedup para $10^{6}$ passos de PTMC considerando diferentes números de passos entre trocas $\left(N_{s w}\right)$, para os nanoclusters $(\mathrm{a}) \mathrm{LJ}_{38}$ e (b) $\mathrm{LJ}_{147}$.

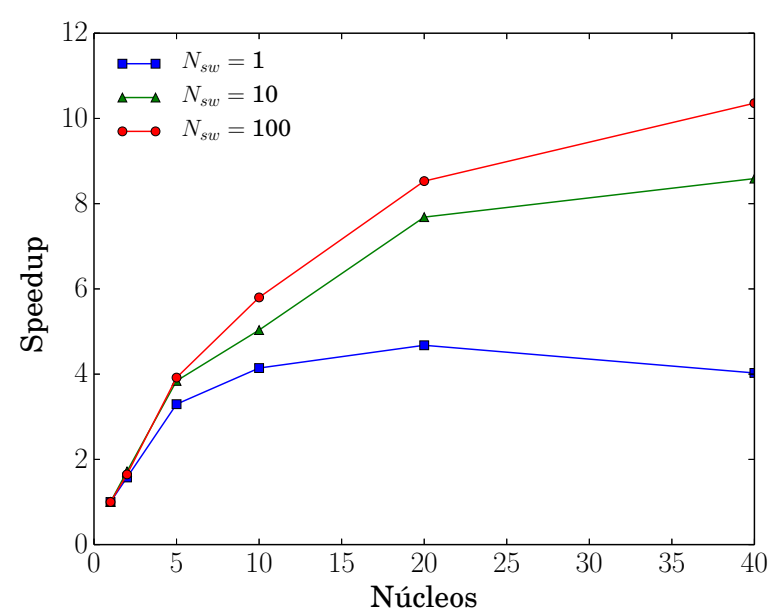

(a) $L J_{38}$



(b) $L J_{147}$

Fonte: Elaborada pelo autor.

à princípio afetar o número de acertos de cache, dada a estrutura de dados utilizada para o cálculo da energia nesse caso. Para verificar a influência do número de passos no speedup, foram realizados dois cálculos, utilizando $10^{6}$ e $5 \times 10^{6}$ passos respectivamente. Os parâmetros do potencial utilizado para esses cálculos, foram os da platina, já que essa é a principal espécie investigada no capítulo 4.

Na figura 17 são mostradas as curvas de speedup para a $\mathrm{Pt}_{55}$. Observa-se nesse caso que as curvas são extremamente similares, diferindo apenas por umas ligeira alteração no speedup, que aumenta com o número de passos em geral quando cinco ou mais núcleos são utilizados. Entretanto, não é possível concluir que o aumento no número de passos é responsável por esse aumento do speedup, já que as curvas foram obtidas após uma execução apenas, e os aumentos podem se tratar de desvios. Ainda assim, é possível concluir que o número de passos não altera de maneira alguma o comportamento, e que em um cenário otimista apenas melhor o speedup. Por esse motivo, os testes cumprem com o objetivo, que é guiar o usuário no número de núcleos à ser utilizado nas simulações.

Outro algoritmo responsável por grande parte do custo computacional é o algoritmo de histograma MAPHPT, e por esse motivo, a paralelização desse algoritmo foi também abordada. Nesse teste $10^{6}$ amostras com o algoritmo PTMC foram obtidas, e à partir delas, o tempo de execução do algoritmo MAPHPT foi obtido. A temporização foi feita considerando somente a sub-rotina principal do algoritmo do MAPHPT. Ou seja, a temporização inclui: a inicialização do MAPHPT, o cálculo dos histogramas, cálculo das ineficiências estatísticas, convergência da densidade de estados e cálculo dos valores esperados para cada temperatura. Os speedups obtidos com os dados dessa temporização, para dois valores de $N_{\text {bins }}$ (número de caixas no histogramas), podem ser vistos na figura 18. O número de temperaturas para as 
Figura 17 - Curva de speedup para o nanocluster de $\mathrm{Pt}_{55}$ sendo o cálculo realizado com (a) $10^{6}$ passos e (b) $5 \times 10^{6}$ passos.

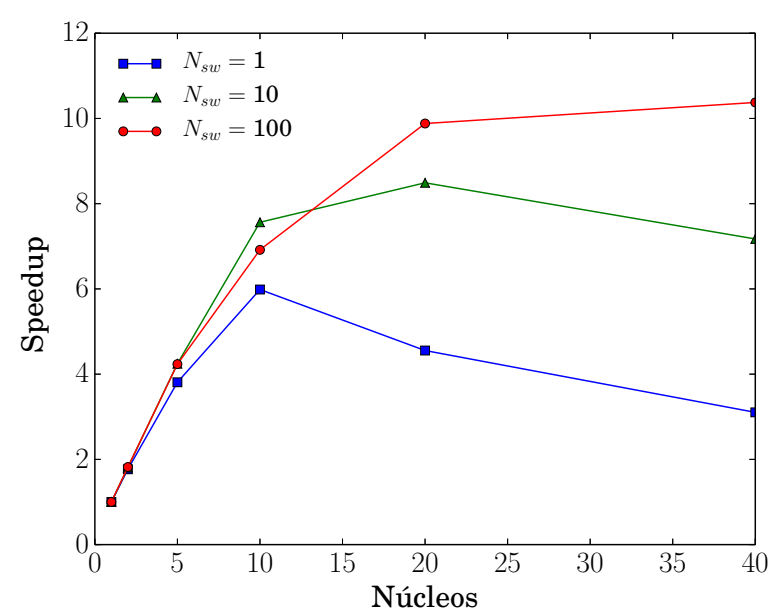

(a)

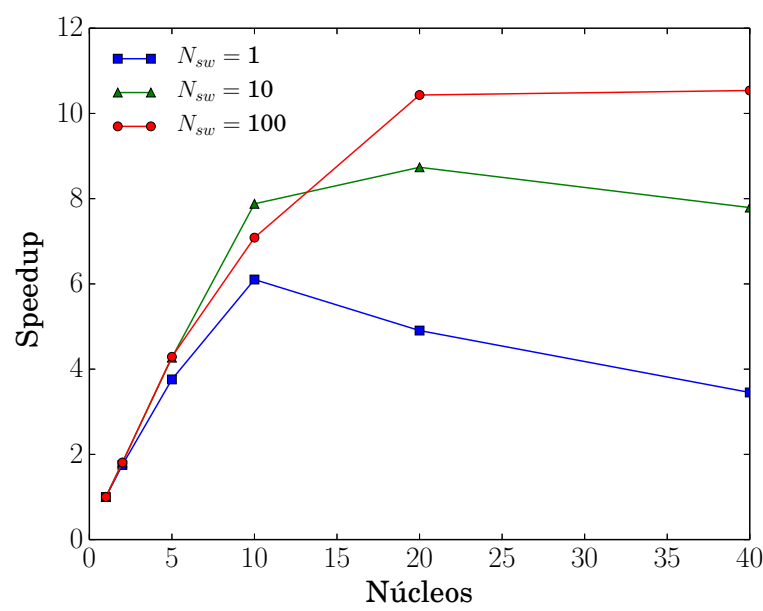

(b)

Fonte: Elaborada pelo autor.

Figura 18 - Speedup obtido na execução do algoritmo MAPHPT. $N_{b i n s}$ indica o número de caixas utilizado na construção dos histogramas.

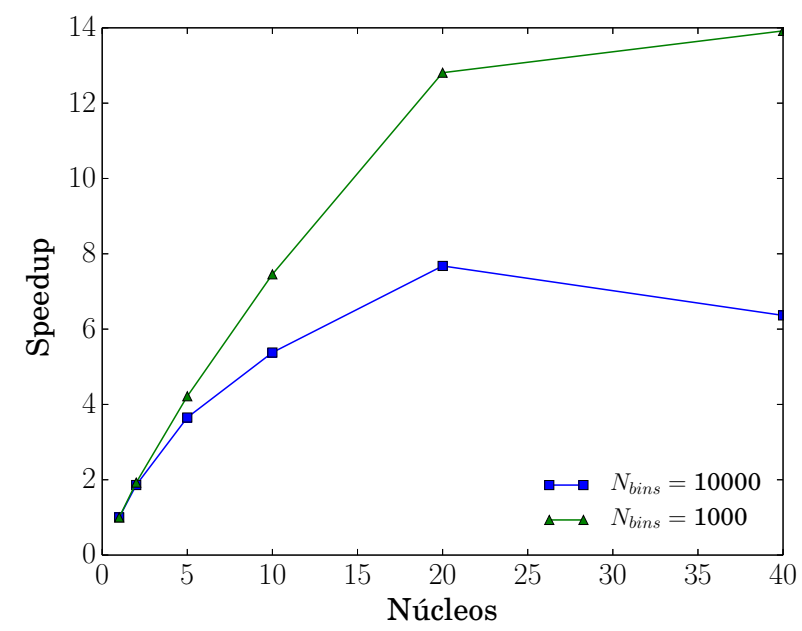

Fonte: Elaborada pelo autor.

quais os valores esperados foram estimados foi de 180 para ambos os casos, número o qual é tipicamente o suficiente para produzir uma curva contínua nos intervalos de temperatura tipicamente simulados.

Observa-se na figura 18 que a paralelização do MAPHPT pode alcançar maiores speedups quando o número de caixas dos histogramas $N_{\text {bins }}$ é menor. Isso ocorre devido ao número de acertos de cache, que é maior quando o número de caixas é menor, já que os dados nesses casos ficam localizados num menor número de blocos. A paralelização em todos os casos, incluindo os speedups dos passos de PTMC, escala de maneira razoável até o uso de 5 núcleos (onde o speedup é da ordem de 4). Contudo, especialmente para alguns casos, o uso 
de 10 núcleos por exemplo pode trazer um ganho considerável, apesar de os speedup estar longe do ideal. 


\section{Capítulo 4}

\section{Resultados}

\subsection{Nanoclusters de Lennard-Jones}

Nanoclusters de LJ possuindo até algumas centenas de átomos já foram previamente estudados por diversos autores na literatura (veja por exemplo a referência 40, e outras citadas no capítulo 1). A eficiência computacional do cálculo de energia desse potencial, dado pela equação 2.44, faz com que o mesmo seja utilizado como sistema modelo de nanoclusters no teste de algoritmos. Além disso, sistemas como o $\mathrm{LJ}_{38}$ possuem uma SEP complexa, (89) que leva a mudanças de fase e propriedades termodinâmicas interessantes. $O$ estudo dessas propriedades pode também levar a uma maior compreensão dos resultados obtidos para sistemas ainda mais complexos, como os nanoclusters de metais de transição também estudados nesse capítulo.

\subsubsection{Estruturas de mais baixa energia}

Obter as estruturas candidatas à mínimo global é uma tarefa de extrema importância antes do início do estudo das propriedades termodinâmicas. Não somente essas são utilizadas como estrutura inicial no cálculo com o algoritmo PTMC, como também as estruturas contém informações relevantes sobre a SEP, que podem ser fundamentais para o entendimento profundo dos resultados das simulações. Novamente, nanoclusters de LJ costumam ser o sistema teste padrão para o desenvolvimento de algoritmos que buscam encontrar a estrutura de mais baixa energia de clusters e NPs, e por esse motivo, as estruturas de mínimo global para até algumas centenas de átomos já foram encontradas e tabeladas, e podem ser encontradas na literatura. $(83,90,91)$

Utilizando a implementação do método RBHMC disponível no código GOTNano, foi possível encontrar a estrutura de mínima energia para os sistemas $\mathrm{LJ}_{n}$ com $n=38,55,98$ e 147 . As estruturas e grupos de simetria obtidos para cada um dos nanoclusters são exibidos na 
Figura 19 - Estruturas e grupo de simetria dos nanoclusters de LJ estudados.

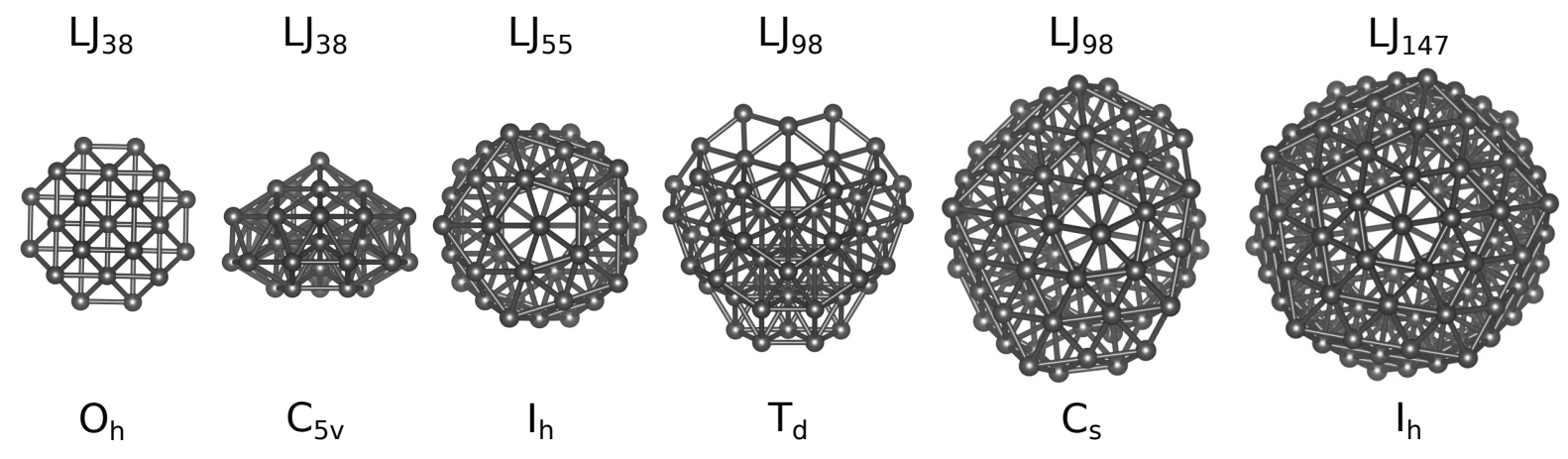

Fonte: Elaborada pelo autor.

figura 19, onde para o $\mathrm{LJ}_{38}$ e $\mathrm{LJ}_{98}$ a segunda estrutura de menor energia também é exibida. $\mathrm{A}$ escolha do número de átomos de cada sistema foi feita baseada nas características da SEP dos mesmos, onde os nanoclusters $L_{38}$ e $L J_{98}$ são sistemas com um mínimo não icosaédrico, apesar de possuírem um icosaedro incompleto como primeiro isômero de maior energia, e os $\mathrm{LJ}_{55}$ e $\mathrm{LJ}_{147}$ são icosaedros completos. As SEPs desses nanoclusters são similares nos casos de $n=55$ e 147 , possuindo essas um profundo funil contendo a estrutura icosaédrica. A SEP do $\mathrm{LJ}_{38}$ por outro lado, possui dois funis separados: (89) um contendo a estrutura cúbica de face centrada octaédrica truncada e o outro a estrutura icosaédrica. Já a SEP do $L J_{98}$ possui um mínimo global contendo uma estrutura tetraédrica (92) e outro mínimo mais largo contendo o icosaedro incompleto. Essas informações sobre os sistema $\mathrm{LJ}_{38}$ e $\mathrm{LJ}_{98}$ são obtidas na exploração da SEP durante a otimização, ou por meio da análise de grafos de desconectividade.

\subsubsection{Propriedades termodinâmicas}

As características da SEP obtidas durante a otimização se apresentam novamente durante a exploração realizada pelo algoritmo PTMC no cálculo das propriedades termodinâmicas. Na figura 20 são mostradas as curvas de energia interna e calor específico calculadas para os mesmos sistemas de LJ com os mínimos exibidos na figura 19. Para essas simulações, 60 temperaturas distribuídas geometricamente (equação 2.17) foram simuladas, sendo que 500 milhões de passos foram utilizados para a termalização das estruturas, e 1.5 bilhão de passos de MC foram realizados para o cálculo das médias das propriedades. As estruturas foram trocadas à cada 5 passos utilizando o algoritmo PID e os valores máximos de deslocamento foram ajustados com o algoritmo MTA durante os passos de termalização à cada 7000 passos. $O$ raio da esfera restritora utilizada (dada pela equação 3.1) foi $20 \%$ maior que o raio da estrutura de mais baixa energia, de modo que a pressão exercida nos nanoclusters nesse caso não afetasse os resultados para o $\mathrm{LJ}_{38}$, (87) nem para os nanoclusters maiores, onde raio da esfera restritora não afeta drasticamente os resultados (conforme discutido na seção 3.4).

Os resultados apresentados na figura 20 estão de acordo com os previamente reportados 
Figura 20 - Energia interna por átomo, $u$, e calor específico por átomo, $c_{v}$, dos nanoclusters $\mathrm{LJ}_{n}$ com $n=38,55,98$ e 147.
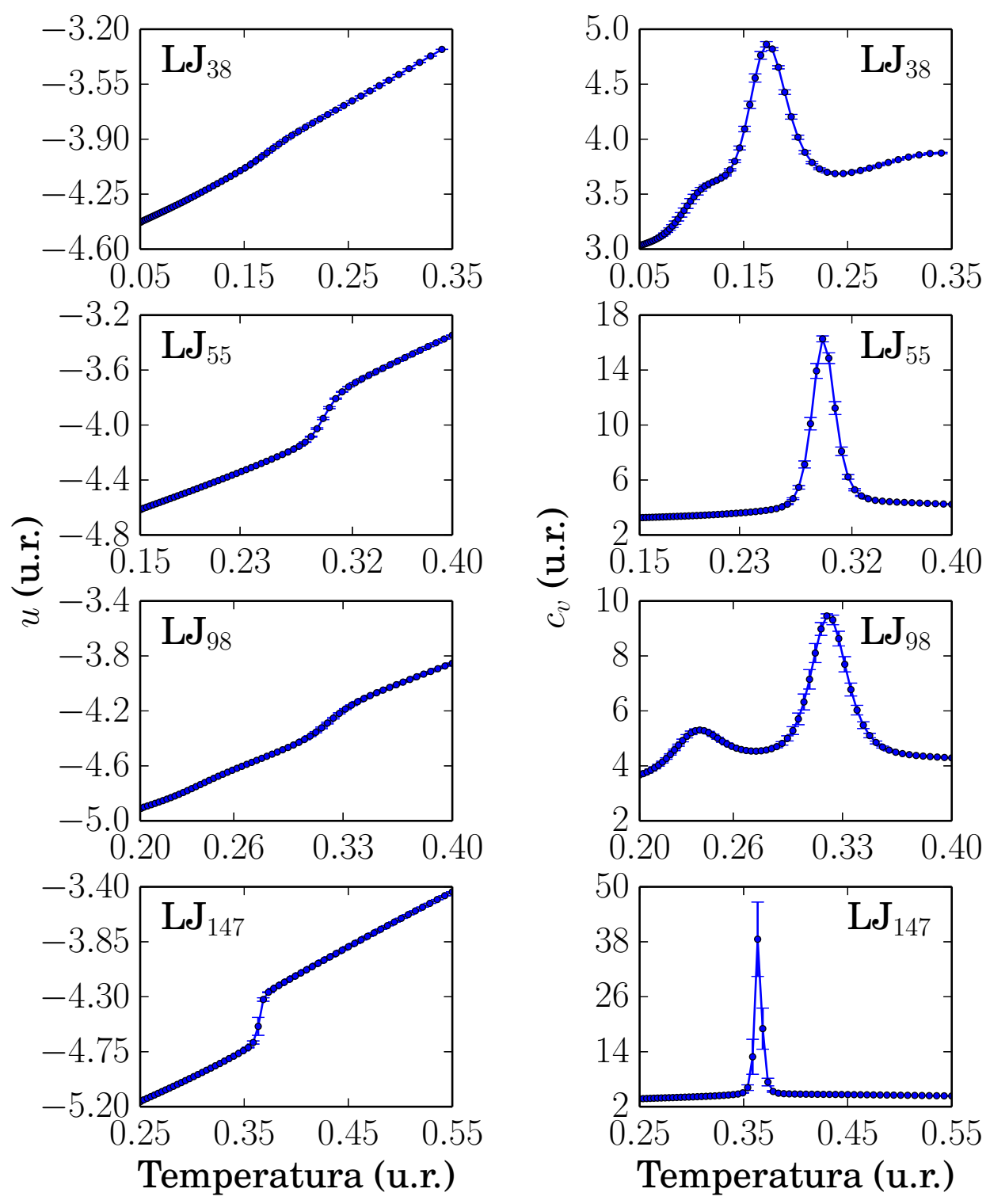

Fonte: Elaborada pelo autor.

na literatura para os nanoclusters $\mathrm{LJ}_{38}$, (41) $\mathrm{LJ}_{55}$ e $\mathrm{LJ}_{147}$, (40) possuindo temperatura de fusão $T_{m}$ e transições estruturais similares em todos os casos. Para o $\mathrm{LJ}_{98}$, pelo menos ao nosso conhecimento, não existem resultados na literatura, sendo esses aqui apresentados de forma inédita. Pela energia interna por átomo, $u$, fica clara a existência de uma mudança de fase em todos os nanoclusters, indicada pela mudança na inclinação na curva de energia interna que é típica do ganho de calor latente. Essa mudança de fase representa a fusão do nanocluster e pode ser melhor visualizada por meio do calor específico, onde a fusão é caracterizada por um pico. Utilizando o calor específico por átomo, $c_{v}$, as temperaturas de fusão $T_{m}$, de aproximadamente 0,17 u.r., 0,30 u.r., 0,32 u.r. e 0,36 u.r. para os nanoclusters com 38,55,98 e 147 átomos respectivamente, são encontradas. 
Além da temperatura de fusão, o calor específico adiciona informações que à princípio não são vistas pela energia interna, como o pré-derretimento, existente nesse caso para o $L_{38} \mathrm{e}$ $\mathrm{LJ}_{98}$. Esse pré-derretimento, representado pela mudança no valor da derivada redor de 0.10 u.r. no $\mathrm{LJ}_{38}$, e um pico em aproximadamente 0.24 u.r. para o $\mathrm{LJ}_{98}$. A não existência de um pico definido para o pré-derretimento do $\mathrm{LJ}_{38}$ está provavelmente relacionada a junção dos picos de fusão e pré-derretimento nessa região de temperatura.

\subsubsection{Análise estrutural}

Para compreender o as mudanças estruturais que geram o pré-derretimento, algum tipo de análise estrutural é necessária. Na literatura, a utilização de parâmetros de ordem como $Q_{4}$ e $Q_{6}$ na caracterização estrutural de nanoclusters de LJ é comum. $(41,43)$ Neste trabalho, propomos uma análise alternativa, que utiliza algoritmo de similaridade apresentado na seção 3.10 .

Partindo das estruturas geradas durante a amostragem feita com o PTMC, foi realizada uma redução do conjunto de dados, visando eliminar efeitos espúrios da amostragem. * Para isso, foram selecionadas estruturas somente à cada 50000 passos, de modo que, utilizando somente os últimos 500 milhões de passos amostrados, $10^{4}$ estruturas para cada temperatura são obtidas. À partir desse conjunto reduzido, aplicando a análise de similaridade descrita na seção 3.10 para as amostras de temperaturas distribuídas ao redor das transições dos nanoclusters, é possível obter as estruturas mais representativas para cada temperatura analisada. A análise foi feita considerando $\Delta=400 \times 10^{-6}$ como critério de eliminação, e contando o número de estruturas eliminadas por cada amostra, de modo que ao final da análise, a frequência (número de estruturas similares no conjunto total) de cada estrutura pôde ser obtida.

Na figura 21 são exibidos, juntamente com o calor específico, os resultados da análise de similaridade para o $\mathrm{LJ}_{38}$. Os resultados dessa análise, são apresentados por meio das frequências de cada estrutura. Analisando a figura, fica clara a transição sólido-sólido existente no pré-derretimento. Para temperaturas abaixo dessa transição, estruturas similares à de mínima energia são dominantes, como o esperado, já que essa é a estrutura que representa a temperatura de 0 u.r. Durante a transição, há a coexistência das duas estruturas exibidas na figura 19, de modo que com o aumento da temperatura estruturas similares à icosaédrica se tornam cada vez mais frequentes, e para temperaturas ainda mais altas, finalmente a fusão do nanocluster começa a ser observada. Fica claro nesse caso o papel da temperatura na exploração da SEP, que permite que os dois funis presentes sejam explorados com a importância necessária em cada temperatura. Para temperaturas maiores que a temperatura de fusão, o conjunto de estruturas representativas para cada temperatura cresce, ao mesmo tempo em que

\footnotetext{
* As estruturas de amostras de passos consecutivos costumam ser extremamente similares, e as trocas introduzidas pelo PTMC, podem introduzir logo após as trocas, informações imprecisas para aquela temperatura.
} 
Figura 21 - Calor específico e estruturas mais frequentes em temperaturas selecionadas para o nanocluster $\mathrm{LJ}_{38}$.

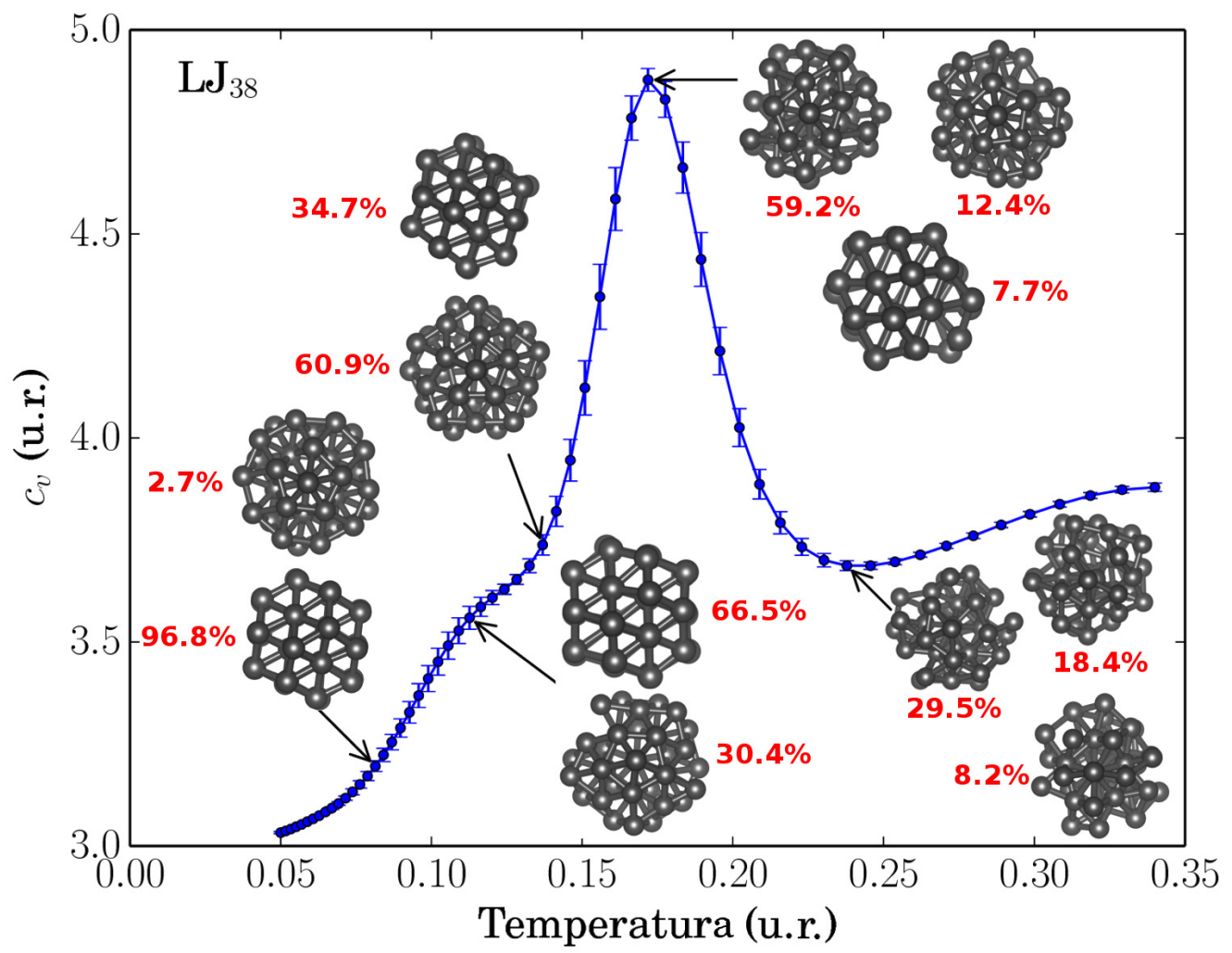

Fonte: Elaborada pelo autor.

a frequência com que cada uma dessas estruturas aparece é reduzida.

A fusão do nanocluster $L_{55}$ é ilustrada na figura 22. Como esperado devido ao único funil presente na SEP, a estrutura dominante antes da fusão é a icosaédrica. Para temperaturas ao menos 0.1 u.r. abaixo de $T_{m}$, a estrutura icosaédrica quase não sofre alterações, de modo que $99.9 \%$ das estruturas observadas possuem essa forma. $O$ aumento da temperatura inicia a fusão da estrutura pela camada externa, como visto em quase $67 \%$ das estruturas à 0.27 u.r. Na temperatura de fusão, cerca de $44 \%$ das estruturas ainda possuem estruturas similares à icosaédrica, indicando uma fusão que ocorre de maneira gradual. Em temperaturas acima de $T_{m}$ as estruturas observada possuem pouca simetria, como o esperado da fase líquida. Resultados similares à esse são exibidos pelo $\mathrm{LJ}_{147}$ devido à semelhança da $\mathrm{SEP}$, ${ }^{*}$ e por esse motivo, a discussão dos mesmos é omitida.

Assim como no caso do $\mathrm{LJ}_{38}$, a análise de similaridade do $\mathrm{LJ}_{98}$ mostra os detalhes das transições sólido-sólido e sólido-líquido. Na temperatura de aproximadamente 0.21 u.r. (abaixo do pré-derretimento), é observada, como o esperado, uma maior frequência da estrutura tetraédrica $\left(T_{d}\right)$ do mínimo global. Entretanto, nota-se que as outras duas estruturas mais frequentes são estruturas similares à icosaédrica. A estrutura presente em cerca de $27 \%$ das

\footnotetext{
* Que possui um único funil associado à estrutura icosaédrica.
} 
Figura 22 - Calor específico e estruturas mais frequentes em temperaturas selecionadas para o nanocluster $\mathrm{LJ}_{55}$.

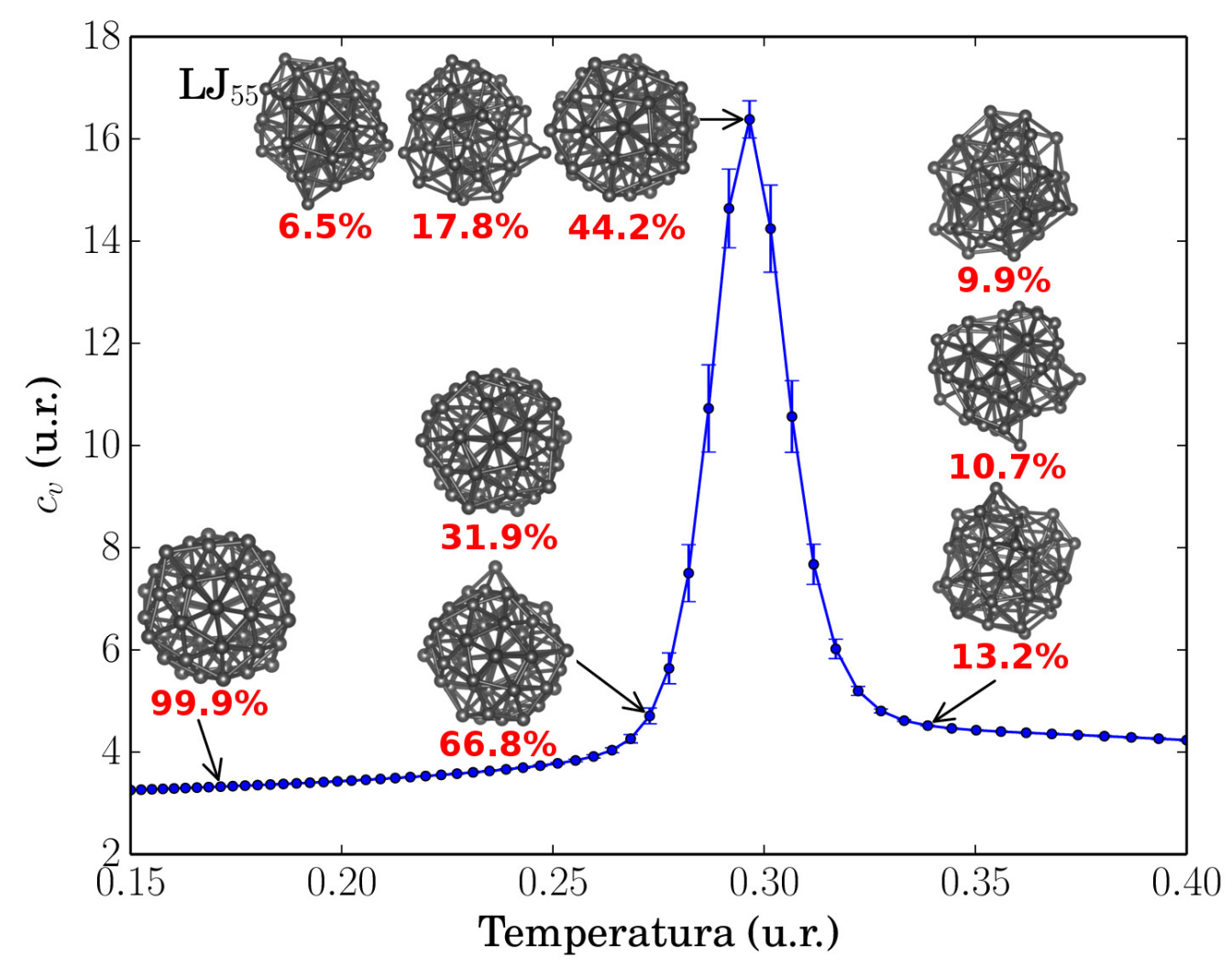

Fonte: Elaborada pelo autor.

amostras, apesar de similar a um icosaedro, possui uma estrutura diferente da do mínimo icosaédrico representado pela estrutura de simetria $C_{s}$. A coexistência dessas duas estruturas icosaédricas, indica que a menos frequente delas é utilizada na transição de $T_{d}$ para $C_{s}$, já que a mesma não é observada em outras temperaturas. Na temperatura do topo do pré-derretimento, a estrutura icosaédrica de simetria $C_{s}$ se torna a mais frequente, mantendo-se dessa maneira até $T_{m}$, quando estruturas líquidas são observadas.

Os resultados apresentados, obtidos com a análise de similaridade, concordam com aqueles obtidos na literatura para o $\mathrm{LJ}_{38}$ com o auxílio de parâmetros de ordem, (41) e exibem de uma forma mais visual, as mudanças estruturais observadas com as transições. Como o esperado, as mudanças estruturais estão intimamente ligadas à características da SEP, e devido a funis mais largos associados às estruturas icosaédricas, é observada uma preferência desse tipo de estruturas em temperaturas imediatamente anteriores à de fusão.

\subsection{Nanoligas de metais de transição}

Nanopartículas de Pt podem ser sua atividade catalítica alterada com a mudança da estrutura atômica. (16) Resultados recentes mostram que nanoligas de PtCo e PtNi, podem 
Figura 23 - Calor específico e estruturas mais frequentes em temperaturas selecionadas para o nanocluster $\mathrm{LJ}_{98}$.

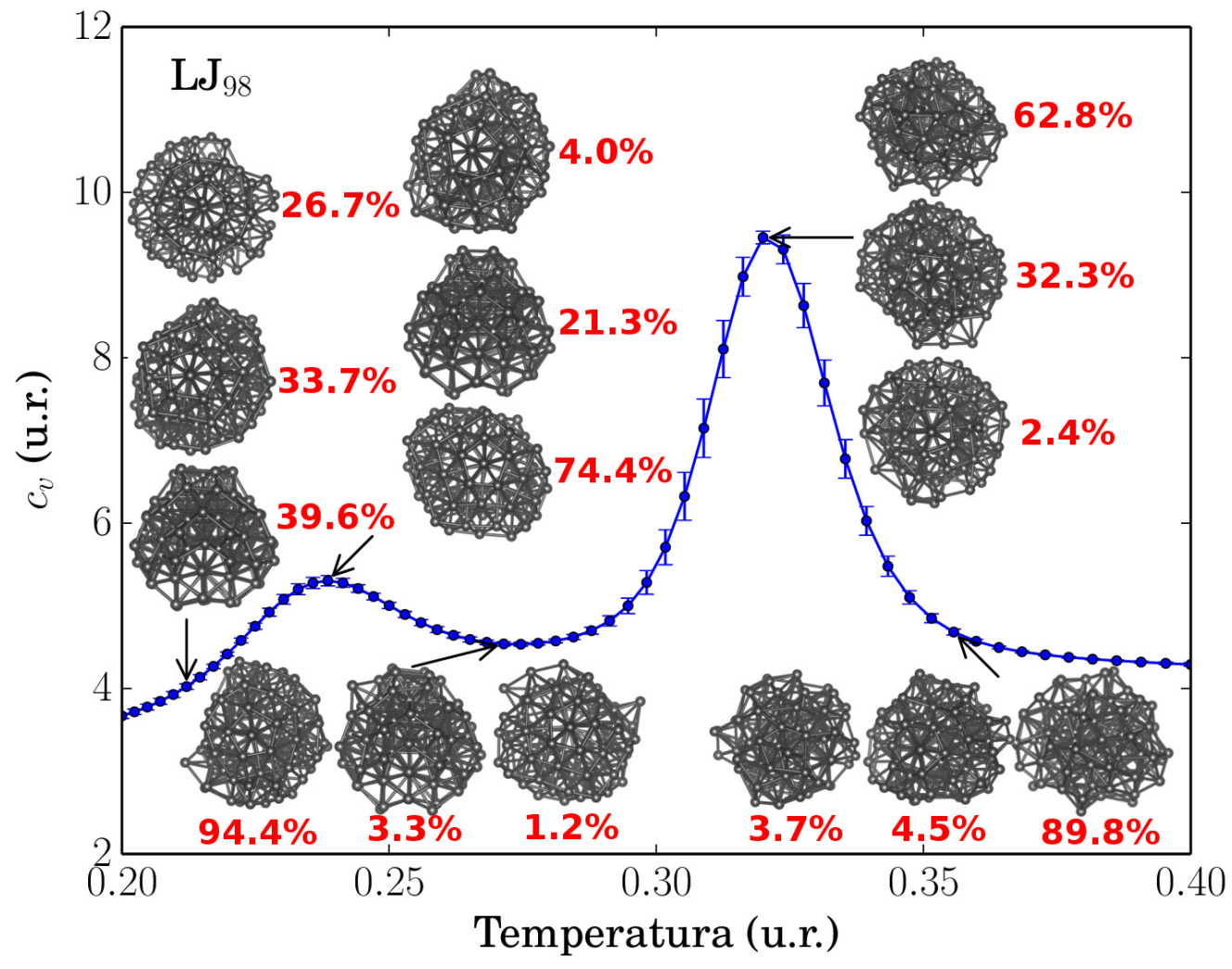

Fonte: Elaborada pelo autor.

ter atividade catalítica superior a da Pt pura. (93-95) Baseado nessas observações, um estudo das propriedades eletrônicas das ligas $(\mathrm{PtCo})_{55}$ e $(\mathrm{PtNi})_{55}$, levando em conta as variações estruturais originadas de mudanças de fase, é realizado. Para isso, as estruturas mais frequentes em temperaturas de interesse são obtidas, de maneira análoga a da subseção 4.1.3.

\subsubsection{Estruturas de mais baixa energia e avaliação do uso do potencial de Gupta para o estudo de nanoligas baseadas em Pt}

O potencial de interação utilizado para a descrição das nanoligas, foi o potencial de Gupta. Os parâmetros empregados nesse estudo são os obtidos por Cleri e Rosato, (77) exibidos na tabela 1. Para a interação de átomos de espécies químicas diferentes, os parâmetros foram obtidos à partir da combinação dos parâmetros dos sistemas puros, conforme descrito na subseção 2.4.1.

As estruturas de mínima energia para todas as composições das nanoligas de PtCo e PtNi com 55 átomos, foram obtidas utilizando o algoritmo RBHMC. As estruturas encontradas para algumas composições selecionadas, são mostradas na figura 24. Pode-se observar que com exceção da $\mathrm{Pt}_{55}$, todas as estruturas possuem um mínimo global icosaédrico. Para a nanoliga 
Tabela 1 - Parâmetros do potencial de Gupta utilizados para os cálculos de energia dos metais de transição. Os parâmetros de interação entre espécies foram obtidos pelo autor com as regras mostradas na subseção 2.4.1.

\begin{tabular}{llllll}
\hline & Pt-Pt & Pt-Co & Pt-Ni & Co-Co & Ni-Ni \\
\hline$A(\mathrm{eV})$ & 0.2975 & 0.1681 & 0.1058 & 0.0950 & 0.0376 \\
$\xi(\mathrm{eV})$ & 2.6950 & 2.0025 & 1.6981 & 1.4880 & 1.0700 \\
$p$ & 10.6120 & 11.1080 & 13.8055 & 11.6040 & 16.9990 \\
$q$ & 4.0040 & 3.1450 & 2.5965 & 2.2860 & 1.1890 \\
$r_{0}(\AA)$ & 2.7747 & 2.6409 & 2.6329 & 2.5070 & 2.4910 \\
\hline
\end{tabular}

Fonte: Adaptada de CLERI; ROSATO. (77)

Figura 24 - Estruturas de diferentes composições das nanoligas $(\mathrm{PtCo})_{55}$ e $(\mathrm{PtNi})_{55}$.
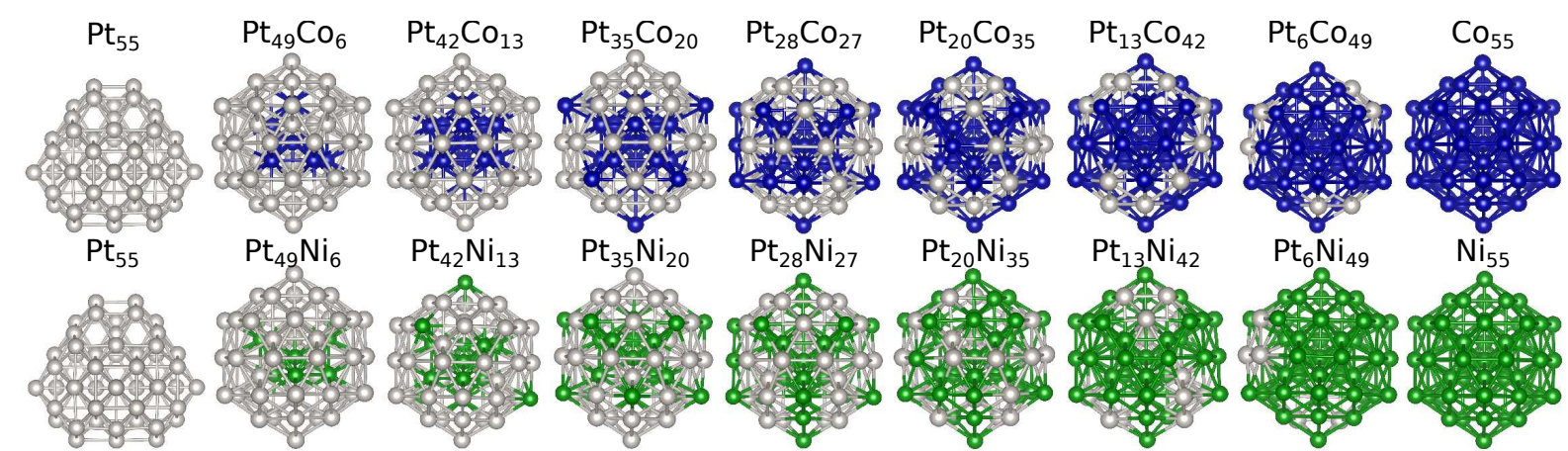

Fonte: Elaborada pelo autor.

$\mathrm{Pt}_{42} \mathrm{Co}_{13}$ é observada uma uma estrutura do tipo núcleo-casca, o que está de acordo com dados existentes de cálculos de primeiros princípios. * O mesmo não é válido para o nanocluster $\mathrm{Pt}_{42} \mathrm{Ni}_{13}$ que, segundo o mínimo do potencial de Gupta, possui uma estrutura com os átomos de $\mathrm{Ni}$ mais distribuídos.

As estruturas obtidas com o potencial de Gupta para os sistemas puros, mantém características qualitativas comparáveis às das estruturas candidatas de mínimo global obtidas com DFT utilizando o funcional PBE. ${ }^{\dagger}$ Para os nanoclusters $\mathrm{C}_{55}$ e $\mathrm{Ni}_{55}$, a estrutura obtida com DFT, e com o potencial de Gupta é icosaédrica, entretanto, a estrutura distorcida de núcleo reduzido observada para a $\mathrm{Pt}_{55}$ com DFT, não é encontrada para a $\mathrm{Pt}_{55}$.

Um comparativo entre as semelhanças e diferenças para os mínimos observados com DFT e o potencial de Gupta pode ser feito analisando o comprimento de ligação ponderado médio e o número de coordenação efetiva, descritos na subseção 2.3.2. A tabela 2 contém os valores dessas propriedades para as estruturas encontradas utilizando ambos os potenciais. Observando esses dados conclui-se que os comprimentos de ligação ponderados médios não variam drasticamente como se poderia esperar, ${ }^{\ddagger}$ tendo variações entre $0 \%$ para a $\mathrm{Pt}_{55}$ e $2.4 \%$

\footnotetext{
* Por exemplo, dados de Guedes Sobrinho et al.(96)

† Cálculos realizados utilizando o código VASP. (96)

¥ Já que esses parâmetros são ajustados para reproduzir os comprimentos de ligação do bulk, e não de nanoclusters e NPs.
} 
Tabela 2 - Comprimento ponderado médio de ligação $d_{a v}$ e NCE médio para os sistemas puros utilizando o potencial de interação de Gupta e DFT. * indica dados obtidos da referência 96.

\begin{tabular}{lll}
\hline & $\begin{array}{l}d_{a v} \\
(\AA)\end{array}$ & $\mathrm{NCE}$ \\
& \\
\hline $\mathrm{Pt}_{55}$ (DFT)* & 2.67 & 6.84 \\
$\mathrm{Pt}_{55}$ (Gupta) & 2.67 & 7.98 \\
$\mathrm{Co}_{55}$ (DFT) & 2.44 & 8.36 \\
$\mathrm{Co}_{55}$ (Gupta) & 2.47 & 8.44 \\
$\mathrm{Ni}_{55}$ (DFT)* & 2.44 & 8.39 \\
$\mathrm{Ni}_{55}$ (Gupta) & 2.50 & 8.46 \\
\hline
\end{tabular}

Fonte: Adaptada de GUEDES SOBRINHO et al. (96)

para $\circ \mathrm{Ni}_{55}$.

Apesar de o comprimento médio de ligação da $\mathrm{Pt}_{55}$ ser o mesmo com DFT e o potencial de Gupta, o NCE médio para os dois casos é completamente diferente, sendo o da estrutura do mínimo da DFT cerca de $14 \%$ menor, indicando uma estrutura diferente e provavelmente com mais átomos na superfície.* Os NCE médios das outras estruturas por outro lado pouco variam, já que nesses casos, todas as estruturas são icosaédricas.

A composição mais estável das nanoligas pôde ser obtida por meio da energia de excesso desses materiais. A energia de excesso, é obtida através da equação

$$
E_{\text {exc }}=\frac{1}{55}\left[E_{\text {tot }}^{\mathrm{PtMT}}-\frac{(55-n)}{55} E_{t o t}^{\mathrm{Pt}}-\frac{n}{55} E_{t o t}^{\mathrm{MT}}\right],
$$

onde $E_{t o t}^{\mathrm{PtMT}}$ é a energia total da liga, $E_{\text {tot }}^{\mathrm{Pt}}$ a energia total do sistema $\mathrm{Pt}_{55}$ e $E_{\text {tot }}^{\mathrm{MT}}$ a energia total do sistema $\mathrm{MT}_{55}$ (sendo $\mathrm{MT}=\mathrm{Co}$ ou $\mathrm{Ni}$ ). Utilizando essa equação, foram obtidas curvas com os valores de $E_{\text {exc }}$ negativos, indicando que a formação dessas nanoligas é favorável. Essas curvas são exibidas na figura $25,{ }^{\dagger}$ e os resultados obtidos com o potencial de Gupta são mostrados. Para permitir uma melhor comparação, as curvas foram normalizadas de forma que o mínimo de cada uma delas fique em $E_{\text {exc }}=-1$. As composições mais estáveis para o potencial de Gupta, foram $\mathrm{Pt}_{30} \mathrm{Co}_{25}$ e $\mathrm{Pt}_{40} \mathrm{Ni}_{15}$. Essas composições, foram as selecionadas para o estudo das propriedades termodinâmicas e eletrônicas nas próximas seções.

Analisando o comportamento das curvas para os potenciais de Gupta e DFT, observa-se que a descrição da liga de Pt e Co é feita de maneira razoável pelo potencial empírico, já que entre 13 e 35 átomos de Co a energia de excesso se mantém praticamente constante (intervalo que compreende o mínimo da $E_{e x c}$ do Gupta), e características como o favorecimento da estrutura núcleo-casca são mantidas. Os resultados obtidos para a nanoliga de PtNi, mostram um favorecimento de estruturas ricas em Pt pelo potencial de Gupta, comportamento ligeiramente diferente do observado pela DFT.

\footnotetext{
* Átomos na superfície costumam possui NCE menor, por fazerem menos ligações.

† Onde os resultados de DFT da referência 96.
} 
Figura 25 - Energia de excesso $E_{\text {exc }}$ normalizada (veja texto) para as nanoligas (a) PtCo e (b) PtNi com 55 átomos.

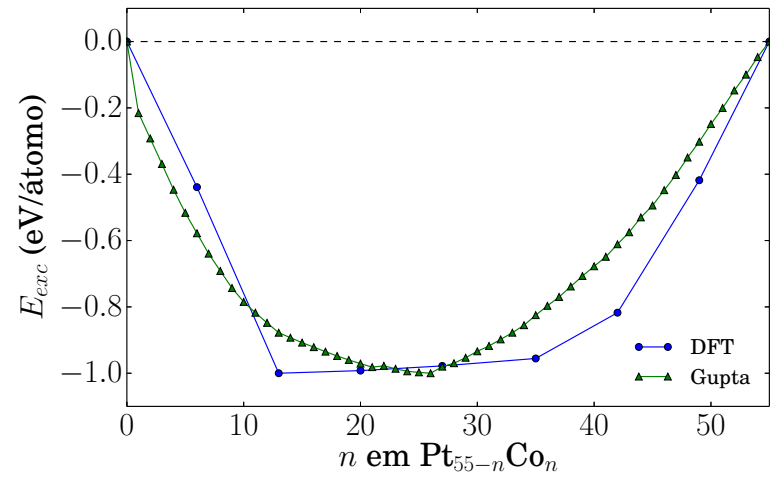

(a)

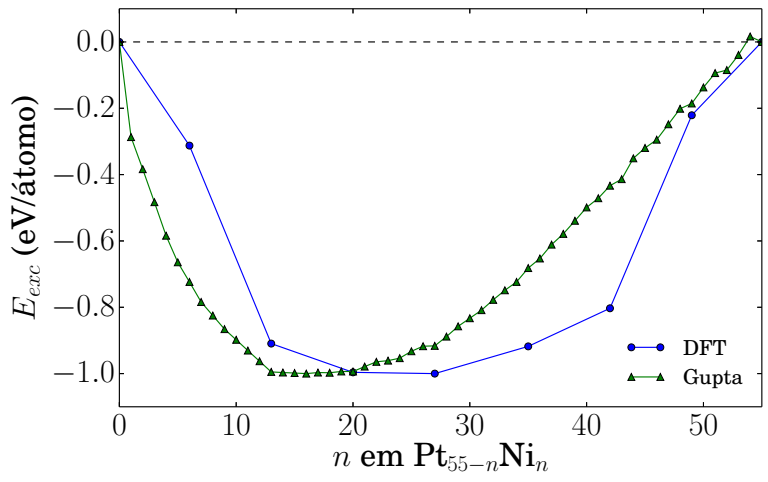

(b)

Fonte: Elaborada pelo autor.

A descrição de propriedades estruturais de maneira similar, e o favorecimento da formação das nanoligas estudadas com os dois potenciais, apontam que ao menos como uma primeira aproximação, o potencial de Gupta pode ser utilizado para o estudo de propriedades termodinâmicas desses sistemas. Especialmente para o nanocluster de $\mathrm{PtCo}$, a descrição do potencial de Gupta deve ser o suficiente para a análise das mudanças de fase e obtenção das estruturas mais frequentes.

\subsubsection{Propriedades termodinâmicas e análise estrutural}

Selecionando as composições das nanoligas mais estáveis pelo potencial de Gupta, as propriedades termodinâmicas dos nanoclusters de $\mathrm{Pt}_{55}, \mathrm{Co}_{55}, \mathrm{Ni}_{55}, \mathrm{Pt}_{30} \mathrm{Co}_{25}$ e $\mathrm{Pt}_{40} \mathrm{Ni}_{15}$ foram estudadas. As simulações foram realizadas com a implementação do método PTMC testada na seção 4.1 , e utilizaram $2,5 \times 10^{8}$ passos de termalização, seguidos de $5 \times 10^{8}$ passos de $\mathrm{MC}$ para o cálculo das médias das propriedades. O número de temperaturas simuladas nesse caso foi $M=48$. Os outros parâmetros referentes a simulação PTMC, foram iguais aos utilizados no estudo dos nanoclusters de LJ mostrados na seção 4.1.

Os resultados da energia interna por átomo $u$ para cada um dos sistemas são exibidos na figura 26. Assim como no caso dos nanoclusters de LJ, é observada uma variação na inclinação da curva, revelando um ganho de calor latente associado a uma mudança de fase. As temperatura na qual essas mudanças de fase ocorrem são de aproximadamente: $727 \mathrm{~K}$ para a Pt, $1027 \mathrm{~K}$ para o Co, $914 \mathrm{~K}$ para o $\mathrm{Ni}$ e $1003 \mathrm{~K}$ e $1051 \mathrm{~K}$ para as nanoligas $\mathrm{Pt}_{30} \mathrm{Co}_{25} \mathrm{e}$ $\mathrm{Pt}_{40} \mathrm{Ni}_{15}$ respectivamente. Como esperado para o caso geral, esses temperaturas estão abaixo da temperatura de fusão do bulk que são de aproximadamente $2041 \mathrm{~K}$ para a $\mathrm{Pt}, 1768 \mathrm{~K}$ para o Co e $1728 \mathrm{~K} \mathrm{Ni}$.

Na figura 27 mostra-se o calor específico e estruturas mais frequentes para temperaturas 
Figura 26 - Energia interna dos sistemas puros de $\mathrm{Pt}_{55}, \mathrm{Co}_{55}$ e $\mathrm{Ni}_{55}$, e nanoligas mais estáveis $\mathrm{Pt}_{30} \mathrm{Co}_{25}$ e $\mathrm{Pt}_{40} \mathrm{Ni}_{15}$.
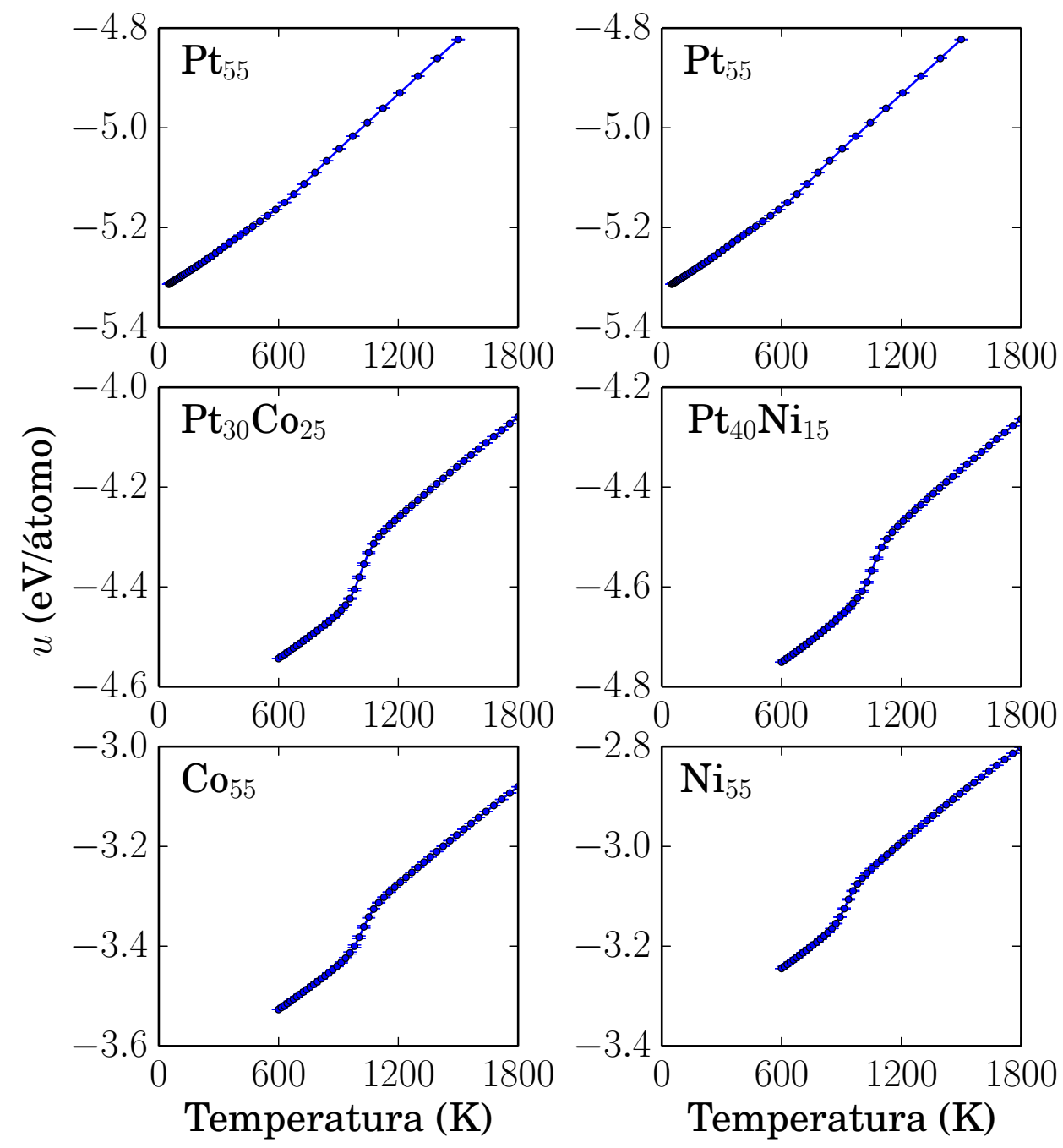

Fonte: Elaborada pelo autor.

em torno da transição para esses mesmos nanoclusters. O método utilizado para obtenção das estruturas mais frequentes é o mesmo descrito na subseção 4.1.3. Nessa figura, fica clara a existência de um pico de pré-derretimento para a $\mathrm{Pt}_{55}$ que ocorre em aproximadamente $300 \mathrm{~K}$, e é seguido pelo pico relacionado à fusão em $727 \mathrm{~K}$. É interessante notar mesmo para temperaturas abaixo da transição sólido-sólido, há a coexistência da estrutura de mínima energia com outra estrutura, presente em cerca de $5 \%$ das amostras. Essa estrutura não é a estrutura para a qual a transição sólido-sólido ocorre, e se trata de uma estrutura pertencente a um mínimo pouco estável e próximo ao mínimo global. A transição sólido-sólido por sua vez ocorre de uma maneira gradual para uma estrutura icosaédrica, que é mantida até o ponto de fusão.

Os calores específicos $c_{v}$ dos nanoclusters $\mathrm{Co}_{55}$ e $\mathrm{Ni}_{55}$ possuem por sua vez um único máximo, atribuído à fusão do material. Em ambos os casos, o mecanismo de derretimento se dá pela distorção da estrutura icosaédrica principalmente em sua superfície, até a temperatura 
Figura 27 - Calor específico e estruturas mais frequentes em temperaturas selecionadas para as nanoligas metálicas estudadas.
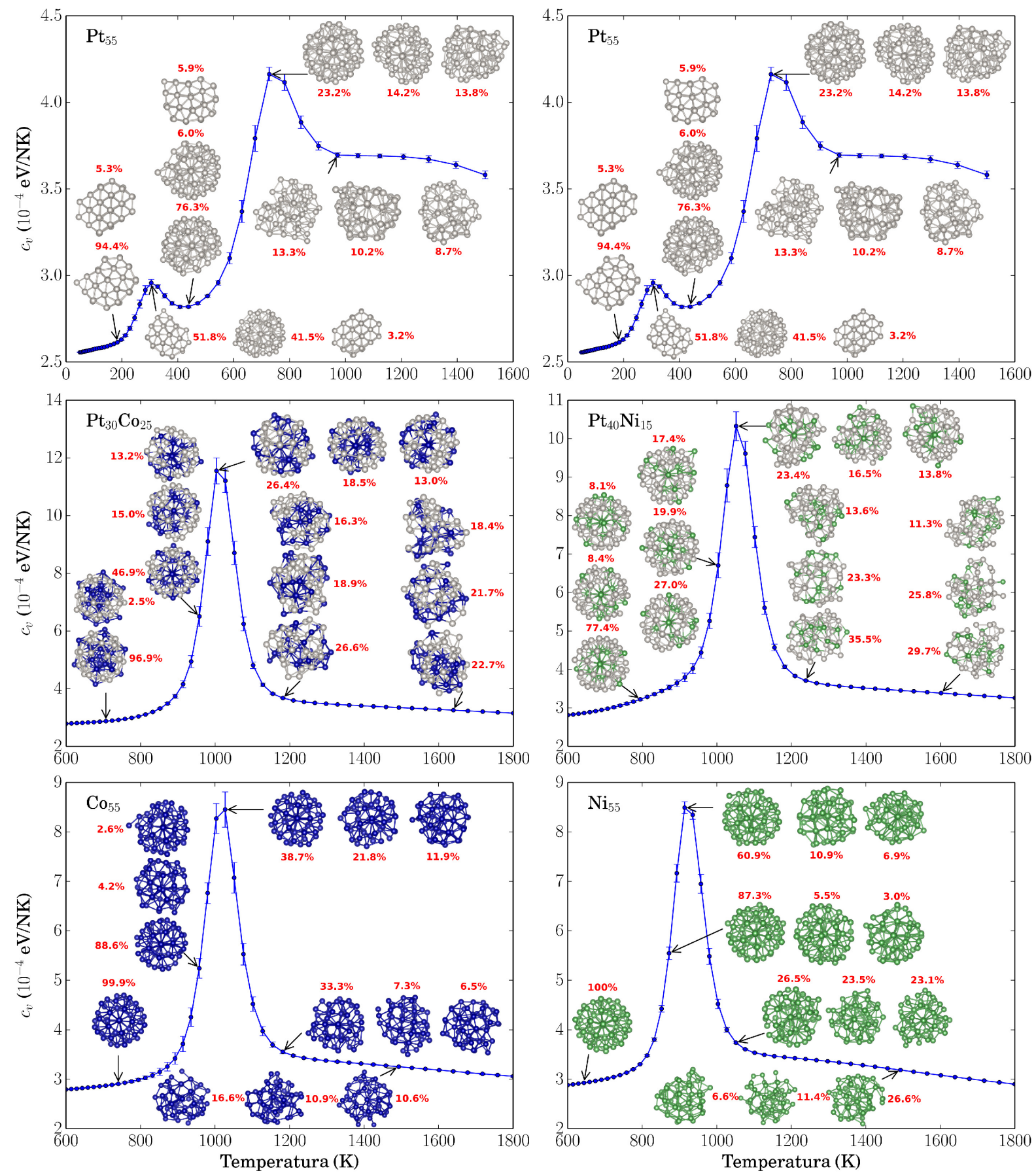

Fonte: Elaborada pelo autor.

de fusão ser atingida. Da mesma maneira, as nanoligas também possuem somente um máximo atribuído à fusão, porém no caso da nanoliga $\mathrm{Pt}_{30} \mathrm{Co}_{25}$ é notada a difusão dos átomos do interior para a superfície da estrutura, de maneira similar à dados previamente publicados para nanoligas de PdPt. (33) A temperatura na qual ocorre a fusão para as ligas, apesar de ambas possuírem uma composição mais rica em $\mathrm{Pt}$ em ambos os casos, é aumentada 
Figura 28 - Gráfico pictórico ilustrando a SEP dos nanoclusters (a) $\mathrm{Pt}_{55}$ e (b) nanoclusters com mínimo global icosaédrico.

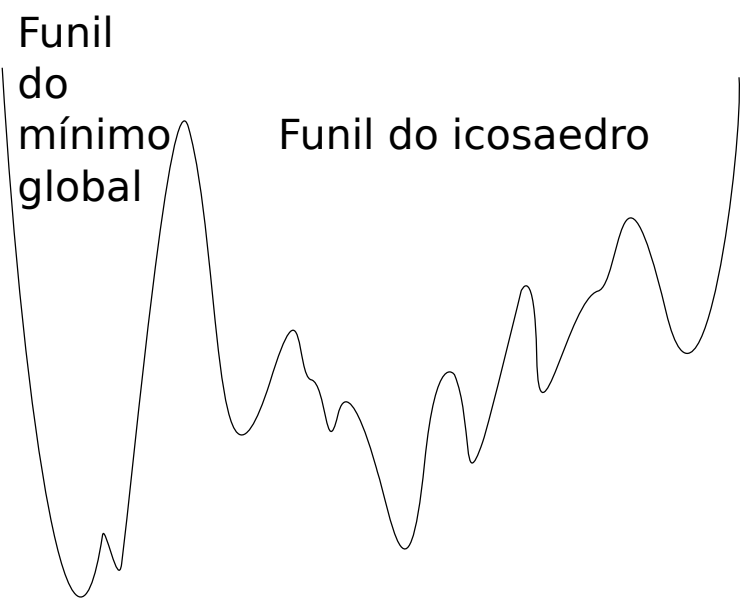

(a)

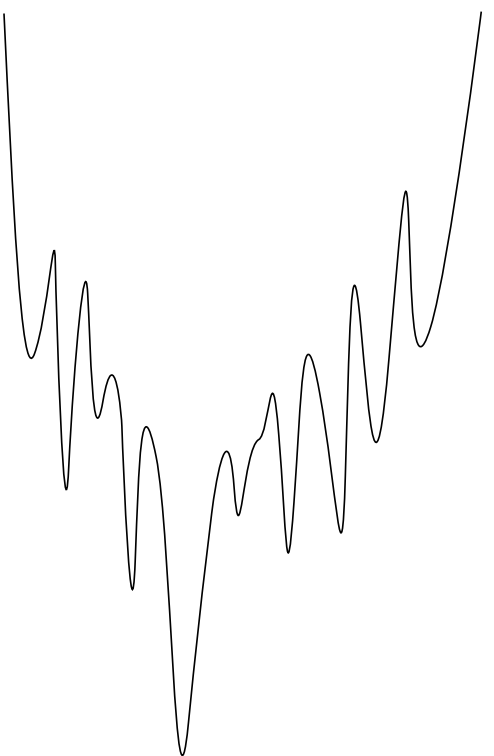

(b)

Fonte: Elaborada pelo autor.

consideravelmente quando comparada à temperatura de fusão da $\mathrm{Pt}_{55}$ pura, criando a ideia de uma maior estabilidade térmica de estruturas icosaédricas, já que em todos os casos estudados (inclusive nos clusters de LJ), esse tipo de estrutura é observada antes do ponto de fusão.

Diferentemente das outras estruturas com um mínimo icosaédrico, a $\mathrm{Pt}_{55}$ tem um ganho de energia pelo calor latente menor, uma temperatura de fusão abaixo da observada para os outros nanoclusters estudados e ainda possui uma transição sólido-sólido. Esses efeitos estão diretamente relacionados a forma da SEP, de onde as energias totais são amostradas. Devido à transição sólido-sólido a existência de dois funis é indicada, sendo o primeiro deles mais profundo e fino, contendo a estrutura de mais baixa energia, enquanto o segundo e mais largo contém a estrutura icosaédrica. Essas características são ilustradas pictoricamente na figura 28, onde também de forma pictórica está ilustrada a SEP dos nanoclusters com candidato a mínimo global icosaédrico em a existência de um único funil é indicada, sendo esse mais profundo que ambos os funis da SEP da $\mathrm{Pt}_{55}$. A profundidade maior nesse caso é inferida à partir da maior estabilidade térmica desses sistemas. Essas informações levam a crer que a forma dos funis tipicamente associados à estruturas icosaédricas tornam esse tipo de estrutura mais estável termicamente que outros tipos de estrutura. Isso se mostra uma verdade não somente para a $\mathrm{Pt}_{55}$, mas também para o nanocluster $\mathrm{LJ}_{38}$, e em outros casos reportados na literatura, como o do $\mathrm{LJ}_{75}$. (43) 


\subsubsection{Propriedades eletrônicas}

Para verificar o potencial dos nanoclusters estudadas para aplicações como catálise e, entender a variação das propriedades eletrônicas dos sistemas com a temperatura, um estudo dos estados eletrônicos por meio da densidade de estados total foi realizado. Assim como as propriedades termodinâmicas dos nanoclusters estão intimamente as estruturas, é esperado que as propriedades eletrônicas também estejam igualmente relacionadas.

Utilizando o pacote Fritz Haber Institute ab initio molecular simulations (FHI-aims), (97) a densidade de estados total foi calculada com o uso da DFT, utilizando a aproximação PBE como funcional de troca e correlação. Esse pacote utiliza funções atômicas centradas nos átomos, e permite a simulação de sistemas não periódicos. Nesses cálculos, o critério de convergência utilizado para a energia foi de $10^{-5}$, e o conjunto de funções base utilizadas, conforme a nomenclatura do FHI-aims, foi o light tier-2. Os cálculos não consideraram a relaxação das estruturas pois ao relaxar essas, as estruturas obtidas não representavam de fato o ponto amostrado, e.g., a estrutura presente em $99.9 \%$ do conjunto total para a temperatura mais baixa estudada do $\mathrm{Co}_{55}$, leva ao mínimo global quando otimizada.

A densidade de estados total das estruturas mais frequentes de cada temperatura analisada dos nanoclusters $\mathrm{Pt}_{55}, \mathrm{Co}_{55}, \mathrm{Ni}_{55}, \mathrm{Pt}_{30} \mathrm{Co}_{25}$ e $\mathrm{Pt}_{40} \mathrm{Ni}_{15}$ foram utilizadas, de modo que a densidade de estados final, consiste de uma média ponderada dos valores obtidos para cada estrutura. As estruturas utilizadas para os cálculos foram selecionadas de modo que ao menos $70 \%$ do conjunto total fosse representado. Isso significa que para temperaturas mais baixas, onde uma única estrutura pode representar $99 \%$ do conjunto, apenas um cálculo foi realizado, enquanto para temperaturas mais altas (após a fusão) dezenas de cálculos foram realizados utilizando a as estruturas mais frequentes, até que o parâmetro de $70 \%$ de representatividade do conjunto fosse atingido.

A combinação dos resultados obtidos para essas estruturas foi feita através de uma média ponderada, considerando como peso a fração da frequência da estrutura pelo tamanho total do conjunto simulado. Por exemplo, dois cálculos foram realizados para a $\mathrm{Pt}_{55}$ na temperatura $183.94 \mathrm{~K}$ (as estruturas são as representadas no ponto mais à esquerda da figura 27 para a $\mathrm{Pt}_{55}$ ), onde as duas estruturas representavam 9967 das 10000 estruturas totais. Os pesos utilizados nesse caso foram: $w_{1}=9440 / 9967 \approx 0.9471$ e $w_{2}=527 / 9967 \approx 0.0529$ para a estrutura similar à do mínimo global e a outra estrutura ilustrada respectivamente.

Os resultados dos cálculos de densidade de estados realizados empregando essa metodologia são mostrados na figura 29. A energia dos gráficos foi deslocada, de modo que o zero se encontra na energia de Fermi. Os resultados para $T=0 \mathrm{~K}$ são os resultados da densidade de estados total para os mínimos globais encontrados com o potencial de Gupta. O centro da banda $d$, foi obtido através de cálculos utilizando um parâmetro de suavização de 0.001 na densidade de estados, entretanto, para uma melhor visualização dos resultados, um parâmetro 
Figura 29 - Densidade de estados total ponderada (veja texto), e centro de banda dos nanoclusters estudadas.
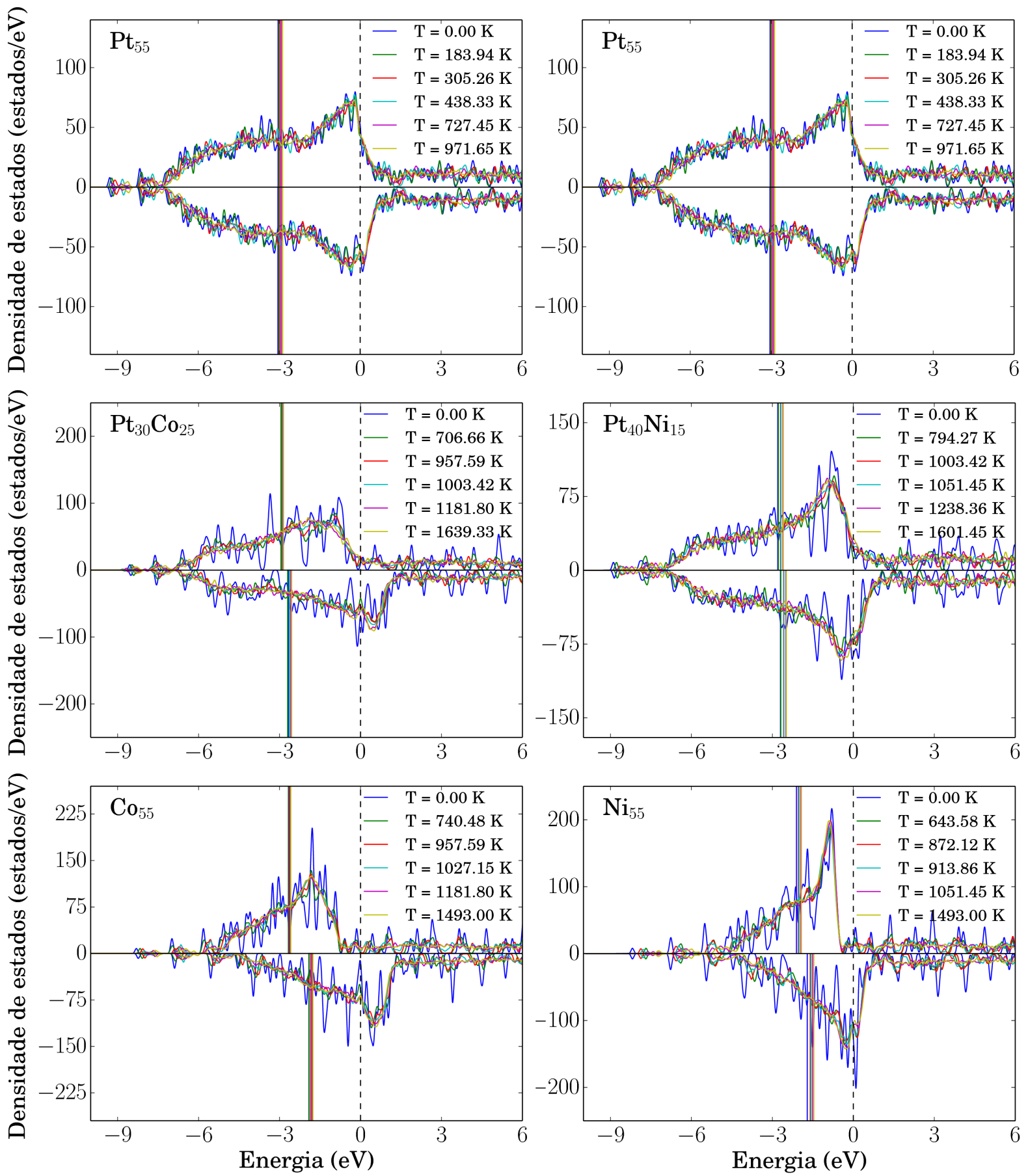

Fonte: Elaborada pelo autor.

de suavização de 0.05 foi utilizado na figura 29 .

De uma maneira geral, é observado que o aumento de temperatura faz com que o centro da banda $d$ seja deslocado levemente em direção ao HOMO (Highest Occupied Molecular Orbital). Esse deslocamento é sutil, e considerando as duas temperaturas extremas simuladas, chega a $0.18 \mathrm{eV}$ para a $\mathrm{Pt}_{55}, 0.15 \mathrm{eV}$ para $\circ \mathrm{Co}_{55}$ e de $0.24 \mathrm{eV}$ para o $\mathrm{Ni}_{55}$. O aumento do 
número de estados eletrônicos próximo ao HOMO pode indicar, partindo de uma generalização das ideias do modelo de Hammer e Norskov (98) válido para superfícies, uma maior reatividade desses nanomateriais.

Desse modo, é possível concluir que o aumento de temperatura leva a uma maior reatividade, e por consequência, pode levar a uma maior atividade catalítica em algumas aplicações. Além disso, o aumento da atividade catalítica das nanoligas em relação ao nanocluster de Pt pura, indicado pelo deslocamento do centro da banda $d$, está de acordo com tendências previamente encontradas na literatura. (93-95) 


\section{Capítulo 5}

\section{Conclusão}

Neste trabalho, foi implementado o método PTMC para o cálculo de propriedades termodinâmicas e estruturais de clusters, nanoclusters e NPs. A implementação foi construída sobre o código GOTNano, e inclui os seguintes algoritmos: otimizado por experiência e de aumento constante de entropia para a otimização do conjunto de temperaturas; os algoritmos par-ímpar determinístico, par-ímpar estocástico e amostragem independente para a troca de réplicas; método de taxa de aceitação para otimização do máximo deslocamento atômico; além do método de análise ponderada de histograma para parallel tempering.

Utilizando essa implementação, testes mostraram problemas na utilização do algoritmo OE para a seleção de temperaturas (devido ao grande calor latente ganho na fusão), fazendo com que o uso desse algoritmo não seja recomendado de maneira geral. A importância do raio de corte do potencial envolvendo a estrutura, principalmente para o caso de clusters pequenos, foi demonstrada, e o princípio básico do uso de um raio de corte $20 \%$ maior do que o raio da estrutura de maior energia foi proposto para nanoclusters com mais de 38 átomos.

O sucesso da implementação foi verificado através do estudo das propriedades de nanoclusters de $\mathrm{LJ}_{n}$ (com $n=38,55,98$ e 147 átomos). Utilizando uma métrica euclidiana, aplicada no contexto da análise de similaridade de estruturas, as mudanças de fase para os sistemas com $n=38,55$ e 147 foram obtidas, mostrando acordo com os resultados previamente publicados na literatura. Com essa mesma técnica, pela primeira vez as mudanças de fase do nanocluster $\mathrm{LJ}_{98}$ foram identificadas e, conforme o esperado devido à SEP do sistema, foi observada, além da fusão, o pré-derretimento decorrente de uma transição sólido-sólido, envolvendo a estrutura tetraédrica do mínimo global e o isômero icosaédrico.

Finalmente, buscando avaliar a hipótese original do uso de métodos de $\mathrm{MC}$ no estudo de propriedades de nanoclusters, foram estudadas as nanoligas (PtCo $)_{55}$ e $(\mathrm{PtNi})_{55}$. A utilização do potencial de Gupta para a descrição da interação foi justificada através do estudo das estruturas de mais baixa energia e comparação com a DFT. Os valores obtidos com os dois potenciais para o comprimento médio de ligação apresentaram variações de no máximo $2.4 \%$ e, 
com a exceção da $\mathrm{Pt}_{55}$ que possui uma estrutura com NCE maior pelo potencial de Gupta, as estruturas de mínimo global candidatas são icosaédricas e equivalentes quando descritas por ambos os potenciais.

Uma única mudança de fase (fusão) em temperaturas entre 900 e $1100 \mathrm{~K}$ foi observada para os sistemas $\mathrm{Co}_{55}, \mathrm{Ni}_{55}, \mathrm{Pt}_{30} \mathrm{Co}_{25}$ e $\mathrm{Pt}_{40} \mathrm{Ni}_{15}$, que possuem um mínimo global icosaédrico. A fusão desses nanoclusters foi ilustrada com a utilização do método de análise de similaridade de estruturas. Por outro lado a $\mathrm{Pt}_{55}$ exibiu antes da fusão a $727 \mathrm{~K}$, pré-derretimento em $300 \mathrm{~K}$, associado a uma mudança de fase sólido-sólido entre as estruturas de mínimo global e a estrutura icosaédrica.

Através de cálculos DFT realizados com o código FHI-aims, foi possível estudar o comportamento dos estados eletrônicos desses nanoclusters em função da temperatura. Utilizando as estruturas mais frequentes, diversos cálculos foram realizados para gerar uma média ponderada da densidade de estados total. Foi possível então observar uma tendência do deslocamento do centro da banda $d$ em direção ao HOMO com o aumento da temperatura, o que seguindo uma generalização do modelo da banda $d$, sugere um aumento da reatividade do sistema nesses casos.

Assim, esse trabalho abre novas portas para a utilização do algoritmo PTMC no estudo de propriedades termodinâmicas e estruturais de nanoclusters e NPs. Entretanto, uma análise comparativa entre a eficiência desse método e da dinâmica molecular para o estudo de propriedades de nanoclusters ainda é necessária. O método proposto para a análise de similaridade de estruturas se mostrou útil, podendo ser utilizado em outros trabalhos independentemente da técnica de amostragem utilizada. 


\section{Referências}

1 BELL, A. T. The impact of nanoscience on heterogeneous catalysis. Science, v. 299, n. 5613, p. 1688-1691, 2003.

2 MOGHIMI, S. M.; HUNTER, A. C.; MURRAY, J. C. Nanomedicine: current status and future prospects. FASEB Journal, v. 19, n. 3, p. 311-330, 2005.

3 NIE, S.; XING, Y.; KIM, G. J.; SIMONS, J. W. Nanotechnology applications in cancer. Annual Review of Biomedical Engineering, v. 9, n. 1, p. 257-288, 2007.

4 EL-SAYED, I. H.; HUANG, X.; EL-SAYED, M. A. Surface plasmon resonance scattering and absorption of anti-EGFR antibody conjugated gold nanoparticles in cancer diagnostics: applications in oral cancer. Nano Letters, v. 5, n. 5, p. 829-834, 2005.

5 GARBER, K. Improved paclitaxel formulation hints at new chemotherapy approach. Journal of the National Cancer Institute, v. 96, n. 2, p. 90-91, 2004.

6 KODAMA, R. H. Magnetic nanoparticles. Journal of Magnetism and Magnetic Materials, v. 200, n. 1-3, p. 359-372, 1999.

7 ZHANG, W.; GE, Q.; WANG, L. Structure effects on the energetic, electronic, and magnetic properties of palladium nanoparticles. Journal of Chemical Physics, v. 118, n. 13, p. 5793-5801, 2003.

8 BANSMANN, J.; BAKER, S. H.; BINNS, C.; BLACKMAN, J. A.; BUCHER, J. P.; DORANTES-DáVILA, J.; DUPUIS, V.; FAVRE, L.; KECHRAKOS, D.; KLEIBERT, A.; MEIWES-BROER, K. H.; PASTOR, G. M.; PEREZ, A.; TOULEMONDE, O.; TROHIDOU, K. N.; TUAILLON, J.; XIE, Y. Magnetic and structural properties of isolated and assembled clusters. Surface Science Reports, v. 56, n. 6-7, p. 189-275, 2005.

9 ANDO, M.; KOBAYASHI, T.; HARUTA, M. Combined effects of small gold particles on the optical gas sensing by transition metal oxide films. Catalysis Today, v. 36, n. 1, p. 135-141, 1997.

10 ZHOU, W. P.; LEWERA, A.; LARSEN, R.; MASEL, R. I.; BAGUS, P. S.; WIECKOWSKI, A. Size effects in electronic and catalytic properties of unsupported palladium nanoparticles in electrooxidation of formic acid. Journal of Physical Chemistry B, v. 110, n. 27, p. 13393-13398, 2006. 
11 KELLY, K. L.; CORONADO, E.; ZHAO, L. L.; SCHATZ, G. C. The optical properties of metal nanoparticles: the influence of size, shape, and dielectric environment. Journal of Physical Chemistry B, v. 107, n. 3, p. 668-677, 2002.

12 SHIPWAY, A. N.; KATZ, E.; WILLNER, I. Nanoparticle arrays on surfaces for electronic, optical, and sensor applications. ChemPhysChem, v. 1, n. 1, p. 18-52, 2000.

13 LI, J.; LI, X.; ZHAI, H.-J.; WANG, L.-S. Au20: a tetrahedral cluster. Science, v. 299, n. 5608, p. $864-867,2003$.

14 AGUADO, A.; JARROLD, M. F. Melting and freezing of metal clusters. Annual Review of Physical Chemistry, v. 62, n. 1, p. 151-172, 2011.

15 JIN, R.; WU, G.; LI, Z.; MIRKIN, C. A.; SCHATZ, G. C. What controls the melting properties of dna-linked gold nanoparticle assemblies? Journal of the American Chemical Society, v. 125, n. 6, p. 1643-1654, 2003.

16 NARAYANAN, R.; EL-SAYED, M. A. Shape-dependent catalytic activity of platinum nanoparticles in colloidal solution. Nano Letters, v. 4, n. 7, p. 1343-1348, 2004.

17 BOND, G. C.; THOMPSON, D. T. Catalysis by gold. Catalysis Reviews, v. 41, n. 3-4, p. 319-388, 1999.

18 CHEN, X.; ZHU, H.-Y.; ZHAO, J.-C.; ZHENG, Z.-F.; GAO, X.-P. Visible-light-driven oxidation of organic contaminants in air with gold nanoparticle catalysts on oxide supports. Angewandte Chemie International Edition, v. 47, n. 29, p. 5353-5356, 2008.

19 PAN, X.; FAN, Z.; CHEN, W.; DING, Y.; LUO, H.; BAO, X. Enhanced ethanol production inside carbon-nanotube reactors containing catalytic particles. Nature Materials, v. 6, n. 7 , p. 507-511, 2007.

20 ROSTRUP-NIELSEN, J. R. Conversion of hydrocarbons and alcohols for fuel cells.

Physical Chemistry Chemical Physics, v. 3, n. 3, p. 283-288, 2001.

21 MURDOCH, M.; WATERHOUSE, G. I. N.; NADEEM, M. A.; METSON, J. B.; KEANE, M. A.; HOWE, R. F.; LLORCA, J.; IDRISS, H. The effect of gold loading and particle size on photocatalytic hydrogen production from ethanol over $\mathrm{Au} / \mathrm{TiO} 2$ nanoparticles. Nature Chemistry, v. 3, n. 6, p. 489-492, 2011.

22 THOMSON, W. On the equilibrium of vapour at a curved surface of liquid. Philosophical Magazine Series 4, v. 42, n. 282, p. 448-452, 1871.

23 COUCHMAN, P. R.; JESSER, W. A. Thermodynamic theory of size dependence of melting temperature in metals. Nature, v. 269, n. 5628, p. 481-483, 1977.

24 BREAUX, G.; BENIRSCHKE, R.; SUGAI, T.; KINNEAR, B.; JARROLD, M. Hot and solid gallium clusters: too small to melt. Physical Review Letters, v. 91, n. 21, p. 215508, 2003.

25 PYFER, K. L.; KAFADER, J. O.; YALAMANCHALI, A.; JARROLD, M. F. Melting of size-selected gallium clusters with $60-183$ atoms. Journal of Physical Chemistry A, v. 118, n. 27, p. 4900-4906, 2014.

26 STEENBERGEN, K. G.; GASTON, N. First-principles melting of gallium clusters down to nine atoms: structural and electronic contributions to melting. Physical Chemistry

Chemical Physics, v. 15, n. 37, p. 15325-15332, 2013. 
27 HOCK, C.; BARTELS, C.; STRABBURG, S.; SCHMIDT, M.; HABERLAND, H.; ISSENDORFF, B. von; AGUADO, A. Premelting and postmelting in clusters. Physical Review Letters, v. 102, n. 4, p. 043401, 2009.

28 BREAUX, G. A.; NEAL, C. M.; CAO, B.; JARROLD, M. F. Melting, premelting, and structural transitions in size-selected aluminum clusters with around 55 atoms. Physical Review Letters, v. 94, n. 17, p. 173401, 2005.

29 SCHMIDT, M.; KUSCHE, R.; KRONMüLLER, W.; ISSENDORFF, B. von; HABERLAND, $\mathrm{H}$. Experimental determination of the melting point and heat capacity for a free cluster of 139 sodium atoms. Physical Review Letters, v. 79, n. 1, p. 99-102, 1997.

30 CHIROT, F.; FEIDEN, P.; ZAMITH, S.; LABASTIE, P.; L'HERMITE, J.-M. A novel experimental method for the measurement of the caloric curves of clusters. Journal of Chemical Physics, v. 129, n. 16, p. 164514, 2008.

31 FRENKEL, D.; SMIT, B. Understanding molecular simulation: from algorithms to applications. 2nd. ed. San Diego: Academic Press, 2001.

32 ERCOLESSI, F.; ANDREONI, W.; TOSATTI, E. Melting of small gold particles: mechanism and size effects. Physical Review Letters, v. 66, n. 7, p. 911-914, 1991.

33 SANKARANARAYANAN, S. K. R. S.; BHETHANABOTLA, V. R.; JOSEPH, B. Molecular dynamics simulation study of the melting of Pd-Pt nanoclusters. Physical Review B, v. 71, n. 19, p. 195415, 2005.

34 AGUADO, A.; LóPEZ, J. M. Electronic shell and dynamical coexistence effects in the melting of aluminum clusters: an interpretation of the calorimetric experiments through computer simulation. Journal of Physical Chemistry Letters, v. 4, n. 14, p. 2397-2403, 2013.

35 STARACE, A. K.; NEAL, C. M.; CAO, B.; JARROLD, M. F.; AGUADO, A.; LóPEZ, J. M. Electronic effects on melting: comparison of aluminum cluster anions and cations. Journal of Chemical Physics, v. 131, n. 4, p. 044307, 2009.

36 LEE, J. K.; BARKER, J. A.; ABRAHAM, F. F. Theory and Monte Carlo simulation of physical clusters in the imperfect vapor. Journal of Chemical Physics, v. 58, n. 8, p. 3166-3180, 1973.

37 LABASTIE, P.; WHETTEN, R. L. Statistical thermodynamics of the cluster solid-liquid transition. Physical Review Letters, v. 65, n. 13, p. 1567-1570, 1990.

38 FERRENBERG, A. M.; SWENDSEN, R. H. Optimized Monte Carlo data analysis. Physical Review Letters, v. 63, n. 12, p. 1195-1198, 1989.

39 HUKUSHIMA, K.; NEMOTO, K. Exchange Monte Carlo method and application to spin glass simulations. Journal of the Physical Society of Japan, v. 65, n. 6, p. 1604-1608, 1996.

40 FRANTSUZOV, P. A.; MANDELSHTAM, V. A. Size-temperature phase diagram for small Lennard-Jones clusters. Physical Review E, v. 72, n. 3, p. 037102, 2005. 
41 NEIROTTI, J. P.; CALVO, F.; FREEMAN, D. L.; DOLL, J. D. Phase changes in 38-atom Lennard-Jones clusters. I. a parallel tempering study in the canonical ensemble. Journal of Chemical Physics, v. 112, n. 23, p. 10340-10349, 2000.

42 SHARAPOV, V. A.; MANDELSHTAM, V. A. Solid-solid structural transformations in lennard-jones clusters: accurate simulations versus the harmonic superposition approximation. Journal of Physical Chemistry A, v. 111, n. 41, p. 10284-10291, 2007.

43 MANDELSHTAM, V. A.; FRANTSUZOV, P. A.; CALVO, F. Structural transitions and melting in LJ74-78 Lennard-Jones clusters from adaptive exchange Monte Carlo simulations. Journal of Physical Chemistry A, v. 110, n. 16, p. 5326-5332, 2006.

44 NOYA, E. G.; DOYE, J. P. K. Structural transitions in the 309-atom magic number Lennard-Jones cluster. Journal of Chemical Physics, v. 124, n. 10, p. 104503-104503-6, 2006.

45 CAR, R.; PARRINELLO, M. Unified approach for molecular dynamics and density-functional theory. Physical Review Letters, v. 55, n. 22, p. 2471-2474, 1985.

46 SUGITA, Y.; OKAMOTO, Y. Replica-exchange molecular dynamics method for protein folding. Chemical Physics Letters, v. 314, n. 1-2, p. 141-151, 1999.

47 JORGENSEN, W. L.; TIRADO-RIVES, J. Monte Carlo vs molecular dynamics for conformational sampling. Journal of Physical Chemistry, v. 100, n. 34, p. 14508-14513, 1996.

48 KRAUTH, W. Statistical mechanics: algorithms and computations. Oxford: Oxford University Press, 2006.

49 KARDAR, M. Statistical physics of particles. Cambridge: Cambridge University Press, 2007.

50 HASTINGS, W. K. Monte Carlo sampling methods using markov chains and their applications. Biometrika, v. 57, n. 1, p. 97-109, 1970.

51 NEWMAN, M. E. J.; BARKEMA, G. T. Monte Carlo methods in statistical physics. Oxford: Clarendon Press, 1999.

52 IBA, Y. Extended ensemble Monte Carlo. International Journal of Modern Physics C, v. 12, n. 05, p. 623-656, 2001.

53 LYUBARTSEV, A. P.; MARTSINOVSKI, A. A.; SHEVKUNOV, S. V.; VORONTSOVVELYAMINOV, P. N. New approach to Monte Carlo calculation of the free energy: method of expanded ensembles. Journal of Chemical Physics, v. 96, n. 3, p. 1776-1783, 1992.

54 MARINARI, E.; PARISI, G. Simulated tempering: a new Monte Carlo scheme. EPL Europhysics Letters, v. 19, n. 6, p. 451, 1992.

55 BERG, B. A.; NEUHAUS, T. Multicanonical ensemble: a new approach to simulate first-order phase transitions. Physical Review Letters, v. 68, n. 1, p. 9-12, 1992.

56 SWENDSEN, R. H.; WANG, J.-S. Replica Monte Carlo simulation of spin-glasses.

Physical Review Letters, v. 57, n. 21, p. 2607-2609, 1986. 
57 LINGENHEIL, M.; DENSCHLAG, R.; MATHIAS, G.; TAVAN, P. Efficiency of exchange schemes in replica exchange. Chemical Physics Letters, v. 478, n. 1-3, p. 80-84, 2009.

58 MALAKIS, A.; PAPAKONSTANTINOU, T. Comparative study of selected parallel tempering methods. Physical Review E, v. 88, n. 1, p. 013312, 2013.

59 CHODERA, J. D.; SHIRTS, M. R. Replica exchange and expanded ensemble simulations as gibbs sampling: simple improvements for enhanced mixing. Journal of Chemical Physics, v. 135, n. 19, p. 194110, 2011.

60 PREDESCU, C.; PREDESCU, M.; CIOBANU, C. V. The incomplete beta function law for parallel tempering sampling of classical canonical systems. Journal of Chemical Physics, v. 120 , n. 9 , p. $4119-4128,2004$.

61 KATZGRABER, H. G.; TREBST, S.; HUSE, D. A.; TROYER, M. Feedback-optimized parallel tempering Monte Carlo. Journal of Statistical Mechanics, v. 2006, n. 03, p. P03018, 2006.

62 SABO, D.; MEUWLY, M.; FREEMAN, D. L.; DOLL, J. D. A constant entropy increase model for the selection of parallel tempering ensembles. Journal of Chemical Physics, v. 128, n. 17, p. $174109-174109-5,2008$.

63 OKAMOTO, Y.; FUKUGITA, M.; NAKAZAWA, T.; KAWAI, H. $\alpha$-helix folding by Monte Carlo simulated annealing in isolated c-peptide of ribonuclease a. Protein Engineering, v. 4, n. 6, p. 639-647, 1991.

64 KOFKE, D. A. On the acceptance probability of replica-exchange Monte Carlo trials. Journal of Chemical Physics, v. 117, n. 15, p. 6911-6914, 2002.

65 BOUZIDA, D.; KUMAR, S.; SWENDSEN, R. H. Efficient Monte Carlo methods for the computer simulation of biological molecules. Physical Review A, v. 45, n. 12, p. 8894-8901, 1992.

66 SWENDSEN, R. H. How the maximum step size in Monte Carlo simulations should be adjusted. Physics Procedia, v. 15, p. 81-86, 2011.

67 ALLEN, M. P.; TILDESLEY, D. J. Computer simulation of liquids. reprint edition. Oxford: Oxford University Press, 1989.

68 KUMAR, S.; ROSENBERG, J. M.; BOUZIDA, D.; SWENDSEN, R. H.; KOLLMAN, P. A. The weighted histogram analysis method for free-energy calculations on biomolecules. i. the method. Journal of Computational Chemistry, v. 13, n. 8, p. 1011-1021, 1992.

69 CHODERA, J. D.; SWOPE, W. C.; PITERA, J. W.; SEOK, C.; DILL, K. A. Use of the weighted histogram analysis method for the analysis of simulated and parallel tempering simulations. Journal of Chemical Theory and Computation, v. 3, n. 1, p. 26-41, 2007.

70 GEHRKE, R.; REUTER, K. Assessing the efficiency of first-principles basin-hopping sampling. Physical Review B, v. 79, n. 8, p. 085412, 2009.

71 HOPPE, R. The coordination number - an "inorganic chameleon". Angewandte Chemie International, v. 9, n. 1, p. 25-34, 1970. 
72 HOPPE, R. Effective coordination numbers (ECoN) and mean fictive ionic radii (MEFIR). Zeitschrift für Kristallographie, v. 150, n. 1-4, p. 23-52, 1979.

73 DA SILVA, J. L. F. Effective coordination concept applied for phase change (GeTe)m(Sb2Te3)n compounds. Journal of Applied Physics, v. 109, n. 2, p. 023502, 2011.

74 GUPTA, R. P. Lattice relaxation at a metal surface. Physical Review B, v. 23, n. 12, p. 6265-6270, 1981.

75 WALES, D. Energy landscapes: applications to clusters, biomolecules and glasses. Cambridge: Cambridge University Press, 2004.

76 JONES, J. E. On the determination of molecular fields. II. from the equation of state of a gas. Proceedings of the Royal Society of London. Series A, v. 106, n. 738, p. 463-477, 1924.

77 CLERI, F.; ROSATO, V. Tight-binding potentials for transition metals and alloys. Physical Review B, v. 48, n. 1, p. 22-33, 1993.

78 LORENTZ, H. A. Ueber die anwendung des satzes vom virial in der kinetischen theorie der gase. Annalen der Physik, v. 248, n. 1, p. 127-136, 1881.

79 BERTHELOT, D. Sue le mélange des gaz. Comptes Rendus Hebdomadaires des Séances de l'Académie des Sciences, v. 126, p. 1703-1706, 1898.

80 HOHENBERG, P.; KOHN, W. Inhomogeneous electron gas. Physical Review, v. 136, n. 3B, p. B864-B871, 1964.

81 KOHN, W.; SHAM, L. J. Self-consistent equations including exchange and correlation effects. Physical Review, v. 140, n. 4A, p. A1133-A1138, 1965.

82 PERDEW, J. P.; BURKE, K.; ERNZERHOF, M. Generalized gradient approximation made simple. Physical Review Letters, v. 77, n. 18, p. 3865-3868, 1996.

83 RONDINA, G. G.; DA SILVA, J. L. F. Revised basin-hopping Monte Carlo algorithm for structure optimization of clusters and nanoparticles. Journal of Chemical Information and Modeling, v. 53, n. 9, p. 2282-2298, 2013.

84 RONDINA, G. G. Novas ideias para o método de basin-hopping Monte Carlo aplicado à otimização global de clusters e nanopartículas. 2013. 163 p. Dissertação (Mestrado em Ciências) - Instituto de Física de São Carlos, Universidade de São Paulo, São Carlos, 2013.

85 MATSUMOTO, M.; NISHIMURA, T. Mersenne twister: a 623-dimensionally equidistributed uniform pseudo-random number generator. ACM Transactions on Modeling and Computer Simulation, v. 8, n. 1, p. 3-30, 1998.

86 SENN, F.; WIEBKE, J.; SCHUMANN, O.; GOHR, S.; SCHWERDTFEGER, P.; PAHL, E. Melting of "non-magic" argon clusters and extrapolation to the bulk limit. Journal of Chemical Physics, v. 140, n. 4, p. 044325, 2014.

87 SABO, D.; FREEMAN, D. L.; DOLL, J. D. Pressure dependent study of the solid-solid phase change in 38-atom Lennard-Jones cluster. Journal of Chemical Physics, v. 122, n. 9, p. 094716, 2005. 
88 DAGUM, L.; MENON, R. OpenMP: an industry standard api for shared-memory programming. IEEE Computational Science Engineering, v. 5, n. 1, p. 46-55, 1998.

89 DOYE, J. P. K.; MILLER, M. A.; WALES, D. J. The double-funnel energy landscape of the 38-atom Lennard-Jones cluster. Journal of Chemical Physics, v. 110, n. 14, p. 6896-6906, 1999.

90 WALES, D. J.; DOYE, J. P. K. Global optimization by basin-hopping and the lowest energy structures of Lennard-Jones clusters containing up to 110 atoms. Journal of Physical Chemistry A, v. 101, n. 28, p. 5111-5116, 1997.

91 LENNARD-JONES Clusters. 1997. Base de dados contendo as mais baixas energias e estruturas para aglomerados de Lennard-Jones. Disponível em: < http: //doye.chem.ox.ac.uk/jon/structures/LJ.html>. Acesso em: 30 dez. 2014.

92 LEARY, R. H.; DOYE, J. P. K. Tetrahedral global minimum for the 98-atom Lennard-Jones cluster. Physical Review E, v. 60, n. 6, p. R6320-R6322, 1999.

93 WU, J.; QI, L.; YOU, H.; GROSS, A.; LI, J.; YANG, H. Icosahedral platinum alloy nanocrystals with enhanced electrocatalytic activities. Journal of the American Chemical Society, v. 134, n. 29, p. 11880-11883, 2012.

94 WU, J.; ZHANG, J.; PENG, Z.; YANG, S.; WAGNER, F. T.; YANG, H. Truncated octahedral Pt3Ni oxygen reduction reaction electrocatalysts. Journal of the American Chemical Society, v. 132, n. 14, p. 4984-4985, 2010.

95 JIA, Q.; CALDWELL, K.; RAMAKER, D. E.; ZIEGELBAUER, J. M.; LIU, Z.; YU, Z.; TRAHAN, M.; MUKERJEE, S. In situ spectroscopic evidence for ordered core-ultrathin shell Pt1Co1 nanoparticles with enhanced activity and stability as oxygen reduction electrocatalysts. Journal of Physical Chemistry C, v. 118, n. 35, p. 20496-20503, 2014.

96 GUEDES SOBRINHO, D.; NOMIYAMA, R. K.; CHAVES, A. S.; PIOTROWSKI, M. J.; DA SILVA, J. L. F. Binary PtnTM55-n nanoclusters: a density functional theory investigation. (Em fase de elaboração).

97 BLUM, V.; GEHRKE, R.; HANKE, F.; HAVU, P.; HAVU, V.; REN, X.; REUTER, K.; SCHEFFLER, M. Ab initio molecular simulations with numeric atom-centered orbitals.

Computer Physics Communications, v. 180, n. 11, p. 2175-2196, 2009.

98 HAMMER, B.; NORSKOV, J. K. Why gold is the noblest of all the metals. Nature, v. 376, n. 6537, p. 238-240, 1995. 